\title{
ACOMPANHAMENTO DE GESTANTES NO PRÉ-NATAL DE ALTO RISCO DA MATERNIDADE CACHOEIRINHA: CONTRARREFERÊNCIA NA ATENÇÃO PRIMÁRIA À SAÚDE
}

Versão corrigida da Dissertação apresentada ao Programa de Pós-Graduação da Escola de Enfermagem da Universidade de São Paulo para obtenção do título de Mestre.

Área de Concentração: Atenção Primária em Saúde no Sistema Único de Saúde

Orientadora: $\operatorname{Prof}^{\mathrm{a}} \mathrm{Dr}^{\mathrm{a}}$ Anna Luiza de Fátima Pinho Lins Gryschek

\section{VERSÃO CORRIGIDA}

A versão original encontra-se disponível na Biblioteca da Escola de Enfermagem da Universidade de São Paulo e na Biblioteca de Teses e Dissertações da Universidade de São Paulo. 


\section{AUTORIZO A REPRODUÇÃO TOTAL OU PARCIAL DESTE TRABALHO, POR QUALQUER MEIO CONVENCIONAL OU ELETRÔNICO, PARA FINS DE ESTUDO E PESQUISA, DESDE QUE CITADA A FONTE.}

Assinatura: Data

Catalogação na Publicação (CIP)

Biblioteca "Wanda de Aguiar Horta"

Escola de Enfermagem da Universidade de São Paulo

Oliveira, Ana Carolina Brito de

Acompanhamento De Gestantes No Pré-Natal De Alto Risco Da Maternidade Cachoeirinha: Contrarreferência Na Atenção Primária À

Saúde / Ana Carolina Brito de Oliveira. - São Paulo, 2018.

$156 \mathrm{p}$.

Dissertação (Mestrado) - Escola de Enfermagem da Universidade de São Paulo

Orientadora: Prof $^{\underline{a}} \operatorname{Dr}^{\mathrm{a}}$ Anna Luiza de Fátima Pinho Lins Gryschek

1. Pré-natal de alto risco 2. Referência e contrarreferência 3. Atenção Primária à Saúde 4. Enfermagem 
Nome: Ana Carolina Brito de Oliveira

Titulo: Acompanhamento de Gestantes no Pré-Natal de Alto Risco da Maternidade Cachoeirinha: Contrarreferência na Atenção Primária à Saúde

Dissertação apresentada ao Programa de Pós-Graduação/Mestrado Profissional da Escola de

Enfermagem da Universidade de São Paulo para obtenção do título de Mestra em Ciências na Atenção Primária em Saúde no Sistema Único de Saúde.

Aprovado em:

\section{Banca Examinadora}

Orientador: Profa. Dra. Anna Luiza de Fátima Pinho Lins Gryschek Instituição: Escola de Enfermagem da Universidade de São Paulo Assinatura:

Prof. Dr. Instituição:

Julgamento: Assinatura:

Prof. Dr. Instituição:

Julgamento: Assinatura:

Prof. Dr. Instituição:

Julgamento: Assinatura: 


\section{DEDICATÓRIA}

Aos meus pais Wagner Galdino e Sandra Regina, por terem me dado a vida e possibilitar ser quem eu sou.

Ao meu amor maior, amigo e filho Lucas Brito, que apesar da pouca idade, esteve comigo em todas as etapas desse processo, com carinho e paciência em entender por vezes a minha ausência.

Ao meu querido Giusepe, que apesar de reclamar da minha ausência soube me apoiar nas horas em que precisava.

Às minhas tias, primas e primos que apoiaram a minha decisão e me incentivaram a percorrer essa jornada.

As minhas queridas amigas Adriana e Joyce que mostraram que a força da amizade não está ligada ao tempo no qual se iniciou e sim na forma como surge e se mantem. 


\section{AGRADECIMENTOS}

A realização do mestrado sempre foi um sonho em minha vida e que muitas vezes teve que ser desviado por motivos que fugiam a minha vontade. Finalmente e com muita luta pude conquistar esse grande sonho com a ajuda de pessoas importantes tanto em minha vida pessoal, como em minha vida profissional. Agradeço a todos que estiveram junto comigo nesta longa, porém fascinante jornada, com os meus mais sinceros sentimentos.

À Prof. ${ }^{a}$ Dr ${ }^{a}$. Anna Luiza Pinho Lins Gryschek pelo apoio, amizade, profissionalismo, leveza de viver, competência e o mais sincero sorriso que já conheci e com quem tive a oportunidade de aprender e por ter sido minha orientadora neste presente trabalho.

A todos os docentes do Departamento de Enfermagem de Saúde Coletiva, com quem obtive valioso aprendizado para a construção dessa dissertação, durante as aulas créditos.

Às Prof ${ }^{\mathrm{as}}$. Dr ${ }^{\mathrm{as}}$. Sayuri Tanaka Maeda, Danielle Alvim de Castro e Rebeca Nunes Guedes de Oliveira pelas valiosas contribuições e sugestões para a elaboração deste trabalho.

Às minhas amigas Joyce e Adriana pelas sugestões.

Ao Rafael pela paciência e colaboração neste trabalho.

Ao Coronel Sidney e a Tenente Lisandra pela compreensão e liberação para realização deste trabalho durante o período em que servi a Força Aérea Brasileira (FAB).

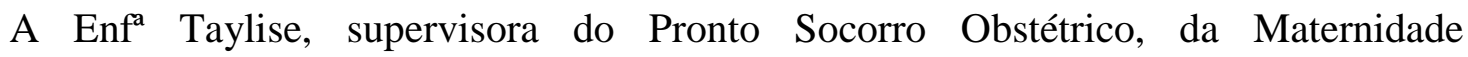
Cachoeirinha, pela liberação e alteração da escala para que eu frequentasse as aulas créditos.

À Coordenadoria da Região de Saúde Norte, pelo carinho, pelo apoio e por prontamente me auxiliar nas etapas dessa jornada.

À Maternidade Cachoeirinha, em especial à Ivonete e a Dr ${ }^{\mathrm{a}}$ Carla por compreenderem a importância desse trabalho e me auxiliarem nas etapas dessa jornada.

Aos funcionários da Biblioteca da Escola de Enfermagem da USP, pelo apoio e prontidão ao atendimento das minhas necessidades. 
"Sorrir às pessoas que não gostam de mim, para mostrá-las que sou diferente do que elas pensam; fazer de conta que tudo está bem quando isso não é verdade, para que eu possa acreditar que tudo vai mudar. Aprender com meus erros afinal eu posso ser sempre melhor. Ter olhos para ver e ouvir estrelas, embora nem sempre consiga entendêlas".

(Charles Chaplin) 


\section{Oliveira ACB. Acompanhamento de Gestantes no Pré-Natal de Alto Risco da}

Maternidade Cachoeirinha: Contrarreferência na Atenção Primária à Saúde.

Dissertação [Mestrado Profissional na Atenção Primária em Saúde]. São Paulo: Escola de Enfermagem, Universidade de São Paulo; 2017.

\section{RESUMO}

Introdução: A atenção durante o ciclo gravídico puerperal é de extrema importância para garantir a saúde materna e infantil, devendo o pré-natal ocorrer prioritariamente na Atenção Primária à Saúde, respeitando-se a realização de no mínimo sete consultas e a captação da gestante o mais precocemente possível, conforme preconizado nas políticas públicas dessa área. Entretanto, muitas vezes, depara-se com situações fora da normalidade obstétrica, em que patologias relacionadas à gestante e/ou ao feto, impõe a referência da assistência para um nível mais complexo de atenção. Nesse momento, frente a ineficácia dos mecanismos de contrarreferência, a Atenção Primária poderá deixar de obter as informações necessárias para o correto acompanhamento dessas mulheres e de seus conceptos. O presente estudo procurou evidenciar como têm ocorrido os mecanismos de referência e contrarreferência das gestantes encaminhadas por Unidades Básicas de Saúde da Zona Norte do município de São Paulo, para uma Maternidade Escola, referência para gestantes de alto risco, nessa mesma região. Objetivo: Investigar limites e potencialidades do sistema de referência e contrarreferência, no acompanhamento de gestantes de alto risco, encaminhadas para a Maternidade Escola Dr. Mário de Moraes Altenfelder Silva, mais conhecida como Maternidade Escola Cachoeirinha. Método: Trata-se de um estudo descritivo, qualitativo, do tipo estudo de caso, tomando como participantes 14 enfermeiros e 9 médicos das UBS Vila Dionísia e Dra. Ilza Hutzler. Além das entrevistas individuais semiestruturadas, realizou-se a caracterização da população estudada. A partir do referencial teórico adotado, emergiram três unidades temáticas: o sistema de saúde; o funcionamento do sistema de referência e contrarreferência e fatores estruturais das Unidades Básicas de Saúde. A análise dos discursos foi realizada empregando-se a técnica de análise de conteúdo de Bardin, tendo sido evidenciadas 7 subunidades temáticas empíricas. Resultados e Discussão: A análise dos dados permitiu a avaliação do sistema de referência e contrarreferência e da observância dos princípios e diretrizes do SUS, com relação ao pré-natal de alto risco, realizado na Maternidade Cachoeirinha. Evidenciou-se que não ocorre a contrarreferência para as UBS, dessa forma, a continuidade da assistência durante o pré-natal de alto risco, no puerpério e para o recém-nascido é prejudicada. Além disso, observou-se que o conhecimento sobre o SUS, por parte dos trabalhadores entrevistados é deficiente e o conteúdo é pouco abordado durante os programas de graduação. Conclusões: Deve haver 
capacitação para os profissionais da atenção primária e terciária de forma integrada, no que se refere aos princípios e diretrizes do SUS, principalmente no que diz respeito à referência e contrarreferência. Faz-se necessária também, a capacitação de médicos e enfermeiros das UBS em pré-natal. Para esse estudo, que se trata de um Mestrado Profissional, foram elaboradas duas ferramentas, o fluxograma e o formulário de acompanhamento da gestante de alto-risco, para serem utilizados nas trocas de informações dentro da APS e da atenção terciária. O formulário deverá ser preenchido pela Maternidade mensalmente, e posteriormente, por mala direta, enviada às UBS.

PALAVRAS-CHAVE: Pré-natal de alto risco; Referência e contrarreferência; Atenção Primária à Saúde; Enfermagem. 


\title{
Oliveira ACB. Pregnant Women Monitoring in High Risk Prenatal of Cachoeirinha Maternity: Counter-referral in Primary Health Care. Thesis [Master degree in Primary Health Care]. Sao Paulo: School of Nursing, University of Sao Paulo; 2017.
}

\begin{abstract}
Introduction: Attention during the puerperal pregnancy cycle is extremely important to ensure maternal and infant health, prenatal care should occur primarily in Primary Health Care, respecting the minimum amount of seven visits being performed plus receiving the pregnant at the earliest in order to follow the advocated public policies of this area. However, there are usual situations apart from the obstetric normality, in which pathologies related to either the pregnant woman or the fetus, imposes the reference of care to a more complex level of attention. At this moment, due to the ineffectiveness of counter-referral mechanisms, Primary Care may fail to obtain the necessary information for the correct supervision of these women and their infants. The present study sought to highlight how the reference and counter - referral mechanisms of pregnant women referred by Basic Health Units of the North region in Sao Paulo for a Maternity School, a reference for high-risk pregnant women in this same region.
\end{abstract} Objective: To investigate the limits and potentialities of the referral and counter-referral system to supervise high-risk pregnant women referred to the Mário de Moraes Altenfelder Silva Maternity School, known as the Cachoeirinha Maternity School. Method: This is a descriptive, qualitative, case-study involving 14 nurses and 9 physicians from the UBS Vila Dionísia and UBS Dr. Ilza Hutzler. In addition to the semi-structured individual interviews, the study population was characterized. Based on the theoretical framework adopted, three thematic units emerged: the health system; the functioning of the reference and counter-reference system and structural factors of the Basic Health Units. The discourse analysis was carried out using Bardin content analysis technique, and seven empirical thematic subunits were evidenced. Results and Discussion: The analysis of the data allowed the evaluation of the referral and counter-referral system and compliance with the principles and guidelines of SUS, with regard to the high-risk prenatal care performed at Maternidade Cachoeirinha. It was evidenced that the counter-referral does not occur for the UBS, therefore, continuity of care during high-risk prenatal care, in the puerperium and for the newborn is impaired. In addition, it was observed that the knowledge about SUS by the workers interviewed is deficient and the content is little approached during undergraduate programs. Conclusions: There should be training for primary and tertiary care professionals in an integrated way, with regard to SUS principles and guidelines, especially in relation to referral and counter-referral. It is also necessary to train physicians and nurses of the UBS in prenatal care. For this study, which is a Professional Master's Degree, two tools, the 
flowchart and the follow-up form of high-risk pregnant women, were developed to be used in the exchange of information within PHC and tertiary care. The form must be completed by the Maternity monthly, and later, by direct mail, sent to the UBS.

KEY WORDS: High risk prenatal care; Reference and counter-reference; Primary Health Care; Nursing. 


\section{APRESENTAÇÃO}

$\mathrm{O}$ que me motivou a retornar à Universidade e consequentemente ao desenvolvimento desse estudo, remonta à toda a minha trajetória profissional, desde a graduação passando pela Estratégia em Saúde da Família (ESF), até a minha inserção como enfermeira no Hospital Maternidade Escola Dr. Mário de Moraes Altenfelder Silva, conhecido também como Maternidade Escola Cachoeirinha.

A Universidade, especialmente a pública, é um espaço de extremo valor para a produção de conhecimento, saberes e práticas, que devem retornar para a sociedade, lembrando da responsabilidade social dessas instituições de ensino, em promover reflexões e colaborar com as mudanças na realidade objetiva.

Nesse sentindo, o mestrado profissional colabora de forma clara e irrefutável, promovendo o desenvolvimento de ferramentas de trabalho que possam, de alguma maneira, qualificar as práticas profissionais e também qualificar a assistência à população atendida.

Iniciei a graduação em 2001 na Escola de Enfermagem da Universidade de São Paulo (EEUSP), com término em 2004, tanto em bacharelado como em licenciatura. Logo após, dei início às minhas atividades profissionais ministrando aulas em uma escola técnica de enfermagem. Em 2006, juntamente com a pós-graduação em Enfermagem do Trabalho, comecei a trabalhar em um hospital público da cidade de Guarulhos, primeiramente no Pronto Socorro e posteriormente na Educação Permanente, realizando a capacitação da equipe multiprofissional, aliada também aos aspectos de prevenção de acidentes e diminuição de riscos ergonômicos.

Depois de cinco anos no ambiente hospitalar, entendi que além da capacitação de profissionais, gostaria de ajudar na prevenção e promoção da saúde de pacientes e da comunidade, percebendo que o papel do enfermeiro é fundamental nessas funções. Então, em 2010, ingressei como Enfermeira na ESF também na Cidade de Guarulhos, em um território extremamente carente, no que dizia respeito às condições sociais, ambientais, de saúde e econômicas.

Entendendo a importância deste trabalho e querendo aprimorar meus conhecimentos em ESF, fiz parte da primeira turma da Universidade Aberta do Sistema Único de Saúde/Universidade Federal de São Paulo (UNASUS/UNIFESP), de pós-graduação multidisciplinar e este curso foi fundamental para a ampliação dos meus conhecimentos técnicos e contribuição junto à comunidade na qual trabalhava. 
Em 2014, sentindo a necessidade de vivenciar novas experiências profissionais, realizei minha inscrição para a Força Aérea Brasileira (FAB) e iniciei um trabalho como tenente enfermeira no Núcleo do Hospital da Força Aérea de São Paulo (NuHFASP), porém em funções que me remetiam à atenção primária: era responsável pela Sala de Vacina e pela Educação Permanente. Durante esse período, realizei pós-graduação em Gestão Pública pela UNIFESP, pretendendo retornar à atenção primária à saúde cada vez mais preparada.

Após dois anos como militar, fui convocada a assumir o cargo de enfermeira, num concurso público da Prefeitura do Município de São Paulo (PMSP), que havia realizado anteriormente. Ao comparecer na escolha de vagas, confesso que sofri uma grande surpresa: não haviam vagas para a atenção primária, somente para a Maternidade Escola Cachoeirinha. Neste momento, pensei em não aceitar o cargo, pois como poderia realizar um mestrado profissional em atenção primária no Sistema Único de Saúde (SUS), trabalhando na atenção terciária?

Então, refletindo sobre o assunto, entendi que poderia ser um desafio e ao mesmo tempo uma possibilidade de unir a atenção primária à atenção terciária de uma maneira real e não somente em protocolos desenvolvidos pelo Ministério da Saúde (MS).

Dessa forma, comecei meu trabalho como enfermeira na Maternidade Escola Cachoeirinha, no Pronto Socorro Obstétrico (PSO) e ao realizar o atendimento dessas gestantes pude perceber que aquelas que eram consideradas de alto risco, e, portanto, eram referenciadas para realizar o pré-natal na maternidade, durante os nove meses de gestação, praticamente perdiam seu vínculo original com a atenção primária e após o parto, retornavam abruptamente para as Unidades Básicas de Saúde (UBS), sem qualquer histórico dessa importante fase da vida.

Sabendo que cabe à atenção primária o acompanhamento das gestantes, dos recém-nascidos $(\mathrm{RN})$ e de qualquer problema oriundo desse período, como morte materna, morte fetal e recém-nascido de baixo peso, pensei em desenvolver um relatório mensal dessas gestantes de alto risco, para serem enviados às UBS de origem, para auxiliar no acompanhamento e no compartilhamento de responsabilidades, já que a elaboração do prontuário eletrônico, sua implantação e livre acesso a todos os profissionais da rede, ainda permanece distante de sua concretização. Acredito que tal medida poderá colaborar como acompanhamento, monitorização e intervenções necessárias para à saúde de mulheres e crianças, qualificando a assistência à saúde dessas pessoas. 


\section{LISTA DE ILUSTRAÇÕES}

Figura 1 - Pirâmide do Sistema de Saúde 


\section{LISTA DE MAPAS}

Mapa 1 - Distritos de Saúde do Município de São Paulo

Mapa 2 - Estabelecimentos e Serviços de Saúde da Rede Municipal por Coordenadoria Regional de Saúde, Supervisão Técnica de Saúde do Distrito Administrativo, Município de São Paulo

Mapa 3 - Distrito de Saúde Norte 


\section{LISTA DE QUADROS}

Quadro 1 - O Processo Histórico da Organização do Setor de Saúde e o Antecedente para o Sistema Brasileiro de Cuidado da Saúde - Readaptado.

Quadro 2 - Quadro de Risco Gestacional

Quadro 3 - Procedimentos Realizados na Maternidade Escola Cachoeirinha em 2016 a maio de 2017

Quadro 4 - Gestantes Encaminhadas ao Alto Risco da UBS Vila Dionísia para HMEC

Quadro 5 - Perfil dos Trabalhadores Entrevistados no Estudo 


\section{LISTA DE GRÁFICOS}

Gráfico 1 - Razão de Mortalidade Materna no Brasil: 1996, 2001, 2009, 2010 e 2015

Gráfico 2 - Razão de Mortalidade Materna por Causas Obstétricas Diretas e Indiretas (por grupo de 100 mil nascidos vivos) em 1990, 2000, 2010 e 2011

Gráfico 3 - Razão de Mortalidade Materna por Causas Específicas de Morte (por grupo de 100 mil nascidos vivos) em 1990, 2000, 2010 e 2015

Gráfico 4 - Taxa de Mortalidade Infantil de 2000 a 2015

Gráfico 5 - Taxa de Satisfação na Ouvidoria do HMEC de 2010 a maio de 2017

Gráfico 6 - Avaliação do Atendimento de Enfermagem pelos Pacientes do HMEC de 2010 a maio de 2017

Gráfico 7 - Porcentagem de Partos Realizados no HMEC dentro e fora da Grade de Referência de janeiro de 2016 a abril de 2017

Gráfico 8 - Número de Atendimentos Ginecológicos e Obstétricos no Pronto Socorro do HMEC de 2010 a maio de 2017 


\section{LISTA DE SIGLAS}

ABRASCO - Associação Brasileira de Pós-Graduação em Saúde Coletiva ACS - Agente Comunitário de Saúde

AMA - Assistência Médica Ambulatorial

APS - Atenção Primária à Saúde

ASF - Associação Saúde da Família

BI - Business Intelligence

CAPS - Centro de Atenção Psicossocial

CEBES - Centro Brasileiro de Estudos de Saúde

CID - Classificação Internacional de Doenças

CLT - Consolidação das Leis do Trabalho

CONASS - Conselho Nacional de Secretários de Saúde

CNS - Conferência Nacional de Saúde

CRAS - Centro de Referência de Assistência Social

DIU - Dispositivo Intrauterino

DST - Doenças Sexualmente Transmissíveis

EEUSP - Escola de Enfermagem da Universidade de São Paulo

ESF - Estratégia Saúde da Família

FAB - Força Aérea Brasileira

HCFMUSP - Hospital das Clínicas da Faculdade de Medicina da Universidade de São Paulo

HMEC - Hospital Maternidade Escola Cachoeirinha

IDH - Índice de Desenvolvimento Humano

INAMPS - Instituto Nacional de Assistência Médica da Previdência Social

IST - Infecções Sexualmente Transmissíveis

LOS - Lei Orgânica de Saúde

MIF - Mulher em Idade Fértil

MPAS- Ministério da Previdência e Assistência Social

MS - Ministério da Saúde

NASF - Núcleo de Assistência à Saúde da Família

NHS - National Health Service

NOAS - Normas Operacionais Administrativas

NOB - Normas Operacionais Básicas 
NuHFASP - Núcleo do Hospital de Força Aérea de São Paulo

OMS - Organização Mundial de Saúde

OPAS - Organização Pan-Americana da Saúde

OSS - Organizações Sociais de Saúde

PAISM - Programa de Assistência Integral à Saúde da Mulher

PHPN - Programa de Humanização de Pré-Natal e Nascimento

PSF - Programa Saúde da Família

PMSP - Prefeitura do Município de São Paulo

PMP - Programa Mãe Paulistana

PSO - Pronto Socorro Obstétrico

$\mathrm{RC}$ - Rede Cegonha

RN - Recém-Nascido

RSB - Reforma Sanitária Brasileira

RRAS - Redes Regionais de Atenção à Saúde

SAE - Sistematização da Assistência de Enfermagem

SAMU - Serviço de Atendimento Médico de Urgência

SIAB - Sistema de Informação da Atenção Básica

SISPRENATAL - Sistema de Informação do Programa de Humanização do Pré-Natal e Nascimento

SHEG - Síndrome Hipertensiva Específica da Gestação

SUS - Sistema Único de Saúde

SUDS - Sistema Unificado e Descentralizado de Saúde

UBS - Unidade Básica de Saúde

UNASUS - Universidade Aberta do Sistema Único de Saúde

UNIFESP - Universidade Federal de São Paulo 


\section{SUMÁRIO}

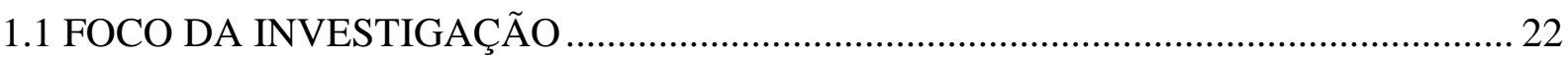

1.2 BASES POLÍTICAS PARA FORMULAÇÃO DO SUS - HISTÓRIAS E

PERSPECTIVAS

1.3 HISTÓRIA DO PRÉ-NATAL NO BRASIL

2 REFERENCIAL TEÓRICO: O SISTEMA DE REFERÊNCIA E CONTRARREFERÊNCIA

3 OBJETIVOS

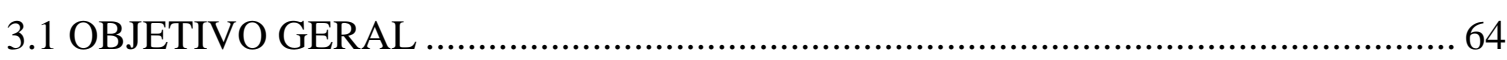

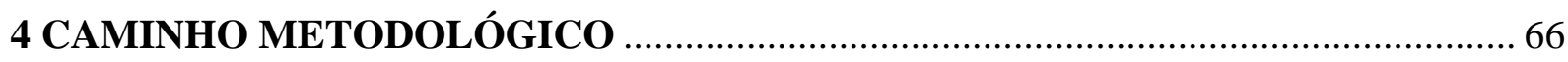

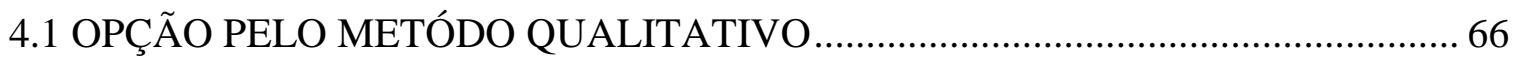

4.2 O ESTUDO DESCRITIVO TENDO COMO OBJETO O ESTUDO DE CASO ...... 67

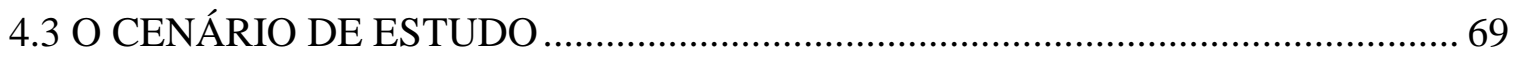

4.3.1 Maternidade Escola Dr. Mário De Moraes Altenfelder Silva................................. 73

4.3.2 Ambulatório da Maternidade Cachoeirinha ......................................................... 78

4.3.3 UBS Dra. Ilza Weltman Hutzler ....................................................................... 81

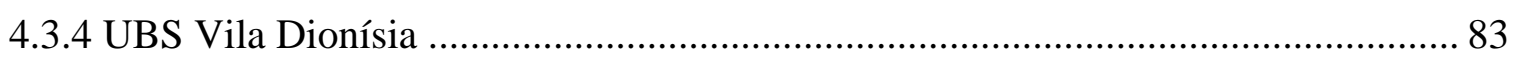

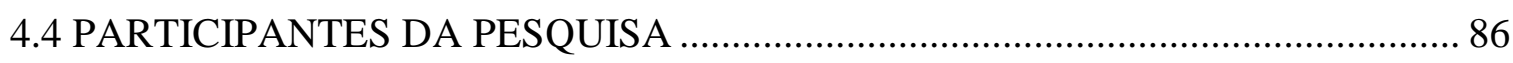

4.5 DESCRIÇÃO DOS INSTRUMENTOS DE COLETA DE DADOS …...................... 87

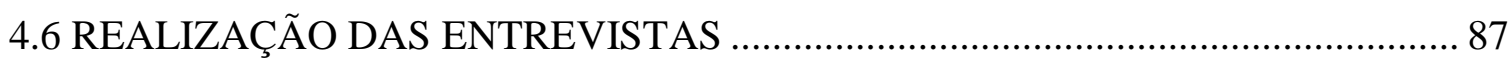

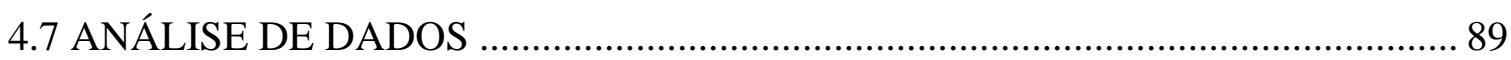

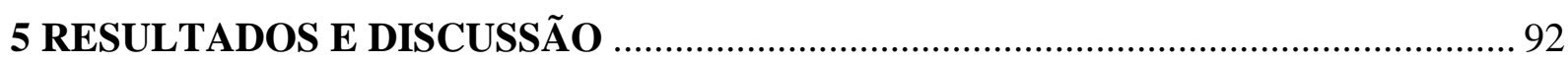

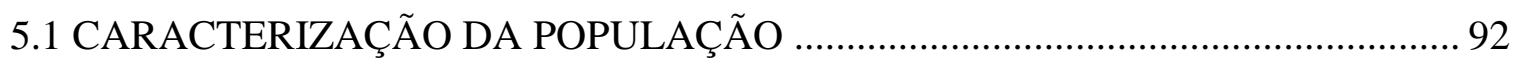

5.2 AS UNIDADES TEMÁTICAS INTENCIONAIS DO ESTUDO............................. 96

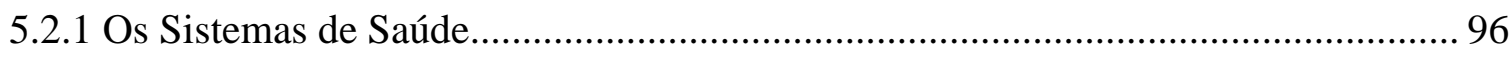

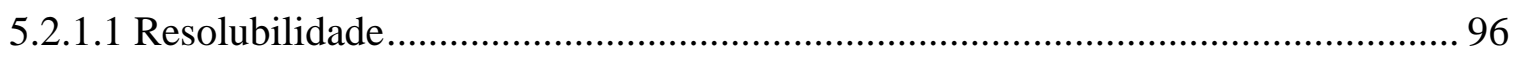

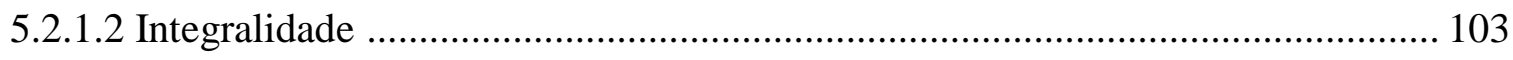

5.2.1.3 Lógica Adotada pelos Usuários do Sistema Único de Saúde ............................. 105

5.2.2 O Funcionamento do Sistema de Referência e

Contrarreferência...................................107

5.2.2.1 A Visão do Sistema de Referência e Contrarreferência ....................................... 107

5.2.2.2 Desafios de Comunicação entre os Níveis de Atenção....................................... 109

5.2.2.3 Importância da Contrarreferência ................................................................... 113

5.2.3 Fatores Estruturais das Unidades Básicas de Saúde ........................................... 115

5.2.3.1 Organização dos Serviços .......................................................................... 115 
5.3 FLUXOGRAMA E INSTRUMENTO DE REFERÊNCIA E

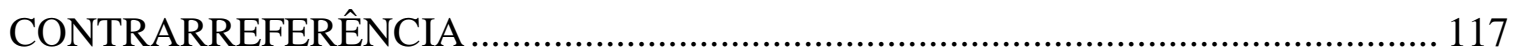

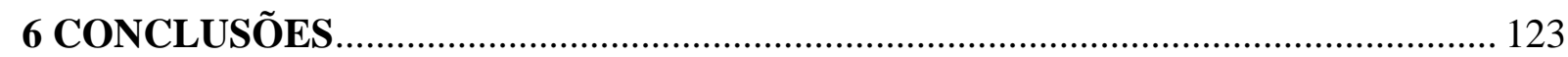

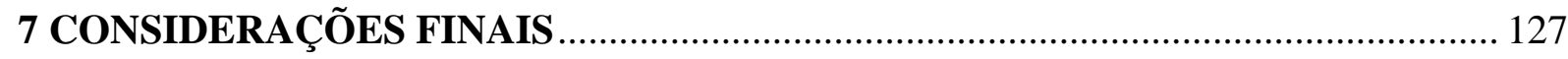

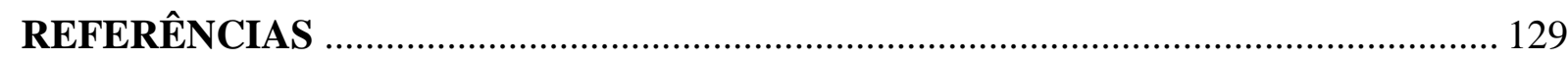

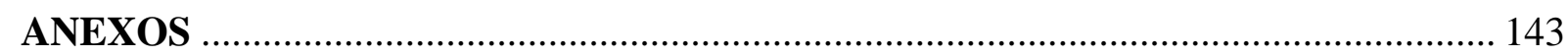

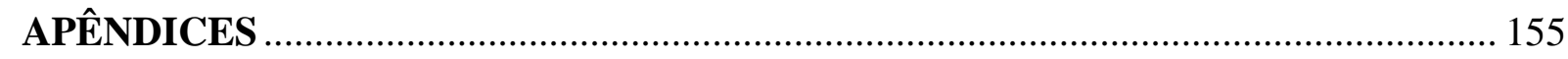


1 INTRODUÇÃ̃O 


\section{INTRODUÇÃO}

\subsection{FOCO DA INVESTIGAÇÃO}

A atenção ao ciclo de pré-natal e puerpério não deve se ater somente ao número de consultas e à diminuição da mortalidade materno-infantil. Além desse importante objetivo, há que se buscar uma maior integração entre os profissionais, gestores e usuários, assim como considerar todos os aspectos subjetivos envolvidos, entres eles, o social, espiritual e o econômico que permeiam essa importante fase da vida e que influenciam de forma direta ou indireta a condução da gestação. Para isso, faz-se necessário construir uma cultura de respeito aos direitos humanos, entre os quais, os direitos sexuais e os direitos reprodutivos, fundamentais para uma assistência de qualidade e um trabalho eficiente com resultados verdadeiramente positivos (BRASIL, 2006).

Contudo, a realidade tem evidenciado que os serviços hierarquizados geram assistência fragmentada e descontinuada, à medida que não consideram as ações integrais e sistêmicas. Cabe à coordenação do Sistema Único de Saúde (SUS) investir em capacitação profissional, de infraestrutura, tecnológica e de orientação à população, para que as ações interinstitucionais realmente funcionem como preconizado (MAEDA, 2002).

Dentro dos princípios do SUS, está a hierarquização, da qual decorre a divisão do trabalho, já que nem sempre é possível resolver todas as necessidades de um paciente/comunidade em um determinado local, dessa forma, a assistência sofre o efeito da fragmentação de funções e ações entre as diversas instituições e por vezes, há falta de integração entre as pessoas envolvidas, diminuindo ou mesmo impedindo a resolubilidade do problema (MAEDA, 2002).

Na prática, as ferramentas que firmam o compromisso de atendimento em relação aos encaminhamentos para a complementariedade da assistência em níveis de complexidade progressiva, não têm sido eficientes, como forma de transformar a situação de saúde dos pacientes, que necessitam de cuidados especializados. Uma das questões impeditivas, entre muitas outras, seria o não preenchimento da folha de atendimento especializado, para ser devolvido à unidade de contrarreferência, possibilitando ao 
profissional da atenção primária à saúde um maior entendimento sobre a situação e as necessidades de saúde do paciente em questão (SERRA; RODRIGUES, 2010).

No caso da assistência prestada no ciclo gravídico-puerperal, o deslocamento da paciente, ao ser referenciada para o nível terciário, faz com que ela muitas vezes vivencie a fragilidade do SUS e a falta de integralidade da assistência. Os instrumentos formais de referência, não garantem que o atendimento seja prestado, como é pactuado entre as diversas esferas do governo. Além disso, o desconhecimento por parte dessas usuárias, aumenta a possibilidade de serem encaminhadas para outros serviços, sob a alegação de diversos fatores, como a falta de vagas, ou de equipamentos necessários para realização de exames, aumentando ainda mais a peregrinação por atendimento. Quando conseguem ser atendidas, muitas vezes, a folha de referência não é devolvida com a parte de contrarreferência preenchida, e ao retornarem para a Unidade Básica de Saúde (UBS) de origem, não sabem relatar o que ocorreu durante o atendimento no nível referenciado, prejudicando a continuidade da assistência (MAEDA, 2002; SERRA; FAGUNDES, 2010).

A questão condutora dessa pesquisa foi: quais são as dificuldades enfrentadas pelos profissionais (médicos e enfermeiros) das UBSs Vila Dionísia e Dra. Ilza Huztler, pertencentes à região Norte, do município de São Paulo, na contrarreferência das gestantes encaminhadas para a realização de pré-natal de alto risco na Maternidade Cachoeirinha?

Tal estudo se originou a partir da problemática evidenciada, quando as gestantes das UBSs Vila Dionísia e Dra. Ilza Hutzler, ao serem classificadas como de alto risco, eram encaminhadas para a realização do Pré-Natal na Maternidade Cachoeirinha e os profissionais da Atenção Primária à Saúde perdiam as informações com relação às condutas e procedimentos adotados, no nível hospitalar, devido à fragilidade do sistema de referência e contrarreferência existentes no município de São Paulo.

As UBSs se caracterizam como a porta de entrada da população e são responsáveis pelo encaminhamento aos demais níveis de complexidade, diante de serviços dispostos em hierarquia em forma de pirâmide. $\mathrm{Na}$ parte intermediária da pirâmide, estão localizados os serviços de atenção secundária, como pronto-socorros, ambulatórios de especialidades, serviços de apoio e diagnóstico e hospitais distritais. O topo da pirâmide é ocupado por hospitais com graus diferenciados de incorporação de tecnologias, onde os hospitais regionais se incubem em fornecer os recursos de maior densidade tecnológica (ELIAS, 2004). 
Figura 1 - Pirâmide do Sistema de Saúde

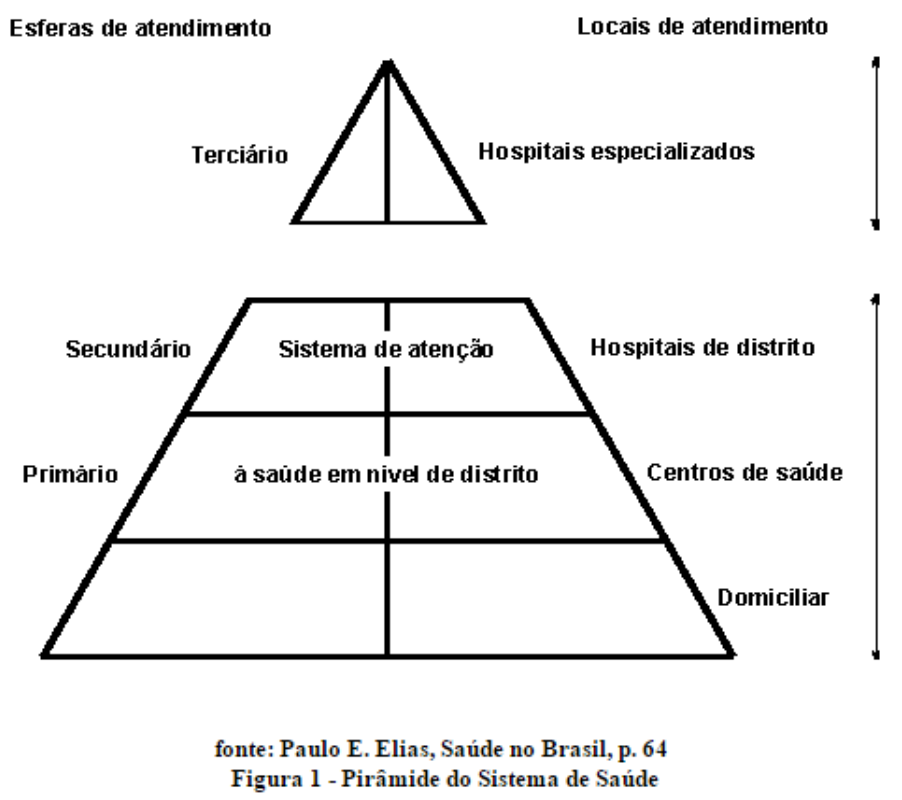

Infelizmente, essas unidades de saúde por estarem organizadas muitas vezes em regimes jurídicos diferentes e por questões político-administrativas, acabam por não cumprirem o princípio da integralidade, propiciando a desarticulação e diminuindo a capacidade funcional do sistema como um todo (IBAÑEZ et al., 2001; MAEDA, 2002).

Sendo assim e dentro dos pressupostos da distritalização, incorporados na Constituição de 1988 e aos princípios do SUS, as mulheres deveriam ser atendidas utilizando-se todos os recursos necessários, com o mínimo de deslocamento possível e o máximo de informação e qualidade da assistência prestada (SILVA et al., 1995).

\subsection{BASES POLÍticas PARA A FORMULAÇÃO DO SUS - HISTÓRIAS E PERSPECTIVAS}

Considerando as desigualdades e as injustiças existentes, inerentes ao sistema capitalista, surgem as políticas públicas, também reivindicadas pelo movimento operário, como forma de minimizar as diferenças existentes entre as diversas camadas sociais. Atualmente, as políticas públicas estão voltadas não somente às causas trabalhistas, mas também às questões de educação, saúde, assistência social, transporte, segurança 
alimentar, transferência de renda, entre outras. Entende-se por política pública um conjunto de ações realizadas pelo Estado e seus agentes, com participação ou não da sociedade, com a finalidade de garantir os direitos sociais previstos em lei (SOUSA; BATISTA, 2012).

Desde o Brasil Colônia, passando pela sua Independência, Governo Vargas, até o período de Ditadura Militar, o Brasil passou por inúmeras mudanças de cunho político e social, entre elas, a abolição da escravidão, surgimento do trabalho assalariado e as conquistas gradativas aos direitos trabalhistas e de saúde (MATA; PONTES, 2007).

A partir da Conferência Internacional sobre Cuidados Primários de Saúde, ocorrida em Alma-Ata (Cazaquistão, antiga União Soviética), em 1978, ficou estabelecido dentro de um contexto mundial, através de um documento elaborado no próprio evento, a participação efetiva dos Estados na saúde de sua população, através de políticas de saúde que visassem o bem-estar físico, mental e social como direitos fundamentais dos seus habitantes, enfatizando-se principalmente o cuidado primário à saúde. Afirmou-se também, que a saúde por ser uma importante meta social, deveria estar correlacionada com setores sociais e econômicos (VENTURA, 2003; SOUZA; COSTA, 2010).

Concomitantemente a esses acontecimentos mundiais, durante a década de 1980, o Brasil passava por um processo de luta popular e política em busca da redemocratização do país, para a existência de eleições diretas que colocassem no poder um presidente civil e, no âmbito da saúde, voltado para um atendimento mais amplo, igualitário e democrático, confrontando o modelo médico, privatista e assistencialista vigente na época (MEDEIROS, 2004).

Antes da criação do SUS, o Estado entendia que a obrigação em cuidar da saúde era uma responsabilidade individual e que cada indivíduo deveria arcar com soluções para suas doenças. A ação do Estado só ocorria em situações graves, como em casos de epidemia, ou de ocorrências que pudessem ameaçar o processo de crescimento econômico. Porém, com o desenvolvimento urbano e o aumento da aglomeração populacional nas grandes cidades, a questão da saúde passou a refletir uma questão social como descreve Paim (2009, p.45):

“[...] a organização dos serviços de saúde no Brasil antes do SUS vivia em mundos separados: de um lado, as ações voltadas para a prevenção, o ambiente e a coletividade, conhecidas como saúde pública; de outro, a saúde do trabalhador, inserida no Ministério do Trabalho; e, ainda, as ações curativas e individuais, integrando a medicina previdenciária e as modalidades de assistência médica liberal, filantrópica e, progressivamente, empresarial". 
A reforma do sistema de saúde brasileiro estava no antagonismo do que vinha acontecendo em países europeus, que começavam a rever suas políticas de bem-estar social. A proposta brasileira começou a ser formulada na década de 1970 e modelou-se junto com o processo de redemocratização. Um vasto movimento social tomou conta de todo país, reunindo iniciativas de diversos setores da sociedade, desde a classe média, movimentos sociais e sindicatos, muitos deles ligados a partidos políticos que criticavam o sistema militar vigente (ALMEIDA, 1995; PEGO; ALMEIDA, 2002).

A convicção política e ideológica do movimento pela reforma sanitária brasileira, defendia a saúde não somente como uma questão a ser resolvida pelo indivíduo, dentro do consultório médico, elencado somente nas questões biológicas e sim como uma questão social e política, que deveria ser abordada no espaço público (BIRMAN, 1991; ALMEIDA, 2002; PAIM et al., 2011).

Professores de saúde pública, pesquisadores da Sociedade Brasileira para o Progresso da Ciência, profissionais da saúde de orientação progressista e estudantes da área da saúde, aderiram na luta dos movimentos de base e dos sindicatos, para proporcionar a Reforma Sanitária. Com o objetivo de propiciar a base institucional da reforma, foi de indispensável importância a criação em 1976, do Centro Brasileiro de Estudos de Saúde (CEBES) e em 1979, da Associação Brasileira de Pós-Graduação em Saúde Coletiva (ABRASCO) (PEGO; ALMEIDA, 2002; PAIM et al., 2011).

De 1979 em diante, foram realizadas diversas reuniões de técnicos e gestores municipais e em 1980 constituiu-se o Conselho Nacional de Secretários de Saúde (CONASS) (ESCOREL, 1998). Em 1986, a VIII Conferência Nacional de Saúde (CNS) ratificou o conceito de saúde como um direito do cidadão e enumerou os fundamentos do SUS, com base no desenvolvimento de várias estratégias que permitiram a coordenação, integração e a transferência de recursos entre as diversas instituições de saúde dos governos federais, estaduais e municipais. Essas mudanças administrativas foram os alicerces para a formação do SUS. Sendo assim, foi na Constituição de 1988 que a saúde então, passa a ser um direito de todos e um dever do Estado (TEIXEIRA, 1987; PEGO; ALMEIDA, 2002).

A VIII CNS se tornou um dos grandes símbolos de saúde no Brasil, podendo ser considerada como o marco inicial para a Reforma Sanitária Brasileira (RSB). Propiciou o surgimento de temas como: necessidade de ampliação do conceito de saúde, a criação de um novo Sistema Nacional de Saúde, a separação da "Saúde" da "Previdência" e a 
orientação da política de financiamento para o setor saúde. O relatório então produzido, serviu como uma ferramenta que influenciou o Estado em garantir o direito à saúde para toda a população, através de serviços gratuitos e com qualidade, o que culminou na construção do Sistema Unificado e Descentralizado de Saúde (SUDS), como um ponto de início para a criação do SUS (BRASIL 1986; 1988).

Conforme descrito, a Constituição Federal, artigo 196, de 1988 consagrou a saúde como:

"Direito de todos e dever do Estado, garantida mediante políticas sociais e econômicas que visam à redução do risco de doença e de outros agravos e possibilitando o acesso universal e igualitário às ações e serviços para promoção, proteção e recuperação".

Atualmente, o sistema de saúde brasileiro vive uma época de grandes avanços e também de grandes problemas a serem superados. Pode-se colocar como avanços a implantação da Estratégia Saúde da Família (ESF), a diminuição da mortalidade maternoinfantil, o Programa Nacional de Infecções Sexualmente Transmissíveis, do Vírus da Imunodeficiência Humana (IST/AIDS) ${ }^{1}$ e das Hepatites Virais, entre outros. Como problemas, pode-se destacar a gestão em saúde e seus desdobramentos na falta de recursos materiais e humanos, impactando negativamente no atendimento da população (BRASIL, 2006a).

A criação do SUS, talvez seja um dos maiores movimentos sociais ocorridos no Brasil, reafirmando o compromisso político do Estado com a saúde dos seus cidadãos. Ele insere-se em um contexto mais amplo da política pública - que abrange além das políticas de saúde, as políticas de previdência e seguridade social (BRASIL, 1988; BRASIL, 2006; PAIM et al., 2011).

Com isso, pelo menos três inovações estão presentes: uma proposta de maior integração entre os diversos setores do Estado, com políticas econômicas e sociais que promovam a saúde, habitação, saneamento, transporte, lazer entre outros; a proposta de um sistema de saúde igualitário, que atenda a todos conforme as suas necessidades e a propositura de um sistema de saúde único, que atenda a todos nos seus diversos níveis de

\footnotetext{
1 Por meio do Decreto no 8.901/2016, do Ministério da Saúde, o termo Doenças Sexualmente Transmissíveis (DST), passa a ser denominado Infecções Sexualmente Transmissíveis (IST). A palavra Doenças implica em sinais e sintomas visíveis no organismo do indivíduo, já o termo Infecções, indica que pode haver períodos assintomáticos (herpes genital, sífilis, condiloma acuminado, por exemplo), ou podem se manter assintomáticos durante toda a vida do indivíduo (casos de infecção pelo HPV e vírus Herpes) e são somente detectados por exames laboratoriais. Fonte: Ministério da Saúde, 2016.
} 
complexidade, viabilizando o acesso às ações de prevenção, promoção, curativas e reabilitadoras (LIMA; BAPTISTA, 2003).

A Lei nº 8.080 de 19 de setembro de 1990, Lei Orgânica da Saúde, dispõe acerca das condições para a promoção, proteção e recuperação da saúde, organização e funcionamento dos serviços correspondentes, mostrando de forma clara os objetivos do SUS, suas competências e atribuições da União, dos Estados e Municípios (BRASIL, 1990).

Além disso, objetiva identificar e divulgar os determinantes de saúde, formular as políticas de saúde para desenvolver os campos econômico e social, para diminuir os riscos de agravos à saúde, além de executar ações no campo de promoção, proteção e recuperação da saúde integrando práticas assistenciais e preventivas. Por fim, a saúde deve realizar estudos epidemiológicos sobre os condicionantes e determinantes de saúde, do trabalho, alimentação, moradia, saneamento, educação, lazer, acesso a bens e serviços essenciais e divulgá-los para discussão e intervenção em tempo hábil (CARVALHO et al., 2001).

A Lei 8.142, de 28 de dezembro de 1990, dispõe sobre a participação da comunidade na gestão do SUS e sobre as transferências entre as três esferas do governo de recursos financeiros na área da saúde. Tais leis, consolidam o papel do município como principal responsável das ações de saúde, caracterizando o processo de descentralização, que significava um avanço ao processo ditatorial existente (BRASIL, 1990).

O SUS tem como principais funções regulação, fiscalização, controle e execução. A regulação ocorre nas ações de saúde do sistema público e privado, estabelecendo normas para o funcionamento dessas instituições (hospitais, clínicas, farmácias entre outras). Como exemplo, pode-se citar: como ocorrerá o processo de vacinação no território nacional? Como se dará a liberação para venda e distribuição gratuita de medicamentos? Como se dará a porta de entrada no sistema e seu prosseguimento para os demais níveis de atenção? (ALMEIDA; MACINKO; 2006).

A função de fiscalização e controle ocorre para empresas públicas e privadas, pessoas físicas e jurídicas, que estejam envolvidas com atividades dentro do SUS, e também dos recursos financeiros e materiais distribuídos entre federação, estados e municípios. A execução de ações ocorre primordialmente através de serviços públicos, (vigilância sanitária e epidemiológica, saúde do trabalhador, alimentação e nutrição, saúde da pessoa portadora de deficiência), porém, podem ser contratados serviços privados (CARVALHO et al., 2001). 
As diretrizes e princípios fundamentais do SUS têm seu base e alicerce na Constituição Federal e na Lei nº 8.080 (BRASIL, 1990). Como princípios encontram-se: 1. Universalidade: todos os cidadãos são iguais perante o SUS e devem ser atendidos conforme suas necessidades até o limite que o sistema possa oferecer. O acesso ao serviço ocorrerá através de uma rede hierarquizada (da menor para a maior complexidade) e com tecnologia apropriada para cada nível.

2. Integralidade: acesso a um conjunto articulado e contínuo de ações e serviços preventivos e curativos, individuais e coletivos, exigidos para cada caso, em todos os níveis de complexidade do sistema, devendo o sistema de saúde propiciar ao indivíduo e à coletividade, as condições de atendimento, de acordo com as suas necessidades.

3. Descentralização com direção única do sistema: apresenta-se no contexto da Reforma Sanitária Brasileira, como uma estratégia de distribuição e democratização do poder decisório na saúde, já que até então se estabeleciam práticas centralizadoras de poder na esfera federal.

A descentralização exige um novo formato na condução e organização da política. Nesse sentido, apresentam-se as 'diretrizes do SUS' de regionalização e hierarquização dos serviços, com a organização de um sistema de referência e contrarreferência, incorporando os diversos níveis de complexidade do sistema (primário, secundário e terciário) (SOUZA; COSTA, 2010).

Regionalizar acarreta um melhor conhecimento por parte de estados e municípios, dos problemas sociais e de saúde de seu território, propondo-se desenvolver políticas de saúde para realidades diferentes. Quem passa a decidir as prioridades de cada região é o gestor, que leva em consideração as características geográficas, o fluxo da demanda, o perfil epidemiológico, a oferta de serviços e as necessidades expressas pelos usuários (MATA; PONTES, 2007).

A hierarquização dos serviços segue a mesma lógica, organizando a rede de saúde, a partir dos diferentes níveis de complexidade dos serviços e de acordo com as realidades local e regional. A referência e contrarreferência funcionam como conexões de ligação dessa rede. Caso um município ou um determinado serviço de saúde não apresente condições de atender a um determinado problema de saúde, seja ele, individual ou coletivo, deve-se remetê-lo a uma outra unidade de saúde (referência), com a capacidade de solução do problema e de assegurar seu atendimento e seu retorno com informações 
necessárias para a continuidade da assistência (contrarreferência) (MATA; PONTES, 2007; SOUZA; COSTA, 2010).

Com o princípio da descentralização e as diretrizes de regionalização e hierarquização, observa-se o surgimento de organização e gestão dos sistemas de saúde, ainda assim, essa proposta, somente se concretiza se houver acordo entre as três esferas do governo, assim como lisura, reciprocidade e coparticipação em busca de um objetivo comum: qualidade para os serviços de saúde ofertados (VASCONCELOS; PASCHE, 2006).

4. Participação popular: trata-se da garantia constitucional que a população, por meio de suas entidades representativas, poderá participar do processo de formulação das políticas e do controle de execução dos serviços ofertados (MATA; PONTES, 2007).

A participação social foi descrita na Constituição de 1988 e regulamentada na lei do SUS de 1990 (lei 8.142/1990), onde se define a configuração dos conselhos de saúde (em cada esfera do governo) e a realização periódica, a cada quatro anos, das conferências de saúde, em cada esfera do governo (BRASIL, 1990; SOUZA; COSTA, 2010).

Os princípios e diretrizes do SUS deleneiam para governantes e gestores as bases para a formulação das políticas de saúde (PAIM, 2009). Em uma análise apurada da política e de todas as estratégias adotadas visando a operacionalização do SUS, é possível elencar alguns desafios que se apresentam de forma constante, como o da descentralização e da participação popular, ainda arraigados no autoritarismo, na centralização decisória e no clientelismo, ratificados na prática social no Brasil (BAPTISTA, 2007). 
Quadro 1: O processo histórico da organização do setor de saúde e o antecedente para o sistema brasileiro de cuidado da saúde - Readaptado

\begin{tabular}{|c|c|c|c|c|}
\hline & $\begin{array}{c}\text { Contexto } \\
\text { macroeconômico } \\
\text { e } \\
\text { socioeconômico }\end{array}$ & $\begin{array}{l}\text { Contexto } \\
\text { político }\end{array}$ & Sistema de saúde & Principais desafios de saúde \\
\hline $\begin{array}{c}\text { Transição } \\
\text { democrática } \\
\text { (1985-88) }\end{array}$ & $\begin{array}{l}\text { Fim da recessão, } \\
\text { reconhecimento da } \\
\text { dívida social e planos de } \\
\text { estabilização econômica }\end{array}$ & $\begin{array}{l}\text { - Início da "Nova } \\
\text { República" }(1985) \cdot \\
\text { Saúde incluída na } \\
\text { agenda politica } \bullet 8^{\mathrm{a}} \\
\text { Conferência Nacional } \\
\text { de Saúde } \cdot \text { Ampliação } \\
\text { do Movimento de } \\
\text { Reforma Sanitária } \\
\text { Assembleia Nacional } \\
\text { Constituinte } • \text { Nova } \\
\text { Constituição }(1988)\end{array}$ & $\begin{array}{l}- \text { INAMPS continua a financiar estados e } \\
\text { municipios } \bullet \text { Expansão das AIS } \bullet \text { Sistemas } \\
\text { Unificados e Descentralizados de Saúde - } \\
\text { SUDS }(1987) \cdot \text { Contenção das politicas } \\
\text { privatizantes } \bullet \text { Novos canais de participação } \\
\text { popular }\end{array}$ & $\begin{array}{l}\text { - Redução da mortalidade infantil e de } \\
\text { doenças preveniveis por imunização } \\
\text { Persistencia de doenças cardiovasculares } \\
\text { e cânceres } • \text { Aumento nas mortes } \\
\text { violentas e relacionadas à AIDS } \\
\text { Epidemia de dengue }\end{array}$ \\
\hline $\begin{array}{l}\text { Democracia } \\
(1988-2010)\end{array}$ & $\begin{array}{l}\text { Crise econômica } \\
\text { (hiperinflação) Ajuste } \\
\text { macroeconômico (Plano } \\
\text { Real; 1994) Estabilidade } \\
\text { econômica, recuperação } \\
\text { dos níveis de renda, } \\
\text { movimento cíclico } \\
\text { (altos e baixos), } \\
\text { persistênnia das } \\
\text { desigualdades, } \\
\text { continuidade da política } \\
\text { monetarista }\end{array}$ & $\begin{array}{l}\text { Presidente Fernando } \\
\text { Collor de Mello eleito } \\
\text { e submetido a } \\
\text { impeachment } \\
\text { Restante do mandato } \\
\text { presidencial (1993- } \\
\text { 94) exercido pelo } \\
\text { Vice-Presidente } \\
\text { Itamar Franco } \\
\text { Governos de } \\
\text { Fernando Henrique } \\
\text { Cardoso (1995-1998 } \\
\text { e 1999-2002)- } \\
\text { Partido da Social } \\
\text { Democracia } \\
\text { Brasileira (PSDB) } \\
\text { Reforma do Estado } \\
\text { (1995) Governos de } \\
\text { Luiz Inácio Lula } \\
\text { daSilva (2003-06 e } \\
\text { 2007-10) - Partido } \\
\text { dos Trabalhadores32 }\end{array}$ & 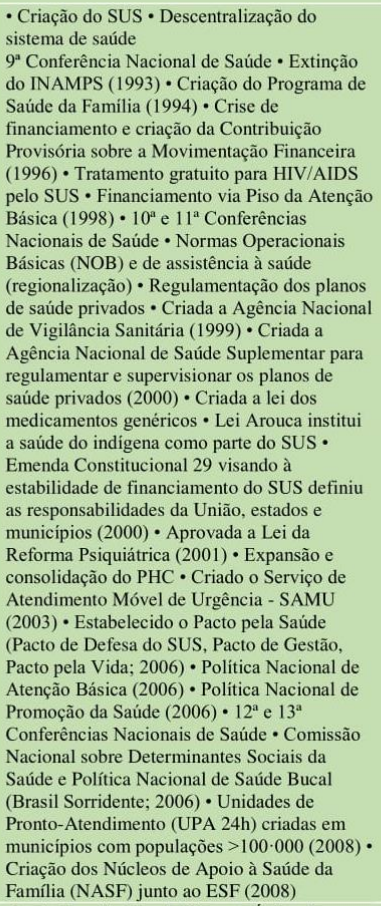 & $\begin{array}{l}\text { Epidemias de cólera e dengue, } \\
\text { mortalidade por causas externas } \\
\text { (sobretudo homicídios e acidentes de } \\
\text { trânsito) Doenças cardiovasculares são a } \\
\text { principal causa de morte, seguidas por } \\
\text { causas externas e cânceres } \\
\text { Redução na mortalidade infantil, } \\
\text { prevalência inalterada de tuberculose, } \\
\text { estabilização da prevalência de AIDS, } \\
\text { aumento na prevalência de dengue e } \\
\text { aumento na incidência de leishmaniose } \\
\text { visceral e malária } \\
\text { Expectativa de vida em torno de } 72,8 \\
\text { anos ( } 69,6 \text { para homens e } 76,7 \text { para } \\
\text { mulheres) no início do século XXI } \\
\text { - Mortalidade infantil de } 20,7 \text { por } 1.000 \\
\text { nascidos vivos (2006) } \cdot \text { Reduçâo na } \\
\text { prevalência de hanseníase e doenças } \\
\text { preveniveis pela imunização } \\
\text { Expectativa de vida sobe para } 72,8 \text { anos } \\
\text { (69,6 para homens e } 76,7 \text { para mulheres; } \\
2008 \text { ) }\end{array}$ \\
\hline 2011-2016 & $\begin{array}{l}\text { Economia em período } \\
\text { de recessão. Indice de } \\
\text { desemprego em rápida } \\
\text { subida. Queda de } \\
\text { consumo devido ao } \\
\text { cenário de acelerada } \\
\text { inflacaão. Desvalorização } \\
\text { cambial no ano de } 2015 . \\
\text { Investimento estrangeiro } \\
\text { em queda. }\end{array}$ & $\begin{array}{l}\text { Reeleição da } \\
\text { presidente Dilma } \\
\text { Rousseff (PT)(2014) } \\
\text { Presidente Dilma } \\
\text { Roussef eleita e } \\
\text { submetida a } \\
\text { impeachment } \\
\text { Restante do mandato } \\
\text { presidencial exercido } \\
\text { pelo Vice-Presidente } \\
\text { Michel Temer (2016) }\end{array}$ & $\begin{array}{l}\text {-Institui, no âmbito do Sistema Único de } \\
\text { Saúde - SUS - a Rede Cegonha.(2011) •Institui } \\
\text { a Rede de Atenção Psicossocial para pessoas } \\
\text { com sofrimento ou transtorno mental e com } \\
\text { necessidades decorrentes do uso de crack, } \\
\text { álcool e outras drogas, no âmbito do Sistema } \\
\text { Únioco de Saúde (SUS)(2011)·Institui o Plano } \\
\text { de Expansão da Radioterapia no Sistema } \\
\text { Único de Saúde (SUS) (2012)•Institui a } \\
\text { Política Nacional de Atenção Hospitalar } \\
\text { (PNHOSP) no âmbito do Sistema Único de } \\
\text { Saúde (SUS), estabelecendo- se as diretrizes } \\
\text { para a organização do componente hospitalar } \\
\text { da Rede de Atenção à Saúde (RAS) (2013) } \\
\text {-Institui o Sistema de Informação em Saúde } \\
\text { para a Atenção Básica (SISAB) (2013)• } \\
\text { Criação vacina contra a Dengue (2016) } \\
\text {-Institui, no âmbito do Sistema Uninico de } \\
\text { Saúde (SUS), o Sistema de Registro de } \\
\text { Atendimento às Crianças com Microcefalia } \\
\text { (2016) • Participação complementar da } \\
\text { iniciativa privada na execução de ações e } \\
\text { serviços de saúde e o credenciamento de } \\
\text { prestadores de serviços de saúde no Sistema } \\
\text { Único de Saúde (SUS) (2016) }\end{array}$ & $\begin{array}{l}\text {-Chegada do Zika Virus ao Brasil em } \\
\text { meados de } 2013 \text {. } • \text { Estudos sobre a } \\
\text { relação entre o Zika e as anomalias em } \\
\text { bebês (2015). } • \text { Em Fevereiro de } 2016 \text { a } \\
\text { Organização Mundial de Saúde declara o } \\
\text { Zika caso de emergência mundial. • Crise } \\
\text { e Luta na Saúde Mental }(2016) \cdot \text { Luta } \\
\text { contra as superbactérias. }\end{array}$ \\
\hline
\end{tabular}

Fonte: O Sistema de Saúde Brasileiro: História, Avanços e Desafios - P. 16 e 17. Paim et al., 2011 


\subsection{HISTÓRIA DO PRÉ-NATAL NO BRASIL}

Uma apropriada assistência ao pré-natal tem papel indubitavelmente positivo na saúde da gestante e do feto, assegurando a identificação prematura de problemas que se não forem detectados e tratados adequadamente podem levar a consequências permanentes (CHEN et al., 2007; RIBEIRO et al., 2009).

No entanto, a história do pré-natal no Brasil evidencia que durante muitos anos, a gestação foi tratada como um acontecimento meramente feminino e fisiológico e que tinha como acompanhamento da gestação e do trabalho de parto mulheres experientes da família, parteiras, amigas e religiosas (PERROT, 2003; CRUZ et al., 2014).

A industrialização possibilitou o avanço tecnológico em diversas áreas, entre elas, a das ciências médicas, o que propiciou a criação de diversos equipamentos, como por exemplo, estetoscópio, sonar, aparelhos de ultrassonografia entre tantos outros. Tais avanços tecnológicos, conjuntamente com a melhoria da estrutura hospitalar, do surgimento de centros diagnósticos, do aprimoramento de técnicas cirúrgicas e das patologias melhores diagnosticadas, contribuíram demasiadamente para a evolução das práticas médicas e do aperfeiçoamento da obstetrícia, consagrando-se como especialização médica e de enfermagem (CAPRA, 1982; OLIVEIRA, 2001).

No Brasil, o direito à licença-maternidade foi introduzido pela Consolidação das Leis do Trabalho (CLT). Foi aprovada pelo Decreto-Lei n ${ }^{\circ} 5.452$, de $1^{\circ}$ de maio de 1943 estabelecendo respectivamente, a licença gestante de quatro semanas antes e oito semanas após o parto, com salário integral e que no caso de aborto não criminoso, devidamente comprovado por atestado médico oficial, a mulher teria direito a duas semanas de afastamento remunerado e o direito de retornar à função anteriormente ocupada (ANSILIEIRO, 2007).

Com o advento da Constituição Federal de 1988, a licença gestante foi ratificada como direito social e passou a ser de cento e vinte dias, nos termos do artigo $7^{\circ}$, para as seguradas empregada, (urbana e rural), trabalhadora avulsa e empregada doméstica. À Constituição Federal, no que tange à Previdência Social, determinou em seu artigo 201, à proteção à maternidade, especialmente à gestante (ANSILIEIRO, 2007).

Em cumprimento a Lei n ${ }^{\circ} 8.213$ de 14 de julho de 1991, estabeleceu que o saláriomaternidade era devido por cento e vinte dias, com início 28 dias antes do parto e a ocorrência deste sem o número mínimo de contribuições (carência), no caso de segurada 
empregada e trabalhadora avulsa. Para empregadas domésticas o benefício seria correspondente ao valor do último salário-de-contribuição (BRASIL, 1991).

Em 2002, a Lei $\mathrm{n}^{\circ}$ 10.421, estendeu o direito ao salário-maternidade para as beneficiárias da Previdência Social que adotassem ou obtivessem a guarda judicial para fins de adoção. O período de licença está vinculado a idade da criança adotada.

A partir de 2010, sob a Lei $n^{\circ} 11.770$ de 2008 e regulamentada pelo Decreto $n^{\circ}$ 7.052 de 2009, a licença-maternidade passa de 120 para 180 dias em serviços públicos e para empresas privadas, àquelas que concederem a extensão do benefício receberão incentivos fiscais. Com a prorrogação do benefício incentiva-se o aleitamento materno exclusivo pelos seis meses preconizado por especialistas, possibilitando o vínculo mãe e filho, além de contribuir para a saúde da criança e do vínculo materno (BRASIL, 2008).

Apesar dos benefícios constitucionais às gestantes datarem da década de 40, na Atenção Primária à Saúde (APS), apenas em 1960 é que houve a inserção de ações prioritárias para assistência à mulher, com ênfase às demandas relativas à gravidez, ao parto, e à criança (BRASIL, 2006).

A partir dos anos 80, o governo brasileiro pressionado pelos profissionais de saúde, movimentos de mulheres e outras instituições da sociedade civil organizada, iniciaram mudanças relacionadas à forma de atendimento à mulher, que valorizavam a maior participação, informação e compreensão dos seus direitos, propiciando o seu empoderamento e a sua cidadania (HALBE, 2000).

Com a publicação do Programa de Assistência Integral à Saúde da Mulher (PAISM) em 1984, marca-se uma ruptura conceitual com os princípios até então condutores da política de saúde das mulheres e as prioridades nessa área. O PAISM concentrou as propostas de descentralização, hierarquização e regionalização dos serviços, assim como a integralidade e a equidade no atendimento, reunindo ações educativas, preventivas, de diagnóstico, tratamento e recuperação, envolvendo o atendimento da mulher na área de ginecologia, pré-natal, parto e puerpério, no climatério, em planejamento familiar, ISTs, câncer do colo de útero e de mama, além do atendimento de outras necessidades identificadas a partir do perfil epidemiológico da população assistida (BRASIL, 2001; ANVERSA et al., 2012).

O PAISM teve como objetivo principal atender a mulher em todas as fases do seu ciclo de vida, identificando suas necessidades e características. Desde sua criação, o ciclo gravídico-puerperal continua sendo uma das áreas prioritárias desse programa. Para a sua adequada execução é necessário a obtenção de consultórios com estrutura física 
adequada, equipamentos como balança, fita métrica, material informativo, recursos humanos acertadamente capacitados e um sistema de referência e contrarreferência adequado para o atendimento das gestantes nos três níveis de complexidade (ANVERSA et al., 2012).

Diante da constatação dos resultados positivos gerados com a diminuição da mortalidade materno-infantil como decorrência das intervenções voltadas para o prénatal, o Ministério da Saúde (MS) tem assumido nos últimos anos, o comprometimento com a maternidade segura. Como exemplo, o estímulo e a maior gratificação financeira ao parto normal, restrição de pagamento de cesáreas pelo Sistema Único de Saúde (SUS), expansão da atenção ao pré-natal, além da criação de protocolos para regulamentação da assistência (SINASC, 2014; AQUINO, 2015).

Sob esse raciocínio, destaca-se em 1994 a implantação do Programa Saúde da Família (PSF) que surgiu para reestruturar o modelo até então vigente, condensado na figura do médico (modelo médico-hegemônico) e voltado para a doença, com práticas curativas e pouco resolutivas. Como característica do PSF, está a atenção voltada para o indivíduo, com poder sobre seu corpo e decisões sobre sua saúde, equipe multiprofissional participativa no processo de construção do atendimento do usuário e da comunidade, de forma igualitária à equipe médica e não meramente de forma complementar. Em 2006, o PSF deixou de ser programa na APS e passou a ser uma estratégia, visto que o termo programa, denota tempo determinado e estratégia é algo permanente e contínuo. Desse modo, passou a ser denominado Estratégia Saúde da Família (ESF) (DALPLAZ; STEDLLE, 2011).

Os objetivos da ESF são regulados pelos princípios do SUS (universalidade, equidade, integralidade, descentralização e participação popular), centraliza as ações na família e não no indivíduo, e presupõe ações resolutivas e de condução com acompanhamento (MERRHY, 2007).

Dessa forma, com a implantação da ESF, os profissionais da saúde passaram a ter papel preponderante no atendimento, na prevenção e promoção à saúde de uma dada população adscrita ao território geograficamente e estrategicamente dividido. (BRASIL, 2006; ANVERSA et al., 2012; CRUZ; et al., 2014).

Com os protocolos, há uma reorganização da equipe de trabalho e uma valorização da equipe multiprofissional. Com relação as funções exercidas pelo enfermeiro, há o atendimento em forma de consultas de pré-natal, solicitação de exames e até a prescrição de medicamentos devidamente protocolados, além de 
ações educativas, o que permite uma maior independência desse profissional e um maior envolvimento com as gestantes. Já com a presença dos Agentes Comunitários de Saúde (ACS) é possível a busca ativa das gestantes faltosas às consultas, a realização das orientações de saúde, identificação de agravos durante a visita domiciliária, verificação e orientação da situação vacinal (GONÇALVES, 2009; ANVERSA et al., 2012).

Em 2000, foi lançado pelo MS um manual técnico com referências para a rede assistencial, capacitação profissional e normatização das práticas de assistência ao pré-natal. Nesse mesmo ano, foram criados o Programa de Humanização de Pré-Natal e Nascimento (PHPN) e o Sistema de Informação do Programa de Humanização do Pré-Natal e Nascimento (SISPRENATAL) (BRASIL, 2000).

O PHPN foi elaborado a partir da exigência da alteração no modelo assistencial onde a questão da humanização e dos direitos surgissem como princípio norteador. Além disso, estabeleceu o número mínimo de consultas de pré-natal e a idade gestacional de início, os exames laboratoriais necessários para um acompanhamento seguro, ações de educação em saúde e um espaço para discussões entre profissionais e gestores para discussão do modelo atual conformando a uma qualidade existente em países que possuem excelência na assistência no pré-natal (ANVERSA et al., 2012; CRUZ; et al., 2014).

O referido programa (BRASIL, 2000) estabelece como garantia de qualidade para a gestante e o bebê os seguintes critérios:

1. Primeira consulta até a $16^{\mathrm{a}}$ semana de gestação;

2. Garantia da realização dos seguintes procedimentos:

a) No mínimo seis consultas de pré-natal;

b) Uma consulta no puerpério até quarenta e dois dias após o nascimento;

c) Exames laboratoriais;

d) Oferta do teste rápido de HIV, já na primeira consulta, para municípios com mais de 50 mil habitantes;

e) Aplicação da vacina antitetânica até a dose imunizante $\left(2^{\mathrm{a}}\right.$ dose $)$ do esquema recomendado ou do reforço para mulheres já imunizadas há mais de cinco anos;

f) Atividades educativas; 
g) Classificação do risco gestacional na primeira consulta e nas consultas subsequentes;

h) Atendimento às gestantes classificadas como sendo de alto risco garantindo o vínculo e o acesso à unidade de referência para atendimento ambulatorial e hospitalar.

O SISPRENATAL tinha como propósito permitir o acompanhamento adequado das gestantes no programa PHPN. Foi formulado na forma de um banco de dados e é um sistema de informação do DATASUS que exige a alimentação de um número mínimo de informações para uma assistência de pré-natal adequada, como por exemplo, a idade gestacional na data da primeira consulta de pré-natal, exames solicitados e realizados dentro da rotina, situação vacinal antitetânica e consulta puerperal. Contudo, esses dados não estão disponíveis para consulta regular, apresentam problemas de sub registro, o sistema é lento, emperra e por muitas vezes, perde-se informações já digitadas (ANDREUCCI; CECATTI, 2011).

Em 2010, o Estado de São Paulo, com a contribuição de diversos profissionais e baseado no Manual do Ministério da Saúde de 2006, criou o Manual Técnico de Pré-Natal e Puerpério e o Documento de Referência da Linha de Cuidado da Gestante e da Puérpera. Como linha de cuidado, entende-se a agregação de saberes, tecnologias e recursos essenciais ao defrontamento de riscos, agravos, ou condições específicas do ciclo de vida, a ser oferecido de forma organizada por um determinado sistema de saúde. Uma linha de cuidado deve se expressar através de protocolos clínicos, ou seja, padronizações a serem utilizadas na oferta do cuidado para portadores de risco e/ou agravos. Para a sua construção, fatores como a atualidade do conhecimento científico e tecnológico, diagnóstico, tratamento, prognóstico e profilaxia, devem ser respeitados no processo assistencial (SÃO PAULO, 2010).

O referido Manual (2010), considerando as ações do Pacto pela Vida de 2006 e as ações do Plano Estadual de Saúde de São Paulo de 2008, possui as seguintes diretrizes:

1. Respeito à autonomia da mulher na tomada de decisões sobre sua saúde, sexualidade e reprodução;

2. Garantia de acesso da mulher a uma rede integrada de serviços de saúde que propicie abordagem integral do processo saúde/doença, visando à promoção da saúde, o início precoce do acompanhamento das gestantes, a prevenção, diagnóstico 
e tratamento adequados dos problemas que eventualmente venham a ocorrer nesse período;

3. Oferta do cuidado sempre referenciado por evidências científicas disponíveis;

4. Garantia adequada de estrutura física e tecnológica das diversas unidades de saúde para atendimento da gestante e da puérpera;

5. Aprimoramento constante dos processos de trabalho dos profisssionais envolvidos na atenção à gestante e puérpera, valorizando o trabalho em equipe e multidisciplinar;

6. Educação permanente continua dos profissionais de saúde;

7. Incentivo ao parto seguro e ao aleitamento materno.

Em 2011, através da portaria nº1459 do Ministério da Saúde foi criado a Rede Cegonha (RC). Estrutura-se de forma a garantir o ingresso, o acolhimento e a resolutividade, por meio de um arquétipo de atenção voltado ao pré-natal, parto e nascimento, puerpério, transporte sanitário e regulação (BRASIL, 2011).

Os principais indicadores que motivaram a criação, estruturação e implantação do RC foram (BRASIL, 2011; GIOVANNI, 2013):

1. Mortalidade infantil, em especial a neonatal e maternas elevadas, principalmente por causas evitáveis por ações de saúde;

2. Grande porcentagem de óbitos infantis por asfixia intraparto;

3. Intensa medicalização no nascimento: sendo em média $98 \%$ de partos hospitalares, $88 \%$ realizado por médicos, com $52 \%$ de cesarianas incluindo rede pública e privada. Quando se considera somente o setor privado, a taxa de cesárea chega a 82\%;

4. Altos índices de cesarianas apresentam altos índices de infecção puerperal (em média 5 vezes maior que o parto normal), e a decorrente produção de morbimortalidade neonatal, com impactos imediatos, tardios e até mesmo efeitos adversos invisíveis;

Além das questões acima citadas, há uma orientação e uma reivindicação da Organização Mundial de Saúde (OMS), para a realização de parto cesárea exclusivamente quanto há risco para a mãe e/ou bebê e não que este procedimento seja realizado por interesse médico ou dos pais na escolha da data, tendo como influência aspectos culturais, como a escolha do signo, da estação do ano, entre outros fatores (IPEA, 2010). 
Uma das muitas ferramentas existentes e que norteiam os profissionais na decisão sobre a realização da cesária é a Classificação de Robson que utiliza como parâmetros o antecedente obstétrico, número de fetos, apresentação fetal, idade gestacional, início do trabalho de parto (MOURA; FEITOSA, 2017).

A Rede favorece o acesso ao pré-natal de qualidade, ao acolhimento e classificação do risco e vulnerabilidade, à vinculação da gestante à unidade de referência e ao sistema logístico, de transporte e regulação, segurança na atenção ao parto e nascimento, atenção à saúde das crianças de 0 a 24 meses com qualidade e resolutividade, além de ações na questão reprodutiva (MARQUES, 2015).

O Ministério da Saúde, através do Rede Cegonha, busca findar com o padrão convencional de cuidado ao pré-natal, parto, nascimento e puerpério e cuidado das crianças até dois anos de idade. Está condensado primordialmente nas mudanças de atenção à saúde, da gestão e do governo, da cultura e do financiamento, salienta em conceder a mulher a vivência da experiência da gravidez, do parto e do puerpério com segurança, honradez e o respeito dentro dos serviços de saúde (condenando e punindo as violências obstétricas por parte dos profissionais da saúde), às dimensões sociais, afetivas e culturais, étnicas e raciais (BRASIL, 2013a).

Com isso, cada um dos componentes acima citados, atinge outras ações de atenção à saúde, tais como (CARNEIRO, 2013):

1. Concessão de teste rápido para HIV, Sífilis, Hepatite e para gravidez;

2. A orientação e a oferta de métodos contraceptivos;

3. Fomentar o mínimo de seis consultas de pré-natal durante a gestação, exames clínicos e laboratoriais;

4. Assegurar o direito de leito e vinculação da gestante a uma determinada maternidade ou hospital público e vale-transporte ou vale táxi até o local no dia do parto;

5. Qualificar os profissionais de saúde;

6. Criar centros de gestante e do bebê para a assistência à gravidez de alto risco em tempo adequado;

7. Oferecer o Serviço de Atendimento Médico de Urgência (SAMU) ao recém-nascido que necessite de transporte de emergência com ambulâncias equipadas com incubadoras, ventiladores neonatais e demais equipamentos imprescindíveis ao transporte;

8. Desenvolver ações de incentivo ao aleitamento materno. 
Entretanto, a inserção da RC com qualidade e que englobe um número cada vez maior de municípios, se torna um grande desafio, parte disso, se deve as diferenças locoregionais e financeiras encontradas dentro dos diversos estados brasileiros e até mesmo, dentro de cidades localizadas dentro de um mesmo estado, falta de disponibilidade de materiais e o impedimento de acesso de forma igualitária aos serviços oferecidos (CASSIANO, 2014).

Pretendendo melhorar cada vez mais a qualidade da assistência de cada região é imprescindível que se conheça os indicadores loco-regionais de morbimortalidade materno-infantil para que se intervenha em fatores desencadeantes e busque ações de planejamento e melhoria da assistência prestada para as gestantes e aos recém-nascidos. No entanto, a redução de indicadores de morbimortalidade não depende de novos conhecimentos e sim da utilização dos recursos já existentes com conhecimento científico e de forma mais adequada e concreta (KASSAR, 2013).

Em relação as mudanças de gestão e de cultura, a RC propõe a criação e validação de diretrizes clínicas, estruturadas em linhas-guia (guidelines) e protocolos clínicos, assim como as ações de estímulos a mudanças de comportamentos dos profissionais da saúde por meio da educação permanente e também a programação, acompanhamento e avaliação da condição da saúde segundo grupos de risco, resultando alterações de comportamento durante o período gravídico-puerperal (GIOVANNI, 2013).

De forma enfática, a RC surgiu para superar os elevados níveis de segregação e fragmentação dos sistemas de saúde das mulheres e das crianças e tem como principal objetivo a redução da mortalidade materno-infantil por meio da ampliação e qualificação dos serviços de saúde, do combate da violência obstétrica, da oferta de boas práticas, da redução da medicalização e da mercantilização do parto (MARQUES, 2015).

A atenção primária é a principal porta de entrada das gestantes no SUS e o primeiro contato que se tem com os profissionais de saúde. Durante a primeira consulta de pré-natal, realizada preferencialmente pelo enfermeiro, o mesmo deve estar capacitado para a classificação dessa gestante quanto ao risco gestacional e se identificada como risco habitual dar sequência ao acompnhamento, além de realizar encaminhamentos pertinentes, encontrando na RC as informações necessárias para basear sua conduta. Como exemplo, lista-se a solicitação de exames laboratoriais e de imagem e seu resultado em tempo hábil, promoção, prevenção e tratamento de IST para que haja interrupção na cadeia de transmissão, realização da educação em saúde e do planejamento reprodutivo, 
são exemplos de ações essenciais para a melhoria da qualidade do serviço prestado (BRASIL et al., 2013).

Com relação ao Parto, Nascimento, Puerpério e Atenção à Saúde da Criança, deve-se realizar a visita na primeira semana de vida da criança, assim como a visita puerperal, visando a promoção do aleitamento materno, orientações quanto à saúde sexual e reprodutiva, além de observar possíveis sinais de infecção puerperal e problemas de saúde do recém-nascido, que se detectados precocemente, podem ser resolvidos, minimizando o risco de complicações (BRASIL, 2011; BRASIL, 2013).

Apesar de pontos positivos acerca da RC, também devem ser consideradas algumas fraquezas que podem limitar a sua ampliação e como efeito contrário diminuir a sua capacidade. Entre eles, a questão do modelo de gestão federativo do SUS, que tanto lutou pela descentralização e municipalização da saúde, mas que relacionado à RC atrapalha que o Ministério da Saúde (MS) coloque em prática a RC sem que o município deseje, gerando certas desigualdades regionais. Outro fator, é a existência de muitos sistemas e instrumentos de pactuação que não se integram fazendo com que a própria equipe do MS tenha várias atuações por vezes sobrepostas por vezes conflitantes, o que prejudica a tomada de decisões corretas. Finalmente, o pagamento do SUS por produção contribui para a diminuição da qualidade do serviço ofertado (FLEURY; OUVERNEY, 2007).

O Programa Mãe Paulistana (PMP), atualmente também chamado de Rede Cegonha, foi criado em 2006 pela Prefeitura do Município de São Paulo e sofreu atualizações com base no programa RC do MS. Tem como objetivo assistir a gestante no ciclo de gravidez, desde a consulta de pré-natal (no mínimo sete), o parto, puerpério até o segundo ano de vida do bebê. As gestantes que necessitam de vale-transporte para consultas e exames, recebem o benefício gratuitamente, além disso, ao final da gestação e mediante o comparecimento nas consultas de pré-natal e na realização dos exames, recebem o enxoval do programa. Conta ainda, com um canal telefônico operado por enfermeiras, no qual a gestante pode esclarecer suas dúvidas sobre a gestação, parto e puerpério. Durante as consultas de pré-natal alguns informativos, na forma de folhetos, sobre temas referentes a amamentação, controle da pressão arterial e o conhecimento da maternidade antes do parto são entregues para as gestantes para ajudar na orientação (PREFEITURA MUNICIPAL DE SÃO PAULO, 2013). 
A gestante, mesmo saudável, deve receber cuidados regulares e individuais, pois uma atenção efetiva, pode significar a diferença entre a vida e a morte da mãe e/ou do concepto (KASSAR et al., 2013).

Os objetivos universais da assistência ao pré-natal podem ser resumidos em três grandes tópicos:

a) prevenir, identificar e/ou corrigir as condições maternas e fetais que interferem adversamente a gravidez, incluindo os fatores socioeconômicos e emocionais, além das intercorrências clínicas e/ou obstétricas;

b) instruir a paciente sobre a gestação, o trabalho de parto, o parto, a amamentação e o atendimento ao recém-nascido, além de reforçar as orientações sobre os hábitos que podem melhorar as suas condições de saúde;

c) promover o suporte psicológico adequado por parte do seu companheiro, sua família e daqueles que a tem sob seu cuidado, especialmente na primeira gestação, possibilitando à paciente uma melhor adaptação à gravidez e aos desafios que enfrentará ao criar uma família (CRUZ et al., 2014).

Correlacionando os objetivos universais da assistência ao pré-natal e os dados do Brasil, é possível observar que ocorreu uma melhora em relação ao passado, porém distante ainda do ideal. Os números do Sistema de Informações sobre Nascidos Vivos do SINASC de 2014, mostram que a proporção de nascidos vivos com 7 ou mais consultas de pré-natal aumentou de 61,6\% em 2012, para 64,6\% em 2014. De maneira geral, ocorreu melhoria na atenção à saúde das gestantes, mas deve-se destacar que esse indicador esconde diferenças inter-regionais importantes no Brasil. Em 2014 a região Sul, por exemplo, apresentou 75,5\% dos nascidos vivos com 7 ou mais consultas de pré-natal, enquanto na região Norte essa proporção foi de $44,7 \%$.

A redução da mortalidade materna é uma inquietude mundial e consta como a $5^{\mathrm{a}}$ meta a ser alcançada na "Declaração do Milênio das Nações Unidas", cujo lançamento ocorreu em setembro de 2000, em Nova Iorque e foi assinado por 191 países, entre eles o Brasil. Por ser subscritor dessa declaração, o país comprometeu-se a reduzir em $75 \%$ a Razão de Mortalidade Materna (RMM) no período entre 1990 a 2015. Define-se como RMM, número de óbitos femininos, por 100 mil nascidos vivos, em determinado espaço geográfico, no ano considerado. Devido as inúmeras subnotificaçãoes e subinformações sobre óbito materno, há duas décadas, para o cálculo dos dados, há que se adotar um fator de correção, divulgado pelo Ministério da Sáude com a aplicação da metodologia de Ramos. (ORGANIZAÇÃO MUNDIAL DA SAÚDE, 2013). 
Dados do Ministério da Saúde demonstram que, entre o período de 1990 e 2015, o Brasil reduziu a RMM de 141 para 58 óbitos por cem mil nascidos vivos o que representa uma redução de 59\%, o que reafirma que embora tenha ocorrido uma redução importante, ainda se encontra distante da meta estabelecida para o ano de 2015. Os dados de 2015, encontram-se estimados, porém, sem o fator de correção, pois ainda não foram disponibilizados pelo governo (Gráfico 1) (BRASIL, 2011; SIM, 2017; SINASC, 2017).

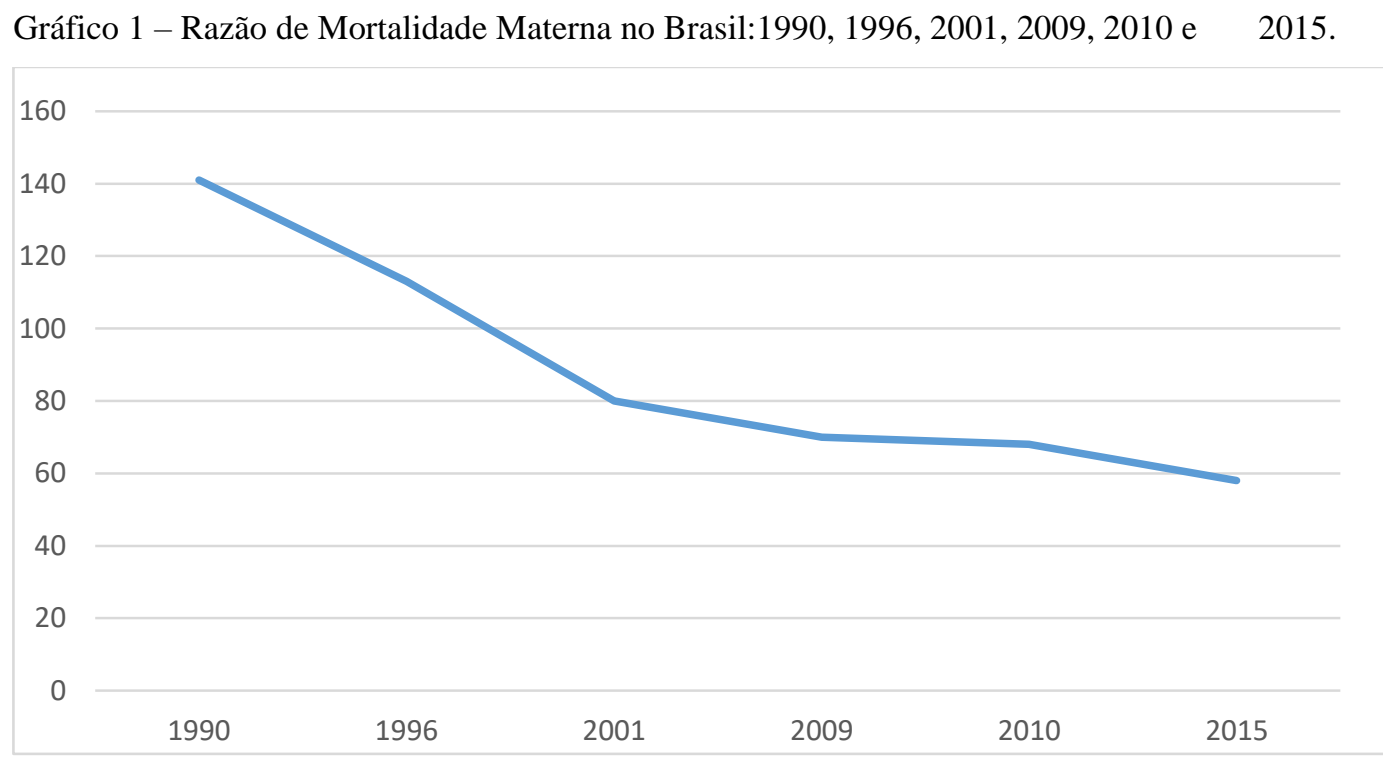

Fonte: SISNAC 2017

Como definição de Mortalidade Materna é toda morte produzida por causa da gravidez, aborto, parto e/ou puerpério até 42 dias após o evento obstétrico, independentemente da duração e do lugar da gravidez, decorrente de qualquer causa relacionada ou agravada pela gestação ou seu manuseio, mas não em consequência de causas acidentais ou incidentais (SAY, 2014).

As mortes maternas podem ser classificadas como ocasionadas por causas obstétricas diretas e indiretas. As diretas são resultadas de complicações surgidas durante a gravidez, o parto ou puerpério (período de até 42 dias após o parto), oriunda de intervenções, omissões, tratamento inadequado ou de uma relação de eventos associados a qualquer um desses fatores, como exemplo, Síndrome Hipertensiva Específica da Gravidez (SHEG), hemorragias, aborto, infecção puerperal e anormalidade da contração uterina (BRASIL, 2012). 
As causas indiretas derivam de doenças preexistentes ou que se desenvolveram durante o curso da gravidez e que foram agravadas pelos efeitos fisiológicos da gestação, como por exemplo, diabetes tipo 1 e 2, hipotireoidismo, hipertireoidismo, hipertensão arterial sistêmica, AIDS, malária, obesidade entre outras. Excetuando-se as infecções urinárias e o aborto, a prevenção de todas as causas mais comum de óbito materno depende basicamente da assistência hospitalar pronta e qualificada às emergências e ao parto (BRASIL, 2012; MARQUES, 2015).

A mortalidade materna por causas obstétricas diretas, vem decaindo de forma expressiva, enquanto aquelas por causas indiretas vêm se mantendo nos últimos anos como resposta da melhoria nas investigações de óbitos suspeitos. A análise da razão entre mortalidade materna por causas diretas e causas indiretas demonstra mudanças importantes no padrão do Brasil. Em 1990, a mortalidade direta era 9,4 vezes superior à mortalidade por causas indiretas. Tal relação reduziu-se para 3,5 vezes, em 2000, e para 2,2 vezes, em 2011, conforme gráfico 2 (DATASUS, 2011).

Gráfico 2 - Razão de Mortalidade Materna por Causas Obstétricas Diretas e Indiretas (por grupo de 100 mil nascidos vivos). Brasil, 1990, 2000, 2010 e 2011.

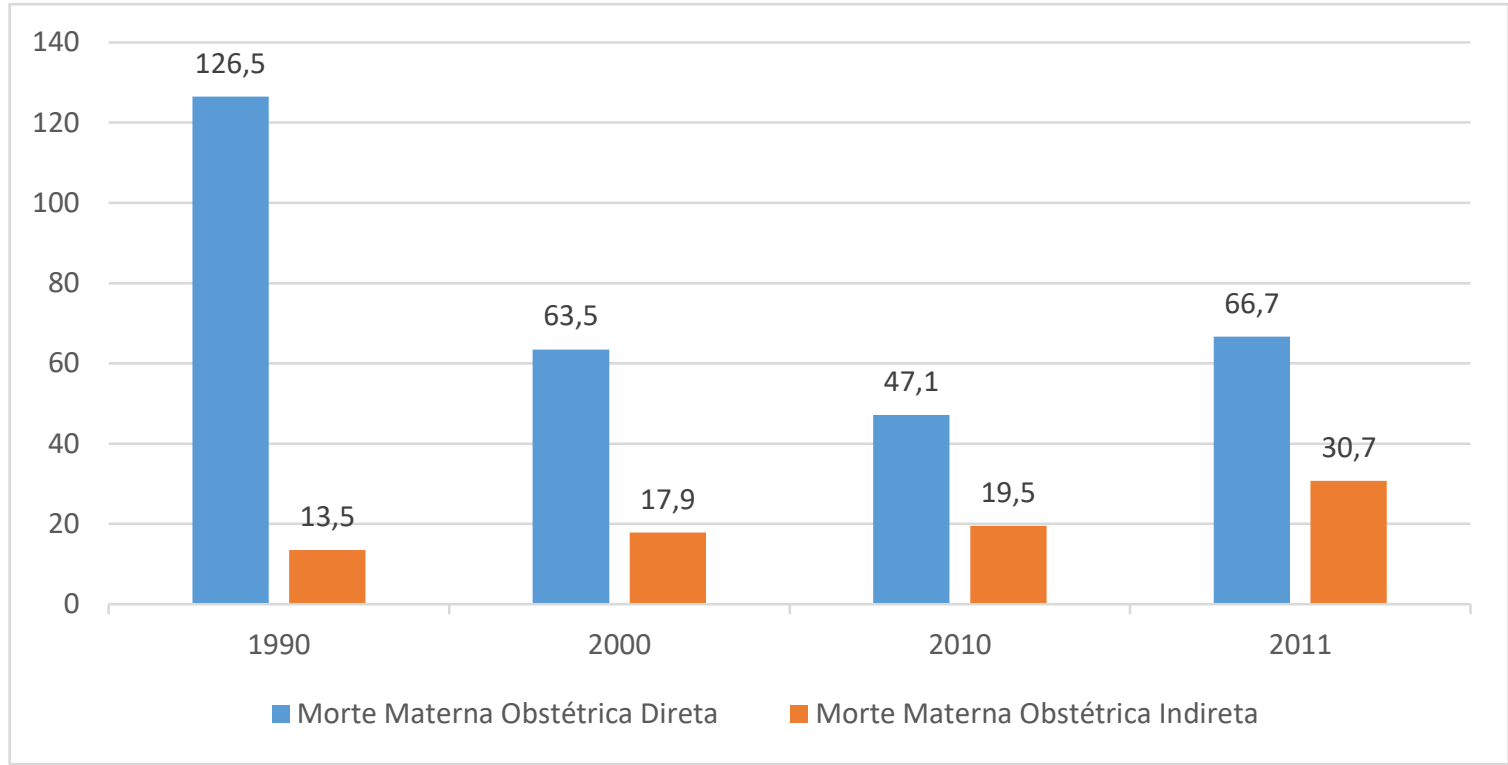

Fonte: Data SUS - 2017

As duas fundamentais causas específicas de morte materna no Brasil são a hipertensão e a hemorragia. Outras causas diretas importantes são a infecção puerperal e o aborto. Entre as causas indiretas, a de maior relevância epidemiológica tem sido a doença do aparelho circulatório (Gráfico 3) (DATASUS, 2011; MARQUES, 2015). 
Gráfico 3 -Razão de Mortalidade Materna por Causas Específicas de Morte (por grupo de 100 mil nascidos vivos). Brasil, 1990, 2000, 2010 e 2015. Dados preliminares 2015, extraídos do SIM.

Fonte: DataSUS - 2017

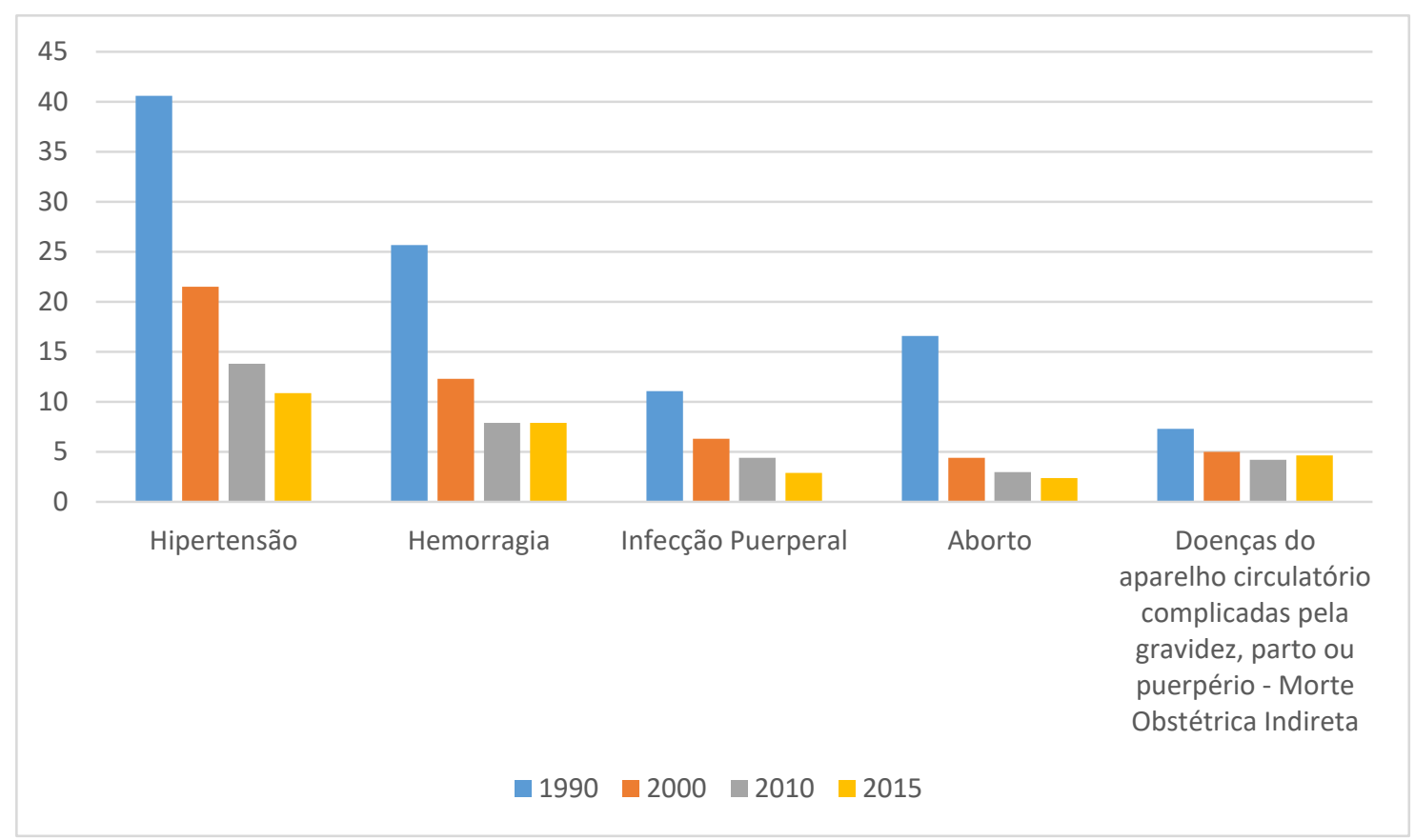

No Brasil, desde 1980, trabalhos vem sendo elaborados com o objetivo de melhorar a cobertura e a qualidade das informações sobre mortes maternas. Entre eles, vale reforçar a implantação e estruturação de comitês de mortalidade materna e a institucionalização da vigilância do óbito materno (PortariaMS/GM nº 119/2008). A vigilância do óbito materno tem como principais metas corrigir as causas de óbitos, identificar os óbitos maternos não declarados e indicar as circunstâncias que propiciaram as mortes e para isso, Comitês de Mortalidade Materna têm sido formados em diversos estados e municípios (BRASIL, 2012).

Uma das estratégias para a expansão da captação (notificação) é a investigação de óbitos de Mulher em Idade Fértil (MIF), com o intuito de conhecer mortes maternas não declaradas. O Ministério da Saúde vem investindo em manuais e na capacitação de profissionais para o adequado preenchimento dos formulários e a devida notificação das investigações em tempo hábil. Ainda assim, há Estados da Federação que permanecem abaixo da taxa de notificação exigida de 60\%, como é o caso dos Estados do Amazonas, Roraima, Alagoas, Goiás, Maranhão, Distrito Federal, Bahia e Pará (SIM, 2011).

Cabe salientar que a vigilância dos óbitos é de suma importância para propiciar dados a gestores e técnicos da saúde nas três esferas do Governo e com isso, implementar 
políticas públicas de saúde efetivas no combate a morte materna e de mulheres em idade fértil por causas evitáveis (BRASIL, 2007).

Em relação à mortalidade infantil, houve diminuição de cerca de 53\% desses óbitos nas últimas décadas. Em 2000, a mortalidade infantil era de 29,02 óbitos por mil nascidos vivos e em 2015, de 13,8 óbitos por mil nascidos vivos. (IBGE, 2016).

Gráfico 4 - Taxa de Mortalidade Infantil por mil nascidos vivos - Brasil - 2000 a 2015

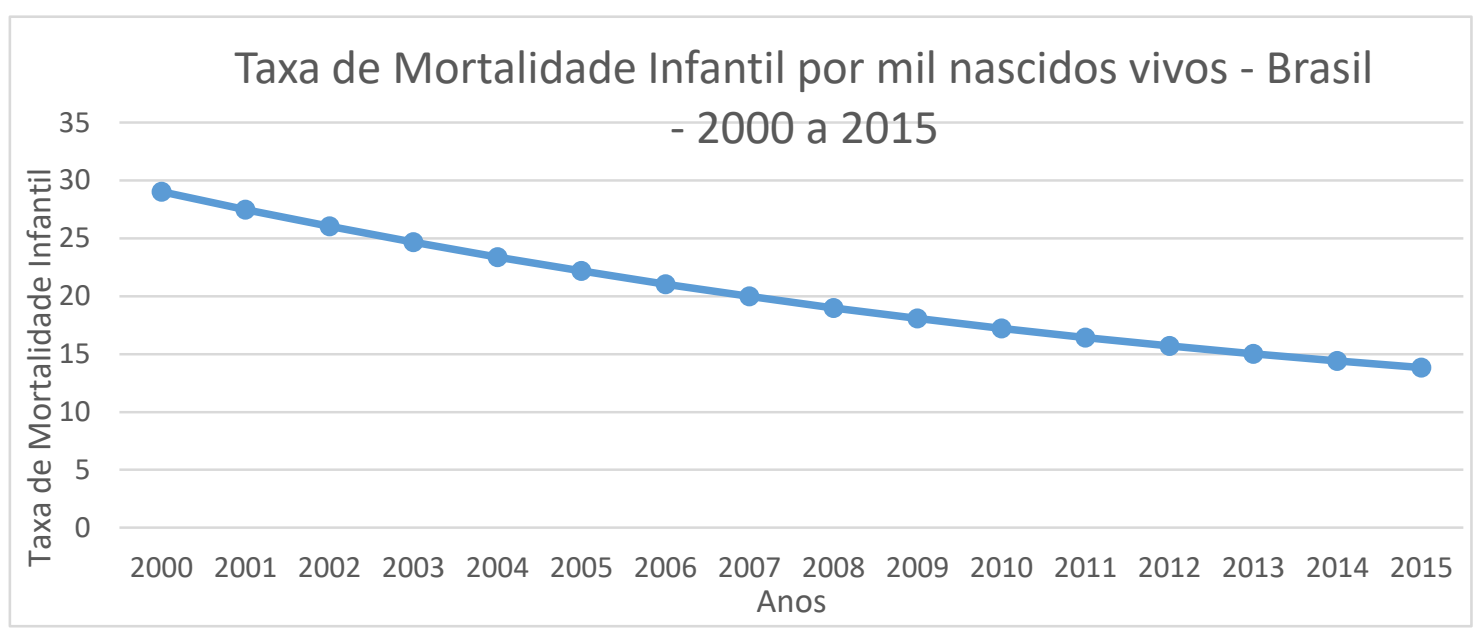

Fonte: IBGE, 2016

Com relação ao Pré-Natal e sua classificação como baixo ou alto risco, a Prefeitura do Município de São Paulo trabalha com um impresso próprio disponibilizado para todas as Unidades de Saúde, no qual médico e enfermeiro durante a consulta com a gestante, realizam a sua classificação e seu posterior encaminhamento, caso ela seja classificada como alto risco. Defini-se como pré-natal de alto risco a existência de qualquer doença materna ou risco sócio-biológico que possa prejudicar a boa evolução da gestação.

Abaixo, segue o quadro utilizado pelos profissionais (médicos e enfermeiros) para a avaliação do risco gestacional (ORGANIZAÇÃO MUNDIAL DA SAÚDE, 2012): 
Quadro 2 - Quadro de Risco Gestacional

Quadro de risco gestacional (na presença de qualquer um desses fatores, a assistência deverá ser individualizada ou referenciada para serviços especializados segundo protocolo de encaminhamento do Rede Cegonha)

\begin{tabular}{|c|c|c|}
\hline $\begin{array}{l}\text { Antecedentes } \\
\text { Obstétricos - AO }\end{array}$ & Gestação Atual - GA & HCG \\
\hline $\begin{array}{l}\text { 1. Óbito } \\
\text { Fetal/Morte } \\
\text { neonatal precoce }\end{array}$ & 1. Gestação \\
múltipla & 1. Diabete Melito \\
Tipo 1
\end{tabular}

Fonte: Ensaio clínico aleatorizado de controle do pré-natal da OMS: "Manual para a prática de um novo modelo de assistência pré-natal” - Organização Mundial da Saúde 2012

Portanto, toda gravidez deveria ser precedida por uma avaliação, que envolve a averiguação no casal e nas suas famílias de condições patológicas que possam dificultar na formação e no desenvolvimento do futuro concepto; diagnóstico e tratamento de patologias (ginecopatias, principalmente) capazes de atrapalhar o engravidar; orientação sobre a fecundação e elucidação das dúvidas sobre o ciclo gravídico-puerperal; e facilitar 
o acesso prematuro às unidades de saúde como forma de iniciar vínculo e continuidade da assistência desde o momento que se inicia o preparo da concepção (FEBRASGO, 2000).

Sendo assim, e seguindo as próprias normatizações do Manual Técnicodo PréNatal e Puerpério do Estado de São Paulo de 2010, o encaminhamento da gestante para a rede referenciada não deve ser compreendido como uma "resolução de problemas" e sim como mais uma forma de cuidado para a saúde da mulher e do feto. A unidade que realizou o encaminhamento deve continuar com a responsabilidade sobre $\mathrm{o}$ acompanhamento dos cuidados prestados, ainda que realizados por outra unidade.

O encaminhamento também deve ser avaliado quanto às questões sociais, de distância e patologias que realmente não possam ser acompanhadas pela APS. Todas as condutas devem ser registradas em prontuário e a unidade de referência deve acompanhar o fechamento da história, além de estabelecer um fluxo para a troca de informações (ESTADO DE SÃO PAULO, 2010).

O relatório de encaminhamento deve ser preenchido em letra legível incluindo nome do profissional responsável e telefone para qualquer esclarecimento necessário. Além disso, informações como diagnóstico, condutas terapêuticas adotadas, medicações prescritas e exames solicitados devem constar no encaminhamento (ESTADO DE SÃO PAULO, 2010). 
2 REFERENCIAL TEÓRICO: O SISTEMA DE REFERÊNCIA E CONTRARREFERÊNCIA 


\section{REFERENCIAL TEÓRICO: O SISTEMA DE REFERÊNCIA E CONTRARREFERÊNCIA}

Os mecanismos de referência e contrarreferência formam um dos instrumentos do princípio da integralidade. Considerando a hierarquização da rede, tais ferramentas representam um dos artifícios de articulação entre as inúmeras instituições. Em conjunto com a integralidade, o princípio da descentralização transpõe a base da edificação do sistema de saúde, por se correlacionar com o poder e a autonomia, tencionando a organização de cada nível de serviço, que forma o cenário de saúde atual (MAEDA, 2002).

O Relatório Dawson, elaborado pelo Ministério da Saúde do Reino Unido em 1920, é considerado um dos primeiros documentos a utilizar o conceito de Atenção Primária à Saúde em uma concepção de organização estruturada de forma regionalizada e hierarquizada dos serviços de saúde, por nível de complexidade e em conformidade com uma base geográfica definida. A origem desse documento interferiu em vários países na criação de sistemas de saúde, entre eles o Brasil e a posterior criação do SUS (LAVRAS, 2011).

Este documento apresentou as concepções de território, populações adscritas, porta de entrada, vínculo e acolhimento, referência e atenção primária como a base do cuidado prestado e implantou uma disposição integrada dos diversos estabelecimentos de saúde com diferentes níveis de complexidade, com a divisão de uma rede de atenção primária, secundária e terciária. Tinha como premissa, o acesso universal e a oferta de serviços de acordo com as necessidades da população e de regiões geográficas anteriormente identificadas. Conjecturou médicos generalistas como profissionais de primeiro contato com o paciente, serviços de atenção domiciliar gerenciada pelo corpo de enfermagem e apoiados por centros de saúde primários, com o auxílio de laborátorios e acomodação para internação, determinando uma visão multiprofissional de assistência ao paciente, contrapondo a visão medicolocêntrica até então existente (MAEDA, 2002; CONASEMS, 2013).

Com a intenção de amparar a abordagem de referência e contrarreferência pretende-se explorar as discussões perfazendo a questão da descentralização, da regionalização e dos distritos de saúde para então, vincular os elementos dos princípios da hierarquização e integralidade e por fim a questão da referência e contrarreferência e 
sua comunhão com a gestão no funcionamento do sistema, garantindo seu êxito, como proposta final.

O texto constitucional define que o SUS deve se estruturar a partir da “descentralização, com direção única em cada esfera de governo” (MATTA, 2007; BRASIL, 1988). A diretiva de descentralização do SUS apresenta-se como uma habilidade de constituição de um Estado federativo que deve promover e respeitar os direitos constitucionais individuais e coletivos em cada esfera de governo, como também como uma ferramenta de reordenação do sistema de saúde (BOBBIO; MATTEUCI; PASQUINO, 1995).

A descentralização não garante por si só sua eficácia, pois, a medida que ela ocorre, formam-se sistemas municipais de saúde, com diferenças de resultados e da qualidade do serviço oferecido, visto que, muitos municípios não possuem infraestrutura e gestão qualificada para o gerenciamento eficiente dos recursos provenientes do Estado e da Federação, e não recebem o apoio técnico (dos Estados e da União) necessário para sanar deficiências muitas vezes simples, que permitiriam resultados promissores junto da população atendida (SPEDO et al., 2009).

A descentralização dificilmente será encontrada em seu estado puro ou será concretizada em sua raiz. Haverá sempre uma simultaneidade com a centralização, na dependência de forças políticas em um dado momento histórico (SPEDO et al., 2009).

O papel dos estados no processo de municipalização tem-se tornado mais burocrático que agregador de estratégias de negociação e de consolidador de pactos e convênios que fortaleçam a rede de ações e serviços de seus cidadãos (GUIMARÃES; GIOVANELLA, 2004; MATTA, 2007; VIEIRA-DA-SILVA et al., 2007).

Ainda assim, os progressos alcançados no sentido de promover a descentralização das políticas de saúde são, claramente, responsáveis por tornar acessível e pelo aumento da qualidade de serviços, principalmente na APS, não somente para a população, como também, pela melhoria dos indicadores de saúde nacional, alavancados vertiginosamente com a implantação da ESF, que permitiu a criação de uma nova categoria profissional, os ACS, que como membro de uma equipe multiprofissional, próximos e inseridos no contexto da população atendida, contribuíram para o aumento da cobertura vacinal, melhoria da assistência ao pré-natal, redução da mortalidade infantil e de internações desnecessárias (DUARTE et al., 2015).

Dessa forma, em conjunto com a descentralização, a regionalização colabora para a formação do SUS e seu funcionamento. Caracteriza-se por uma aplicação racional dos 
recursos de saúde, agregando e compondo dentro de uma disposição hierárquica, o maior número de recursos possíveis para a atenção nos níveis primário, secundário e terciário, de acordo com as necessidades individuais e coletivas da população (NOVAES; CAPOTE, 1990; MAEDA, 2002).

O processo de regionalização pode ser caracterizado de forma ampla, ou seja, consiste na tentativa de estruturar os serviços como forma de torná-los mais eficientes e eficazes, de favorecer com que se atinja os princípios do SUS de universalidade, integralidade e equidade com maior qualidade e ao menor custo financeiro e geográfico, com a elaboração de regiões de saúde a partir das características epidemiológicas de determinada população vivendo em um determinado espaço e tempo (DUARTE et al., 2015).

O processo de regionalização só tem nexo quando associada com a hierarquização. Contudo, a direção dessa regionalização/hierarquização, deveria ser uma via de mão dupla com os chamados encaminhamentos de referência e contrarreferência, no qual o paciente ao ser encaminhado da APS para serviços com suporte tecnológico superior, deverá permanecer com o paciente sob sua tutela, permanecendo com o acompanhamento de sua situação de saúde dentro de todo o sistema. A realização do encaminhamento para uma unidade de referência, não deve ser considerado por gestores e equipe, como um "fïm" dentro do sistema, gerando a sensação de alívio e resolutividade do processo de doença daquele paciente, pois, após sua estabilização deverá o mesmo ser contrarreferenciado, ou seja, retornar para a APS, dando sequência ao seu tratamento e cuidados de saúde, sejam eles preventivos, curativos ou paliativos (DUARTE et al., 2015).

Durante as reuniões sobre a implementação do SUS, muito se abordou sobre as criações de regiões de saúde. Suas construções, estão no fim dos anos de 1980 e início de 1990 com o processo de distritalização que vinha de encontro com as propostas da Organização Pan-Americana da Saúde (OPAS), na elaboração dos Sistemas Locais de Saúde (SILOS), desenvolvidos para responder as necessidades sociais de saúde e não simplismente como contenção de gastos que era orientado pelo Banco Mundial (PESSOTO, 2010).

A teoria da organização do Distrito Sanitário reforça a distinção entre dois modelos conceituais: o Distrito Sanitário como modelo organizacional-gerencial de recursos/serviços de saúde num dado território, e o Distrito Sanitário como modelo assistencial para atenção/prestação de saúde a uma dada comunidade. No primeiro caso, 
as preocupações são essencialmente com a estruturação, o comando gerencial das unidades e com a vinculação e hierarquização dos estabelecimentos de saúde, segundo os níveis primário, secundário e terciário. No segundo caso, as combinações de certas tecnologias são solicitadas em função de problemas de saúde voltados para o individual e o coletivo (PAIM, 1995; MAEDA, 2002).

O processo de criação e instalação do Distrito Sanitário, deve ser visto como um modelo social, assim como é o SUS, isto é, como uma concretização de uma política pública de caráter social. Para a formação dos Distritos Sanitários, são fundamentais a abordagem dos seguintes temas: território, problemas, práticas sanitárias e processo de trabalho (MENDES, 1993).

A territorialização pressupõe o reconhecimento do espaço na óptica de construção de uma região de saúde singular das demais, e, portanto, solicitando políticas de intervenção específicas para uma determinada região, para além das políticas municipais, estaduais e da União (DUARTE et al., 2015).

Por fim, o distrito é uma parcela administrativa com alguma forma de governo local que assume responsabilidades conferidas pelo governo central. É considerado a junção administrativa entre o planejamento de estâncias superiores e a participação da comunidade de estâncias inferiores (WHO, 1993; ALMEIDA et al., 1998, DUARTE et al., 2015).

A hierarquização do sistema, busca organizar por níveis de atenção e designar fluxos assitenciais entre os serviços, de modo a controlar o acesso aos mais especializados. Surgiu no lugar do antigo modelo hospitalocêntrico, que orientava a população a buscar os hospitais para todo e qualquer problema de saúde. Ter um sistema hierarquizado é ter um sistema com um menor número de problemas e mais estruturado, no qual ocorre uma preponderância de ordem e como consequência um aumento de eficiência (QUINELLATO, 2009).

Dessa forma, buscou-se dividir à assistência à saúde em níveis de complexidade crescente, sendo a atenção primária representada pelas UBSs como porta de entrada do usuário, o secundário com serviços de média complexidade e o terciário com serviços de alta complexidade. Porém, a evolução dessa complexidade deve seguir uma averiguação criteriosa da comunidade para o entendimento de suas reais necessidades de saúde. Deve haver recursos terapêuticos e diagnósticos suficientes em cada nível, desenvolvendo de forma correta o sistema de refêrencia e contrarreferência, garantindo o fluxo de pacientes, o acesso aos serviços existentes e a necessidade de construção de normas e protocolos 
que regulem a existência desses níveis. Além disso, devem ser enumerados a distinção de recursos humanos, físicos, tecnológicos, de responsabilidade, de funções e limitações para as necessidades de cada nível de saúde (MAEDA, 2002; QUINELLATO, 2009).

Sendo assim, acarreta aos serviços ofertar para uma determinada comunidade, todas as modalidades de assistência e todo tipo de tecnologia disponível, permitindo ao serviço manter um alto grau de resolubilidade. Entende-se por resolubilidade (BRASIL, 1990): “A exigência de que, quando um indíviduo busca atendimento ou quando surge um problema de impacto coletivo sobre a saúde, o serviço correspondente esteja capacitado para enfrentá-lo e resolvê-lo até o nível de sua competência” (p.5).

Cabe reforçar, que há apenas alguns anos o modelo assistencial enfatizado na APS tem sido visto como um modelo estratégico e de êxito para o atendimento de qualidade de seus usuários e não como um modelo pouco resolutivo, de baixa complexidade, que atende apenas menos afortunados com ações paliativas e simplistas (ROUQUAYROL; FILHO, 2003; QUINELLATO, 2009).

Os sistemas efetivos de APS tem impactos positivos na melhoria de indicadores de saúde da população, já que geograficamente encontram-se juntos a ela, porém não necessariamente mais acessíveis, devido principalmente aos dias e horários de funcionamento (segunda à sexta, no horário comercial). Porém, apesar de ainda de forma precária, já vem ocorrendo em algumas partes do território brasileiro, a mudança na forma de criação e funcionamento dessas unidades, com extensão do horário de fechamento e abertura das unidades aos fins de semana, possibilitando que usuários que antes não conseguiam acesso, tenham a oportunidade de introduzir-se no sistema, e com isso, evoluir na melhoria da situação de saúde (ANDRADE et al., 2006).

Como afirmado anteriormente, a hierarquização do SUS estabelece a porta de entrada do ususário pela APS e que quando bem arquitetado e ordenado, resolve cerca de $80 \%$ dos principais problemas. Os casos não resolvidos neste nível de atenção devem ser referenciados aos demais níveis de complexidade. O nível secundário é formado pelos centros de especialidades e resolve $15 \%$ dos problemas de saúde, o terciário, engloba hospitais de referência e resolvem os $5 \%$ dos problemas de saúde restantes (SILVA; SUZANA, 2007).

A expressão "porta de entrada" é utilizada como sinônimo de acesso e configurase como a forma com que o usuário adentra no sistema de saúde e tem a possibilidade de continuidade na APS ou seu referenciamento para as demais estâncias e pode ser dividido em acesso pontencial e realizado. O primeiro, caracteriza-se pela presença no contexto 
dos indivíduos de fatores capacitantes do uso dos serviços, enquanto o segundo, denota de fato a utilização dos serviços ofertados. Atualmente, novos conceitos foram inseridos no processo de entrada aos sistemas de saúde, como o acesso efetivo, que resulta no uso de serviços que melhore as condições de saúde ou a satisfação das pessoas com os serviços e a utilização eficiente que se refere ao grau de mudança na saúde ou na satisfação em relação ao uso de serviços de saúde utilizados (TRAVASSOS; MARTINS, 2004).

Portanto, embora de fundamental importância para o funcionamento do SUS, a hierarquização possui alguns entraves que devem ser analisados e aprimorados para que de fato a legislação consiga caminhar em harmonia com a realidade, como por exemplo, a ampliação do acesso das equipes de ESF muito além da quantidade, mas também associado a qualidade do serviço ofertado, expandindo o seu poder de resolubilidade, com a qualificação dos profissionais envolvidos na asistência e assegurando o apoio matricial de especialistas com a intenção de orientação no processo de atendimento e conduta terapêutica (QUINELLATO, 2009).

Outro fator imprescindível, é o investimento aplicado na atenção terciária em desalinho com a atenção primária, diminuindo ações de prevenção e promoção à saúde, em busca da construção de grandes centros hospitalocêntricos com atividades sobretudo curativas, porém que são vistos pela população como um modelo de gestão "eficiente" e garantidor de votos (QUINELLATO, 2009).

Em 2016, foram gastos com a saúde pelo governo federal cerca de $\mathrm{R} \$ 111$ bilhões de reais, o Estado de São Paulo gastou $\mathrm{R} \$ 23$ bilhões, uma média de $\mathrm{R} \$$ 536,30 por habitantes/ano e o Município de São Paulo R \$ 54 bilhões, uma média de R \$ 844,82 por habitantes/ano, o correspondente a 38,30\% na APS e de 27,04\% na Assistência Hospitalar e Ambulatorial no primeiro semestre de 2016. Tais dados, demonstram o pouco investimento na saúde, além de gasto muito próximo entre Atenção Primária, Secundária e Terciária, demostrando a precariedade de recursos no setor primário que absorve e resolve a maior parte dos problemas de saúde da população. Devido as políticas de saúde anteriores ao SUS, a hierarquização deixou como herança uma desigual distribuição dos equipamentos de saúde, entre as já desiguais regiões brasileiras, complicando o acesso da população a exames relativamente simples, como exemplo, o número ínfimo de mamógrafos na região Norte do Brasil que impede que milhares de mulheres realizem o exame e tenham a oportunidade de detectar precocemente o câncer de mama e iniciar o tratamento a tempo (SIOPS, 2016). 
Se fosse aplicada da forma como concebida e descrita na Lei do SUS, a hierarquização deveria ocorrer de forma generalizada, no entanto, pacientes ainda têm entraves ao acesso para tratamentos mais complexos, provenientes da falta de organização ao atendimento, principalmente no serviço de referência, pois, ao perceberem a demora que ocorre para encaminhamentos para serviços de maior complexidade "ludibriam" o sistema e utilizam diretamente os hospitais, sobrecarregando os serviços de urgência e emergência com patologias que poderiam ser solucionadas nas UBS. Além disso, a marcação de consultas com especialistas pela APS, provocam longas esperas que resultam muitas vezes, em absenteísmo à consulta agendada. Com tudo isso, a pirâmide representativa da estrutura e organização da saúde, ratifica que há fundamentos teóricos, mas na prática, o usuário se defronta com uma realidade muito diversa (CECÍLIO, 1997; CAMPOS, 2006).

A concepção de integralidade surgiu na Inglaterra em 1948, com a expansão das políticas sociais e dos sistemas de saúde a partir da criação do NHS (National Health Service), o sistema de saúde inglês gratuito e de acesso para toda população que salientava a responsabilidade coletiva por serviços oferecidos (CONILL, 2004).

No artigo $7^{\circ}$, inciso II, da Lei $n^{\circ} 8.080 / 90$ a integralidade é conceituada como (BRASIL, 1990a): “um conjunto articulado e contínuo das ações e serviços preventivos e curativos, individuais e coletivos, exigidos para cada caso, em todos os níveis de complexidade do sistema".

O conceito de integralidade, quando averiguado pode ser entendido como polissêmico, ou seja, com vários sentidos, já que pode ser utilizado como uma mistura de serviços, como visão holística do sujeito sob cuidados, como ações direcionadas ao atendimento integral de reivindicações e necessidades (MAEDA, 2002; SILVA; RAMOS, 2010; BRITO-SILVA et al., 2012).

Nesse sentido, integralidade presume acesso a bens e serviços, criação, gestão e controle participativo nas políticas públicas, assim como a interação usuário/profissional sem que se perca do foco o direito de viver e ser tratado com respeito e dignidade em todas os ciclos da vida, na saúde, na doença e na morte (VIEGAS; PENNA, 2013; SILVA;2015).

Diante de diversos conceitos polissêmicos, este estudo focalizou a integralidade, como uma grade de serviços em diversos níveis de complexidade e competências, no qual as ações entre a atenção primária, secundária e terciária se realizam e se enredam em um conjunto de cuidados demandados para um indivíduo ou determinada comunidade. Como 
papel essencial, destaca-se a atuação de gestores que organizam e coordenam os serviços de saúde e desenvolvem articulações facilitadoras de uma integralidade entre os diversos níveis de complexidade e competências de uma grade de serviços (STARFILD, 2002; SILVA, 2015).

Para a integralidade sistêmica vingar e deixar de apenas se mostrar de forma diferente entre a teoria e a prática, é essencial o uso de tecnologias de gestão que possam diminuir a descompartimentalização entre os diversos serviços existentes e dessa forma, favorecer a integralidade nas ações de saúde. Como sugestão, a instalação de novas equipes de saúde da família, reconhecimento e atualização do território que sempre está em constante alterações e sua redivisão quando necessário, além da clínica ampliada, com a discussão de casos entre os profissionais da APS e da clínica ambulatorial permitindo uma maior resolubilidade de casos, favorecendo a diminuição de referências muitas vezes desnecessárias e que tanto provocam o aumento pela espera por um especialista (COSTAe-SILVA et al., 2007).

Vale ressaltar, que a integralidade não deve apenas se ater entre os níveis de atenção à saúde e sempre que possível deve-se buscar interligação com outras áreas, como educação e comunidade, que influenciam e ocasionam repercussões no indivíduo e na coletividade. A enfermagem, enquanto categotia profissional ligada diretamente ao cuidado, e, portanto, muito próxima ao usuário, em todas as suas esferas de atenção (primária, secundária e terciária), tem papel preponderante na implementação da integralidade em todos os sentidos anteriormente descritos (REIS; ANDRADE, 2008).

Devido ao panorama atual existente, definiu-se a referência como um processo de movimentação do nível de menor para o de maior complexidade e o da contrarreferência como o processo inverso, do nível de maior para o de menor complexidade. Para o seu funcionamento, é necessário o estabelecimento de protocolos clínicos de conhecimento em todos os níveis de atenção, formulário próprio contendo espaços específicos para preenchimento do profissional que encaminha e para o profissional que recebe, tendo o receptor o compromisso de devolvê-lo para emissor, com as orientações da conduta adotada, sugestões de tratamento e forma de condução de eventuais problemas (MAEDA, 2002).

É necessário que facilitadores do processo de referência e contrarreferência sejam implementados para agilizar, qualificar e garantir o êxito do encaminhamento, entre eles:

- A equipe de Atenção Primária à Saúde como coordenadora do cuidado junto a Rede de Atenção à Saúde deve desenvolver ferramentas de encaminhamento para 
consulta especializada, registrar os usuários classificados como de maior risco encaminhados e acompanhar a sua comprovação de atendimento, ter em suas unidades protocolos orientadores de prioridade para encaminhamento e de diretrizes terapêuticas para serem aplicadas;

- Integração da Rede de Atenção à Saúde é responsável pelo ordenamento e definição de fluxos (existência de central de regulação para marcação de consultas especializadas, exames e gerenciamento de leitos, ficha de encaminhamento padronizada nas diversas instituições), referências e fluxos pactuados pela gestão municipal para atendimento de usuários do território, estimular e garantir o contato de profissionais da APS com especialistas para incentivar e proporcionar a troca de informações sobre pacientes encaminhados e condutas tomadas e caso ocorra a devolução do paciente para a APS, que o tratamento possa ser continuado e aprimorado, sem resultar em dúvidas e prejuízos ao usuário, criação de fluxo institucionalizado de comunição entre profissionais (telefone, e-mail, grupos de mensagem) lista de contato nas UBSs para comunicação com especialistas, entre diversas maneiras que possam favorecer a qualidade da assistência prestada ao paciente e consolidar o elo entre os profissionais envolvidos (FRATINI, 2008; PROTASIO et al., 2014).

Um dos grandes entraves encontrados pelos usuários quando são referenciados para a consulta com especialistas é o tempo de espera exarcebado, propiciando muitas vezes, um agravamento da situação de saúde e uma demanda para o Pronto Socorro na intenção de garantir o atendimento médico, ainda que não seja com o especialista. Em um trabalho realizado na Paraíba, dos pacientes encaminhados para consulta com especialista, somente 10,2\% dos usuários saem da UBS com consulta agendada e 47,2\% a consulta é marcada pela unidade de saúde e posteriormente o usuário é avisado, o que pode contribuir muitas vezes para o aumento do absentísmo, pois o paciente pode não ser localizado em data conveniente para se apresentar ao agendamento, ou ainda, os dados fornecidos para contato, já estão desatualizados, impedindo que o paciente seja informado. Esse dado é importante, pois demonstra problemas no fluxo que podem ser imputados à falta de planejamento e organização, ocasionando um tempo médio de espera alto e como efeito o descontentamento dos usuários (FRATINI, 2008; PROTASIO et al., 2014).

Um outro problema, é o excedente do número de encaminhamentos que ocorrem quando a atenção secundária é mal utilizada e a atenção primária faz uso de tal recurso como maneira de se ver livre do problema e pressupor que dentro do seu nível de 
atendimento não existe tecnologia satisfatória para o atendimento de usuários que distoam do padrão habitual de atendimento. No Reino Unido por exemplo, como maneira de diminuir o período do paciente na continuidade dos tratamentos, foram acordadas metas entrelaçadas para cada etapa, contendo consultas com especialistas, realização de exames, referência para outras especialidades e tratamento cirúrgico (WILLCOX, 2007).

Dentro desse panorama, muitos comentários foram designados à estratégia acima descrita, como um método de comedimento de recursos e omissão com a saúde do paciente, porém, observando e analisando sobre outro ponto de vista, é presumível acreditar que quanto mais se melhora a qualidade de vida desse usuário e somente se referencia quando extenuado as formas de controle na APS, diminui-se o tempo de espera e melhora-se o serviço ofertado (SANTIAGO, 2013).

As condições de ingresso da população às ações e aos serviços de saúde dependem tanto da sua distância das unidades dos diferentes níveis de complexidade quanto do cálculo correto da oferta em relação ao número de habitantes de uma determinada região e suas reais necessidades de saúde. Um item crítico e fundamental para assegurar a entrada no sistema de saúde, é o direito que o usuário tem de obter informações quanto ao horário de abertura e fechamento dos serviços, escala de profissionais e as condições necessárias para a utilização de procedimentos especializados. Isso requer que o usuário reconheça e entenda como funciona e como se conecta cada nível de atenção (SERRA; RODRIGUES, 2010).

Com a intenção de diminuir os obstáculos para o acesso a essas informações e a própria utilização ao do sistema de saúde, emergiu a proposta da ESF, entendida como a porta de entrada preferencial do usuário no SUS favorecendo que equipes com população demarcada e adscrita a um determinado território iniciem o atendimento de saúde na prevenção, promoção e reabilitação dentro do processo saúde-doença, uma vez que conseguem se relacionar e compreender as demandas dessa população de uma maneira mais íntima e com a elaboração do vínculo (GIOVANELLA et al., 2009; CORRÊA; DÓI, 2014).

O reconhecimento de um indivíduo como baixo ou alto risco dentro de uma patologia específica permite com que a equipe de saúde disponha de instrumentos diferenciados no processo de recomendar, criar e fomentar cuidados de maneira diferenciada. As necessidades dos usuários classificados como risco habitual são em geral, resolvidas dentro da atenção primária, ao contrário, os pacientes pertencentes ao grupo de alto risco, requerem uma atenção mais especializada que em sua maior parte é 
resolvida na atenção secundária e terciária. Em observância às gestações de risco, na qual até mesmo a palavra de risco pode ser fator assustador, enumeram-se repercussões recíprocas entre a doença e a gravidez e suas prováveis influências à saúde do feto e da mulher, tendo dessa maneira, que abordar o assunto da classificação do risco gestacional para a própria gestante e familiares, de uma forma objetiva e coerente, porém prudente e que produza um empoderamento para o cuidado sobre a saúde do binômio mãe - feto (BUCHABQUI et al., 2006).

O sistema de referência e contrarreferência tem o objetivo de minimizar a demanda reprimida e acelerar o atendimento de pacientes nos demais níveis de atenção antepondo a situação de saúde/doença de cada indivíduo e não sua classificação de chegada na fila de espera por um exame ou consulta (CORRÊA; DÓI, 2014).

No SUS são fundamentais o conhecimento e a agilidade diagnóstica da atenção primária para propor encaminhamentos pertinentes, através da rede de serviços por meio do sistema de referência e contrarreferência e que no caso das gestantes, podem gerar danos à paciente e seu concepto, caso não seja corretamente empregado. Uma das maneiras de se certificar da qualidade da atenção ofertada ao pré-natal por parte dos profissionais da APS, é a averiguação do correto preenchimento da ficha de referência e da elaboração de uma planilha contendo o nome da gestante, a patologia e a data de encaminhamento para a unidade de referência, que deve permanecer como arquivo na UBS afim de propiciar o acompanhamento da gestante encaminhada e caso haja necessidade, a sua busca ativa. A falta de preenchimento de registros, tanto da ficha de encaminhamento, quanto da planilha de quem é referenciado, sugere utilização equivocada e visão parcial no planejamento das ações de saúde do serviço, podendo acarretar danos às gestantes (TANAKA et al., 1989; HALPERN et al., 1998).

Assim sendo, tanto o referenciamento descontrolado, como a não conclusão da contrarreferência geram danos para as gestantes de alto risco. Por diversas vezes, as gestantes não conseguem atendimento especializado em tempo oportuno, além disso, às equipes de saúde, têm as gestantes devolvidas para a atenção primária, mas não são informadas do motivo da devolução e como prosseguir com o acompanhamento, tendo que questionar a própria grávida de como foi sua consulta e quais orientações foram dadas. É notório, que muitas vezes, as gestantes não conseguem serem interlocutoras entre os profissionais da referência e da APS, quanto as condutas técnico-asssitencias adotadas no nível secundário e terciário, ocosionando um dano do tratamento a ser implementado. Além disso, utilizar formulários impressos de referência e contrarreferência e 
responsabilizar a gestante pelo transporte entre as unidades pode ser um tanto prejudicial, a medida que se corre o risco de o formulário ser extraviado e as informaçãoes não chegarem ao destino (CORRÊA; DÓI, 2014).

A abordagem da interação dos sistemas e redes de saúde envolve inúmeros aspectos integrados como a regulação dos serviços, processos de gestão clínica, condições de acesso aos serviços, recursos humanos, sistema de informação e comunicação e apoio de transporte. Vários desses fatores citados, são considerados cruciais para assegurar o intercambiamento entre os serviços e que compõe o Pacto pela Saúde de 2006. Outro fator contributivo, é que a grande maioria das UBS não possuem espaço físico adequado, carecem de computadores e acesso a internet indisponibilizando a existência do prontuário eletrônico e a troca de informações entre os diversos níveis de assistência (HARTZ; CONTANDRIOPOULOS, 2004; BRASIL, 2006).

A regulação dos serviços é tarefa intransfirível do gestor e envolve mecanismos de oferta de ações e serviços com ênfase nas necessidades de saúde da população, criação de responsabilidades e de estabelecimento de metas qualitativas e quantitativas dos atendimentos nos diferentes níveis de atenção à saúde, regulação, monitoramento e avaliação dos serviços existentes, para posterior correção dos processos de trabalho, caso haja necessidade (SERRA; RODRIGUES, 2010).

Os panoramas rígidos, parciais e repressores do modelo de trabalho de muitas administrações ainda hoje atuais, devem conceder um lugar para novos modelos gerenciais englobando bases democráticas, de formulação do trabalhador dentro do seu ambiente de trabalho, permitindo a formação de pessoas inovadoras e arrojadas e não apenas cumpridores de tarefas, tendo como co-participantes o próprio usuário do sistema (MAEDA, 2002).

As gestões locais têm o papel de mediação entre os problemas de saúde e os serviços a serem desenvolvidos, devem ser qualificados periodicamente para a interferência e resolução pacífica e imparcial, administrando o conhecimento adquirido de forma coesa e acertada. Porém, o SUS manifesta grande imprecisão na administração do uso das informações e um déficit estrutural cada vez mais frequente para o atendimento de suas necessidades em um curto espaço de tempo, operando dessa forma, as informações recebidas de forma atrasada e incompleta (MAEDA, 2002; BORGES, 2014).

A importância da gestão da informação em saúde pública é averiguada no exato momento em que se entende que a informação, é um instrumento fundamental utilizado para processos decisórios, o que propicia o reconhecimento do delineamento social e 
sanitário da comunidade e a criação de resoluções capazes de atender corretamente as necessidades e solicitações de saúde. (IUNES, 1995; MAEDA, 2002; CARVALHO, 2009; BORGES, 2014).

O Ministério da Saúde estabelece uma diferenciação ao utilizar o termo gerência, que são ações restritivas ao contexto da instituição e, por gestão que é a introdução de componentes externos ao ambiente institucional, sendo importante o resgate da missão, objetivos e metas que cercam a direção dos serviços. Sendo assim, gestão e gerência precisam estar acordo para que no processo gerencial a escassez de objetivos, direção e envolvimento não se vertam em desinteresse, desarmonia e desalinhamento dos que fazem parte da instituição e dos usuários que a utilizam (BRASIL, 2003).

Para que a gestão da informação se torne eficiente, é fundamental um agrupado de políticas coesas que favoreçam o acesso a informações essenciais, em tempo rápido, com qualidade considerável, possibilitando sua utilização com custo baixo e seu acesso descomplicado por todos os profissionais que requeiram a sua utilização. No campo da saúde, a gestão da informação é fundamental ao Estado e um direito do usuário, ao passo que minimiza gastos, serve como uma etapa de apoio ao processo decisório, permitindo o entendimento da realidade social e sanitária, epidemiológica, demográfica, burocrática e orçamentária, financiando as ações do governo e a elaboração e efetivação de políticas públicas, além de colaborar para as práticas de controle social, gestão e gerência e acelerar a assistência e possibilitar que novos usuários sejam introduzidos no processo (SIMEÃO; MENDONÇA, 2007; CARVALHO, 2009).

A gestão da informação confere subsídio ao poder de decisão, na medida em que provêm recursos quanto às possibilidades de soluções de problemas e dos impactos oriundos de deliberada resolução, tendo uma estratégia política e que promova condições de convívio entre pessoas, setores e unidades organizacionais, com o intuito de favorecer resultados frequentes (BRAGA, 2007; BORGES, 2014).

Apesar disso, não basta que a gestão ceda instrumentos e deles se utilize para avanço do sistema de saúde como um todo, é fundamental também, que a gerência em saúde esteja perfilada ao processo de adaptação entre equipe e usuário, entenda do SUS e de seus princípios e diretrizes, enrende os profissionais e a comunidade nas resoluções de decisões. Nesse contexto, o papel do gerente se torna essencial na junção das relações entre pessoas, estruturas, tecnologias entre os diversos níveis de saúde, objetivos e meio ambiente. A equipe de saúde deve se envolver no processo de tomada de decisões, reforçando e exaltando a responsabilidade de cada membro dentro da assistência de forma 
igualitária e agregadora e não somente pautado na atividade do profissional médico (JUNQUEIRA, 1990).

Diante do exposto, o estudo assumiu a questão da organização da contrarreferência contida no princípio da integralidade para entender como ocorre o cuidado de pré-natal de alto risco e como ocorre o intercâmbio de informações entre a APS e a Maternidade Cachoeirinha, além de propor a produção de um instrumento próprio para a troca de informações entre os profissionais, considerando a adequação do sistema de referência e contrarreferência dentro da realidade do sistema de saúde estruturado no Distrito de Saúde Casa Verde/Cachoeirinha. 


\section{OBJETIVOS}

\subsection{OBJETIVO GERAL:}

Investigar limites e potencialidades do sistema de referência e contrarreferência no acompanhamento de gestantes de alto risco encaminhadas para a Maternidade Cachoeirinha. 
4 CAMINHO METOdOLÓGICO 


\section{CAMINHO METODOLÓGICO}

\subsection{OPÇÃO PELO MÉTODO QUALITATIVO}

Pensando em obter o melhor método para o andamento do estudo em pauta, foi fundamental entender sobre a natureza do fenômeno, os objetivos da pesquisa e as características dos atores envolvidos.

O conhecimento científico é edificado de forma concomitante entre a teoria e a realidade e não deve se ater a uma única forma de saber (MINAYO, 2010).

A pesquisa qualitativa enraiza-se nas ações e relações humanas não quantificáveis em fórmulas e equações matemáticas. Aplica-se a um universo de desejos, saberes, valores e atitudes que equivalem a um processo mais interior das relações humanas e que não podem ser minimizados a resultados sob diferentes variáveis (MINAYO; SANCHES, 1993).

A pesquisa qualitativa em saúde surgiu no século $\mathrm{XX}$, decorrente de estudos desenvolvidos nas Ciências Sociais, como a psicologia, antropologia, sociologia e psicanálise. Tentava elucidar melhor os fenômenos e atitudes interligadas ao homem e a sua relevância no campo saúde/doença (TURATO, 2005).

Para o estudo em pauta, primou-se pela abordagem qualitativa, pois a mesma, por estar intimamente relacionada ao meio social, é apropriada para investigações no âmbito da saúde e pode ser aplicada para fenômenos com um alto grau de dificuldade interna (MINAYO, 2010).

Entre os atributos da pesquisa qualitativa encontram-se a imersão do pesquisador nas conjunturas e nos enredos da pesquisa, além, do aprofundamento no sentido e nas emoções, a constatação dos atores sociais como pessoas que produzem conhecimentos e práticas, as consequências como repercussões de um trabalho coletivo e da interação entre pesquisado e pesquisador, a anuência de todos os fenômenos como de igual importância e valor, como por exemplo: a estabilidade e a ocasionalidade, a frequência e a término, a fala e o silêncio, as divulgações e os encobrimentos, a continuidade e a cessação, o significado aparente e o que permanece escondido (SUGUIHIRO, 1999).

No método qualitativo, o enrendamento indispensável do pesquisador com os personagens e o objeto do estudo, não se caracteriza como falha, imperfeição ou desmerece o método escolhido. Sendo o pesquisador participante da sociedade, compete- 
lhe o cuidado e a capacidade de não tomar como absoluto o seu próprio lugar, ou usar a sua capacidade para se colocar para o lugar do outro. A proximidade, não é inapropriada e sim uma possibilidade para uma melhor compreensão da realidade vivenciada (VELHO, 1978).

Desta forma, uma análise qualitativa completa, explana o conteúdo dos diálogos ou a fala casual dentro de um cenário de referências, onde a ação requerida nas instituições permite transpor a mensagem presente e os significados velados (MINAYO, 2010).

O uso da pesquisa qualitativa não somente busca interceptar a apresentação dos fenômenos, mas também a sua essência, desviando a inércia do saber científico (TRIVIÑOS, 2010).

Dentro desse ponto, considerando os alicerces da pesquisa qualitativa, escolheuse o estudo descritivo, do tipo estudo de caso, pois se tem a compreensão que dadas as peculiaridades do estudo, esta é a melhor abordagem metodológica.

Por se tratar de uma pesquisa qualitativa, os dados numéricos (tabelas e gráficos) sofreram avaliação estatística simples.

\subsection{O ESTUDO DESCRITIVO TENDO COMO OBJETO O ESTUDO DE CASO}

O estudo descritivo tem como ênfase a ânsia de entender a comunidade, seus detalhes característicos e sua realidade. Busca descrever com precisão um fenômeno ou uma situação, possibilitando envolver, com pormenores os aspectos de um indivíduo, uma circunstância, ou um grupo, assim como revelar a conexão entre acontecimentos (SELLTIZ et al., 1965).

A pesquisa descritiva, não tem a atribuição de explanar os eventos que discorre, apesar de servir de alicerce para tal explicação. Estabelece vinculações entre diversos fatores e define a sua natureza (VERGARA, 2000).

Além do estudo descritivo correlacional, ou seja, quando se estabelece correlações entre variáveis, há também, os estudos de casos que têm por propósito a imersão no detalhamento de determinada realidade e que para o tipo de pesquisa qualitativa, talvez seja um dos mais importantes (TRIVIÑOS, 2010). 
Apesar dos resultados obtidos no estudo de caso, não poderem ser difundidos para uma determinada situação, além daquela pesquisada, tem um grande mérito para os estudos científicos, pois propicia o conhecimento de uma determinada realidade de forma detalhada e os resultados encontrados podem subsidiar outras pesquisas (TRIVIÑOS, 2010).

Quando se intenciona averiguar como e o porquê de uma união de eventos atuais, o estudo de caso é o método mais eficiente. $\mathrm{O}$ autor reafirma que o estudo de caso é uma investigação de forma cotidiana, que possibilita o estudo de um fato recente dentro do seu contexto da vida real, principalmente quando tais limites não estão claramente definidos (LIMA; ANTUNES; NETO, 2012).

Segue alguns propósitos do estudo de caso: (GIL, 2009)

1) Estudar situações da vida real nos quais as regras não estão bem definidos;

2) Conservar o caráter individual do objeto estudado;

3) Delinear o fato na qual está sendo feita uma determinada investigação;

4) Desenvolver hipóteses ou elaborar teorias;

5) Explanar variáveis causais de determinado fenômeno em ocorrências elaboradas que não possibilitem o uso de apontamentos e experimentos.

Os estudos de caso devem permitir interpretações alternativas e generalizações naturalísticas, além de permitir a manifestação de várias formas de conhecimento e esse conhecimento adquirido é o mais concreto, contextual e sujeito a interpretações do leitor, do que o conhecimento gerado por outros tipos de pesquisa (LÜDKE; ANDRÉ, 1986).

O estudo de caso tem uma capacidade "heurística", ou seja, a de propiciar descobertas ao leitor e promover novas relações, aumentando suas experiências (GRYSCHEK, 2001).

A validade interna de um estudo de caso deve ser feita de forma ética, ratificando a validade, a verdade e a abrangência que podem ser econtradas através da ponderação do método científico, da explanação correta do método e das etapas utilizados pelo pesquisador, para que de fato haja importância no trabalho desenvolvido (ANDRÉ, 1984; COUTINHO; CHAVES, 2002).

$\mathrm{Na}$ estratégia do estudo de caso, fatores que foram desconceituados e fugiram do controle rígido da pesquisa experimental podem ser pautados. Não há controle de variáveis e o que se deseja é pesquisar o fenômeno dentro desse contexto, e a averiguação está fundamentada dentro de um aglomerado de achados (PEREIRA; GODOY; TERÇARIOL, 2009). 
Finalmente, o pesquisador tem uma colaboração importante dentro do estudo de caso e detalhes como capacidade, sensibilidade, preparo e rigor ético são essenciais para o andamento do estudo de caso (ANDRÉ, 1984; GRYSCHEK, 2002).

Dessa forma, considerando todas essas indagações sobre estudo de caso, esperase que a opção por esta metodologia possa contribuir para a compreensão de forma totalitária e não errônea do "caso" escolhido nesta pesquisa. Sendo assim, pode-se dizer que essa investigação é qualitativa descritiva, e utilizou-se do estudo de caso como acercamento metodológico.

Sendo o caso do presente estudo: "A contrarreferência de gestantes de alto risco da Maternidade Cachoeirinha para as UBSs Vila Dionísia e Dra. Ilza Hutzler”.

\subsection{O CENÁRIO DE ESTUDO}

O município de São Paulo está dividido em seis distritos de saúde (Norte, Oeste, Leste, Sudeste, Centro e Sul) - conforme mapa abaixo:

Mapa 1 - Distritos de Saúde do Município de São Paulo.

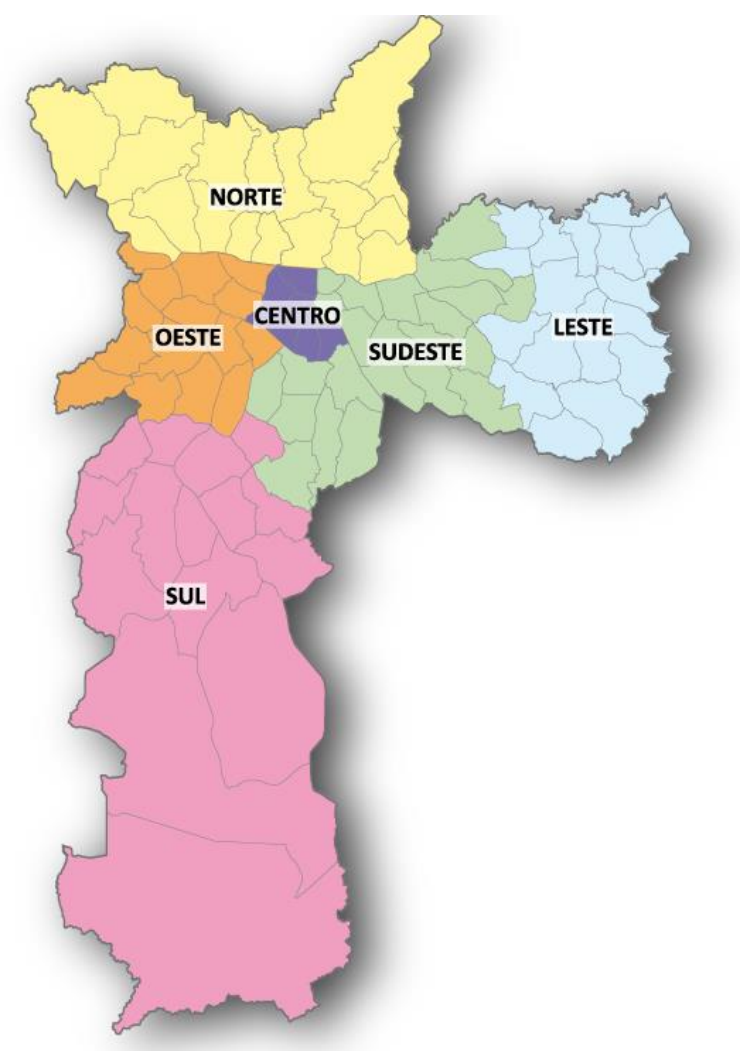

Fonte: site PMSP 
Mapa 2 - Estabelecimentos e Serviços de Saúde da Rede Municipal por Coordenadoria Regional de Saúde, Supervisão Técnica e Distrito Administrativo

ESTABELECIMENTOS E SERVIÇOS DE SAÚDE DA REDE MUNICIPAL POR COORDENADORIA REGIONAL DE SAÚDE, SUPERVISÃO TÉCNICA DE SAÚDE E DISTRITO ADMINISTRATIVO. MUNICÍPIO DE SÃO PAULO

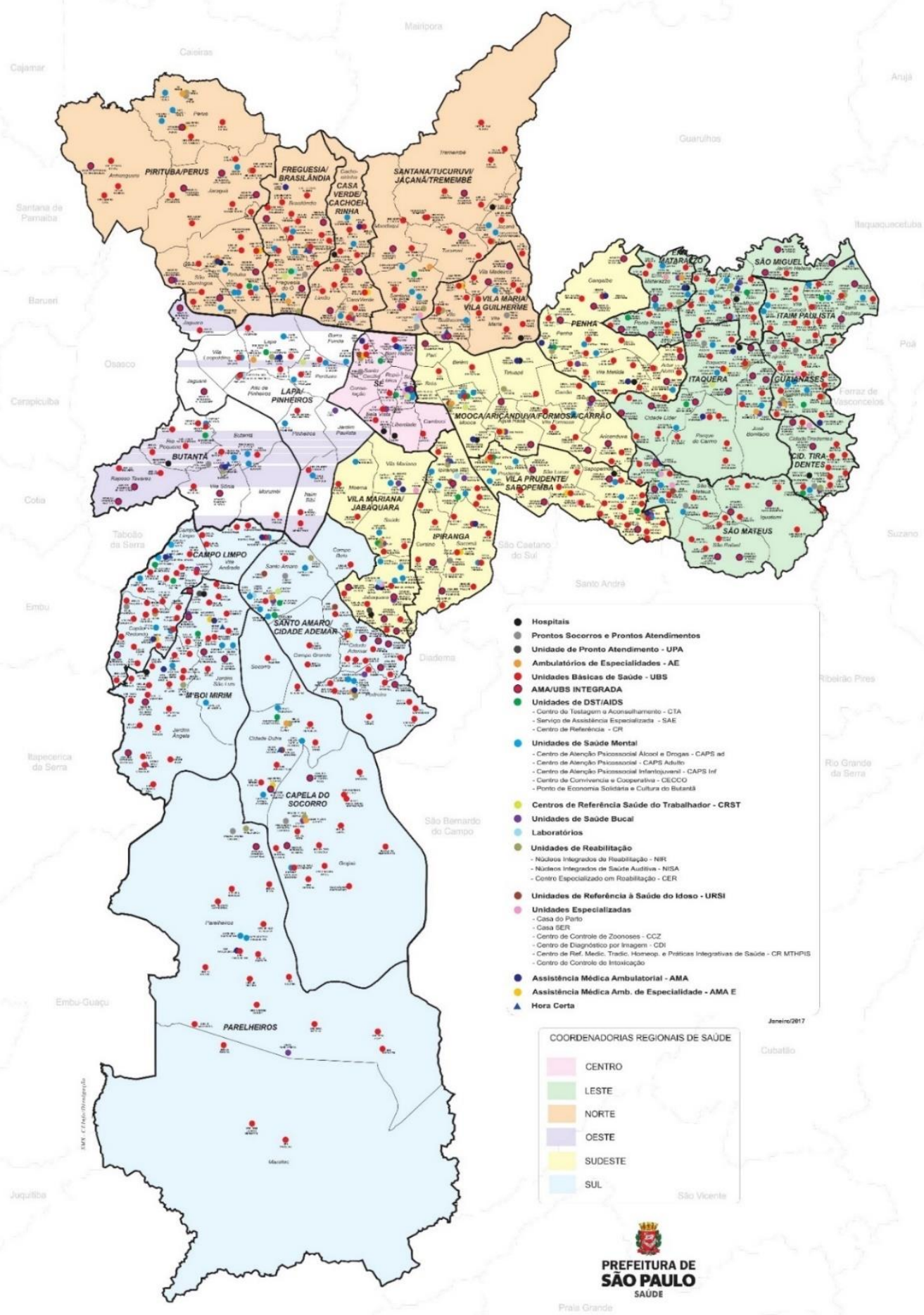

Fonte: Prefeitura do Município de São Paulo, 2017. 
Para um melhor gerenciamento e subdivisão de acordo com suas caractéricas epidemiológicas e geográficas, os distritos se subdivem, com seus respectivos estabelecimentos e serviços de saúde da seguinte forma:

O Distrito de Saúde Norte aparece aqui evidenciado por fazer parte desse estudo. Esta divido da seguinte forma:

- Distrito de Saúde Norte:

1. Distrito de Saúde Casa Verde/Cachoeirinha;

2. Distrito de Saúde Freguesia do Ó/Brasilândia;

3. Distrito de Sáude Pirituba;

4. Distrito de Saúde Perus;

5. Distrito de Saúde Santana/Jaçanã;

6. Distrito de Saúde Vila Maria/Vila Guilherme.

Mapa 3 - Distrito de Saúde Norte

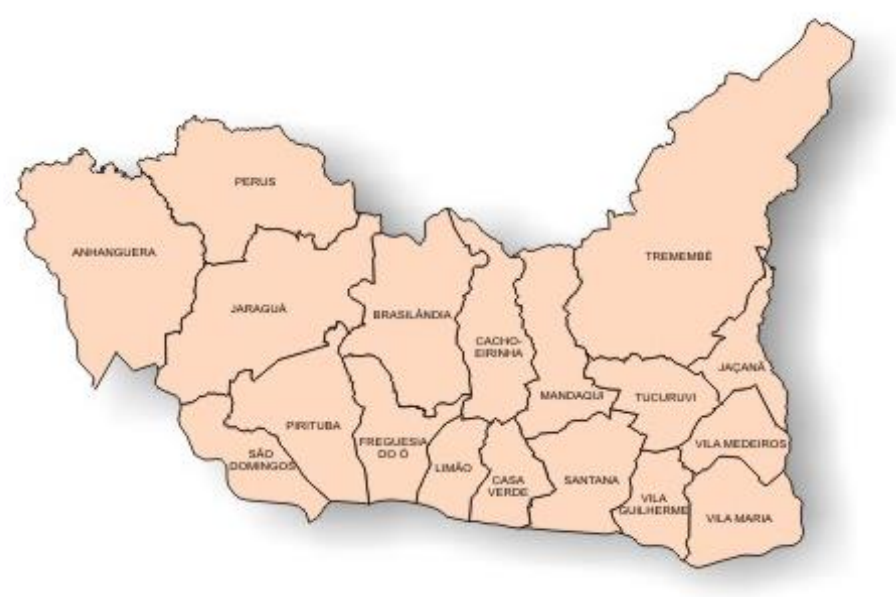

Fonte: Prefeitura do Município de São Paulo, 2017.

A criação do Distrito de Saúde Casa Verde/Cachoeirinha foi determinada pela Lei Municipal $\mathrm{n}^{\mathrm{o}} 11.220$ de 20/05/1992, no governo da prefeita Luiza Erundina, e proporcionou uma nova divisão geográfica da área do Município de São Paulo em Distritos. Em 01/08/2002 através da Lei Municipal nº 13.999, foram criadas as Prefeituras Regionais, entre elas a Prefeitura Regional da Casa Verde/Cachoeirinha, que possui a mesma delimitação geográfica do Distrito de Saúde (PREFEITURA MUNICIPAL DE SÃO PAULO, 2017).

A área demográfica é de $26,7 \mathrm{Km}^{2}$ e conta com uma população de 309.376 habitantes e com uma densidade de 11.587 habitantes por quilômetro quadrado. Possui 
um Índice de Desenvolvimento Humano (IDH) de 0,832, sendo considerado de nível elevado, ocupando a 14 $4^{\mathrm{a}}$ posição entre os demais distritos da cidade de São Paulo (IBGE, 2010).

No Distrito Casa Verde/Cachoeirinha encontram-se diversos equipamentos de saúde, em sua maioria administrados por Organizações Sociais de Saúde (OSS), entre os quais 04 UBS (Vila Dionísia, Dra. Ilza Weltman Hutzler, Vila Dionísia 2, Jardim Peri), 02 Centros de Atenção Psicossocial (CAPS - Infantil II Casa Verde/Cachoeirinha e Adulto II Cachoeirinha), 01 Assistência Médica Ambulatorial (AMA - Jardim Peri) e o Hospital Maternidade Escola Cachoeirinha (PMSP, 2017).

As OSS foram instituídas pelo Governo Federal, primeiramente através da medida provisória $n^{\circ} 159 / 1997$ e depois pela Lei $n^{\circ}$ 9.637/98. No Estado de São Paulo foi aprovada pela Lei no 486/98 com 111 emendas aos seus 19 artigos originais. Surgiram como modelo alternativo de gestão aos existentes anteriormente, que para o governo da época de Fernando Henrique Cardoso, caracterizava-se por ser ineficiente, ineficaz e o modelo de gestão pública favorecia altos custos, além de não propiciar benefícios para os usuários (MELO; TANAKA, 2001).

As OSS caracterizam-se como uma modalidade de parceria entre o Estado e o setor privado, são caracterizadas como instituições do terceiro setor da economia, no qual pessoas privadas e sem fins lucrativos, se unem de forma voluntária para produzirem atividades de relevante interesse coletivo (MODESTO, 1997).

Fizeram parte do estudo três estabelecimentos de saúde pertencentes ao Município de São Paulo e ao Distrito de Saúde Norte: Maternidade Cachoeirinha, UBS Dra. Ilza Hutzler e UBS Vila Dionísia. Todos pertencentes ao Distrito Casa Verde/Cachoeirinha e que estão localizadas no Bairro Vila Nova Cachoeirinha, que também atendem os bairros Jardim Pery Alto e Jardim Princesa. Para melhor conhecimento, a seguir, segue a descrição de cada um deles (IBGE, 2010): 


\subsubsection{Maternidade Escola Dr. Mário de Moraes Altenfelder Silva}

A Maternidade Escola Dr. Mário de Moraes Altenfelder Silva, mais conhecida como Maternidade Escola Cachoeirinha, foi inaugurada e entregue à população em 04 de dezembro de 1971. Conta com as especialidades de ginecologia, oncologia pélvica e mamária, planejamento familiar e atenção à mulher vítima de violência sexual. É referência para algumas unidades de saúde encaminharem suas gestantes para o momento do parto e também fornece vagas para determinadas unidades, estabelecidas durante a pactuação de referência e contrarreferência, via sistema de regulação, para a realização e acompanhamento do pré-natal de alto risco. No Anexo 1 desse estudo, estão as respectivas referências para as Unidades Básicas de Saúde encaminharem às gestantes para as Maternidades de baixo e alto risco da Zona Norte do Município de São Paulo.

Trabalham na Maternidade, 1140 funcionários da administração direta e 247 funcionários terceirizados (cozinha, segurança, laboratório e higienização). Possui um terreno de $22.000 \mathrm{~m} 2$ e área construída de $20.000 \mathrm{~m} 2$. São 182 leitos, sendo 172 operacionais, divididos da seguinte forma:

50 Leitos de alojamento conjunto;

31 Leitos para internação de adultos;

04 Leitos para hospital dia;

20 Leitos para gestantes de alto-risco;

60 Leitos de Unidade de Terapia Intensiva (UTI) neonatal;

07 Leitos de UTI adulto;

06 Salas Cirúrgicas;

04 Salas de Parto Natural;

14 Leitos de Pré-parto;

06 Leitos de Recuperação Anestésica. 
Seguem alguns dados, para caracterização e conhecimento do funcionamento da Maternidade:

Quadro 3: Procedimentos realizados na Maternidade Escola Cachoeirinha em 2016 a maio de 2017

\begin{tabular}{|l|l|l|l|}
\hline Procedimentos & $\mathbf{2 0 1 6}$ & $\begin{array}{l}\text { Janeiro a Maio } \\
\text { de 2017 }\end{array}$ & $\begin{array}{l}\text { Média Mensal } \\
\text { (17 meses })\end{array}$ \\
\hline Internações & 13.134 & 6.129 & 1.133 \\
\hline Total de Partos & 6.750 & 3.100 & 579 \\
\hline Partos Normais & 4.209 & 1.951 & 362 \\
\hline Partos Cesáreas no & 2.118 & 984 & 182 \\
\hline Partos Fórceps no & 423.728 & 165 & 35 \\
\hline $\begin{array}{l}\text { Consultas } \\
\text { Ambulatório Médico }\end{array}$ & 23.403 & 4.714 \\
\hline $\begin{array}{l}\text { Consultas } \\
\text { Ambulatório } \\
\text { Multiprofissional }\end{array}$ & 27.628 & 4.039 \\
\hline $\begin{array}{l}\text { Exames Laboratoriais } \\
\text { Exames de Imagem } \\
\text { (ultrassom, } \\
\text { densitometria, raio X, } \\
\text { mamografia) }\end{array}$ & 56.920 & 113.780 & 20.682 \\
\hline
\end{tabular}

Fonte: PMSP/SMS/HMEC/TabNet maio 2017

Com relação aos dados do quadro acima, é possível verificar que o número de cesarianas em 2016, (2.118) representa 32\% do número total de partos realizados (4.209) e em 2017 já contribui com a mesma porcentagem, ou seja, 32\% (984) do total de partos contabilizados até o mês de maio (3.100). Entretanto, não é possível verificar se tal número realmente está relacionado às patologias obstétricas, pois a Maternidade não correlaciona tais indicadores. Contudo, desde 2002 recebe a certificação como Hospital Amigo da Criança e desde 2013 Hospital Amigo da Mulher (HMEC, 2017).

De acordo com dados do Ministério da Saúde de 2015, o Brasil tem experimentado um aumento considerável no número de cesarianas eletivas, totalizando cerca de $85 \%$ dos partos realizados, em serviços privados de saúde de todo o país. No sistema público de 
saúde, a taxa é substancialmente menor, cerca de $40 \%$, o que ainda é percebido como elevado se forem seguidas as orientações da Organização Mundial da Saúde (OMS), que é de 15\% (BRASIL, 2015).

No Pronto Socorro são realizados exames de laboratório, de imagem como ultrassom e raio $\mathrm{X}$, os demais procedimentos além dos ofertados no Pronto Socorro são fornecidos aos pacientes internados e através de vagas cedidas no software padrão, para a gestão dos recursos e serviços prestados pelo SUS, denominado Sistema Integrado de Gestão e Agendamento (SIGA), da Secretaria Municipal da Saúde para as unidades básicas do município.

A seguir, os gráficos 5 e 6 mostram a satisfação geral dos usuários com a maternidade e com o corpo de enfermagem respectivamente, demonstrando qualidade no atendimento prestado, corroborando para o aumento no atendimento, principalmente de usuárias que não a têm como referência para o parto, mas que fazem questão de terem seus bebês naquela unidade.

Gráfico 5: Taxa de Satisfação com o atendimento na Maternidade Cachoeirinha, expressa pelos usuários à Ouvidoria de 2010 a maio de 2017

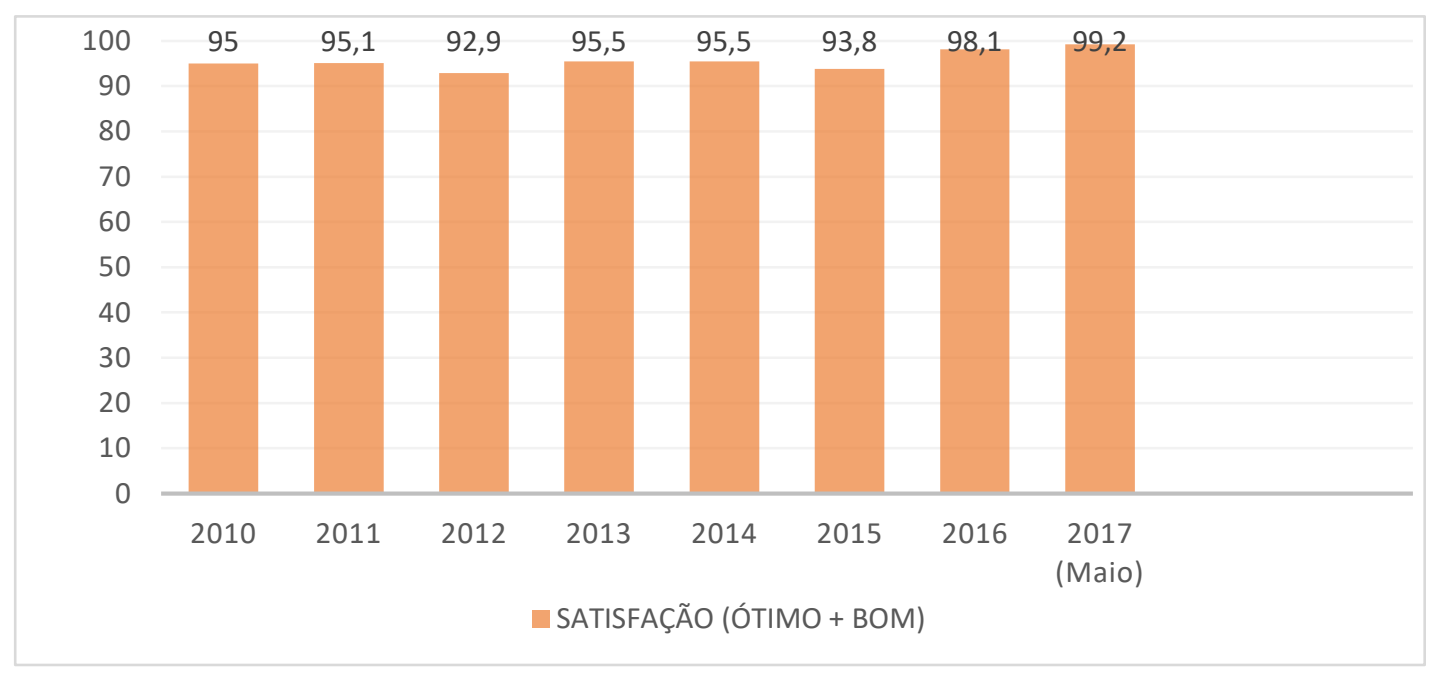

Fonte: PCSP/SMS/HMEC - Coordenação Ouvidoria 
Gráfico 6: Avaliação do Atendimento de Enfermagem pelos Usuários do HMEC de 2016 a maio de 2017

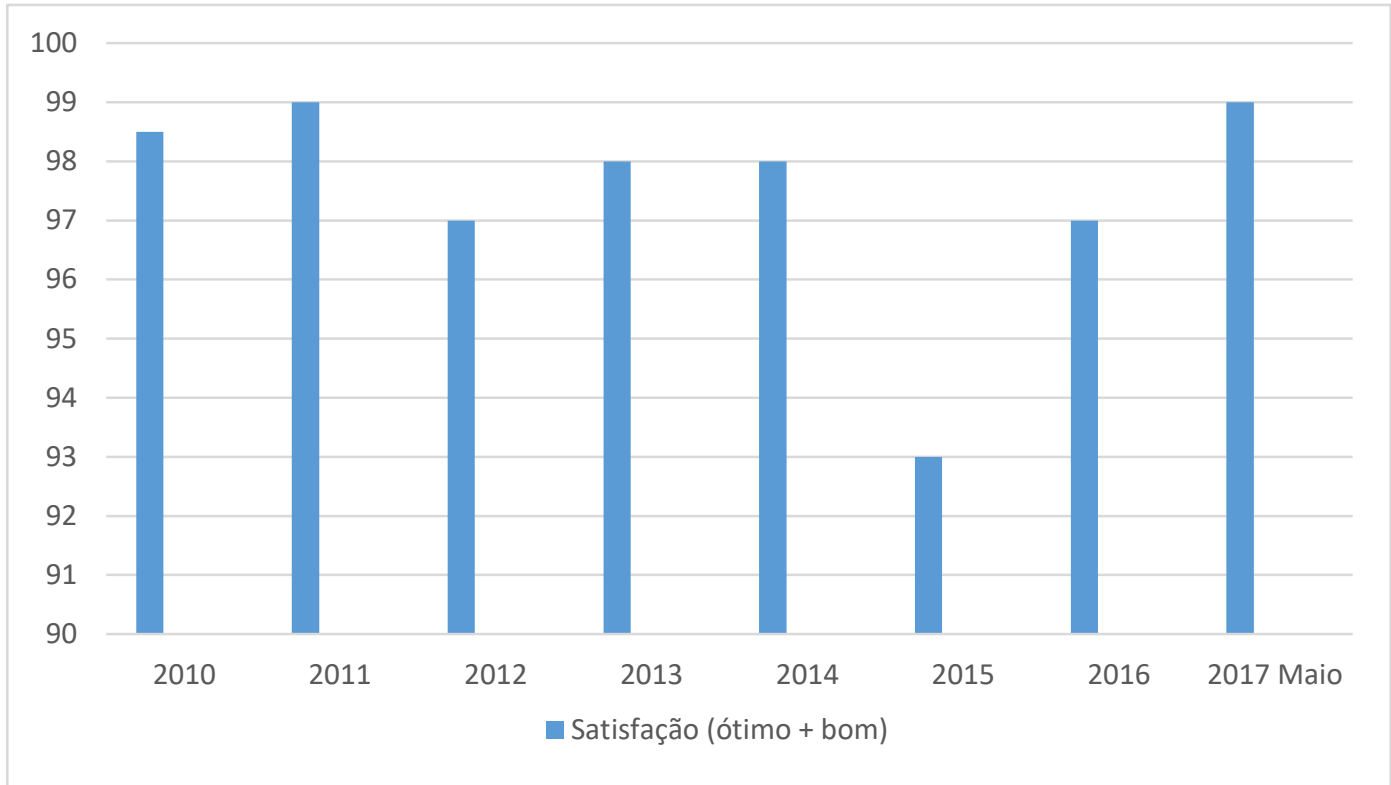

Fonte: PCSP/SMS/HMEC - Gerência Ouvidoria

Gráfico 7: Porcentagem de Partos Realizados no HMEC Dentro e Fora da Grade de Referência de Janeiro de 2016 a Abril de 2017

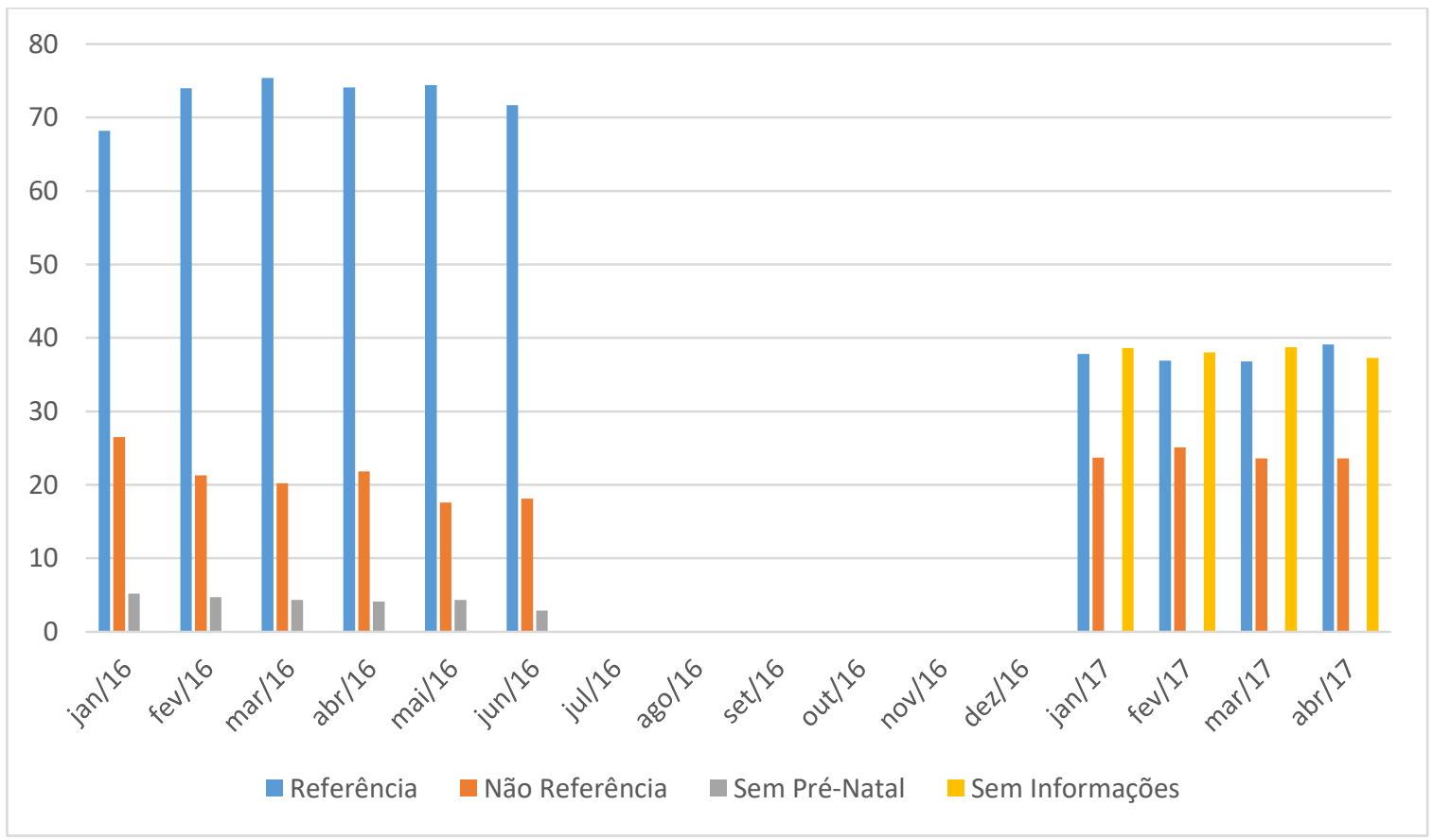

Fonte: PCSP/SMS/HMEC - Coordenadoria de Urgências e Emergências 2016

O gráfico acima mostra que no ano de 2016 a maior parte dos partos realizados no HMEC respeitaram a grade de refêrencia pactuada pelas Secretarias Municipal e Estadual de Saúde, entretanto, há uma dificuldade em realizar a discussão e o 
entendimento desses dados, visto que esse indicador deixou de ser coletado em Julho de 2016 e foi reiniciado em Janeiro de 2017, porém com um grande número de dados registrados como sem informações, o que dificulta saber se a referência para o parto foi realmente respeitada. Além disso, o indicador de Sem Pré-Natal também deixou de ser computado no ano de 2017, o que diminui o conhecimento dos motivos que favoreceram o não acompanhamento dessas gestantes.

Contudo, ao realizar a análise dos meses de 2017 percebe-se que há um aumento do número de partos da rede não referenciada e um dos motivos que podem ser explanados é a ausência de médicos nos Hospitais próximos, como os Hospitais Estaduais Penteado e Mandaqui, ocasionando o deslocamento dessas gestantes para a Maternidade Cachoeirinha. De forma empírica, porém também observada, é o reconhecimento da população da qualidade do serviço prestado pela Maternidade, o que faz com que muitas gestantes, mesmo conhecendo a sua referência para o parto, procurem o hospital para terem seus bebês.

Gráfico 8: Número de Atendimentos Ginecológicos e Obstétricos no Pronto Socorro do HMEC de 2010 a Maio de 2017

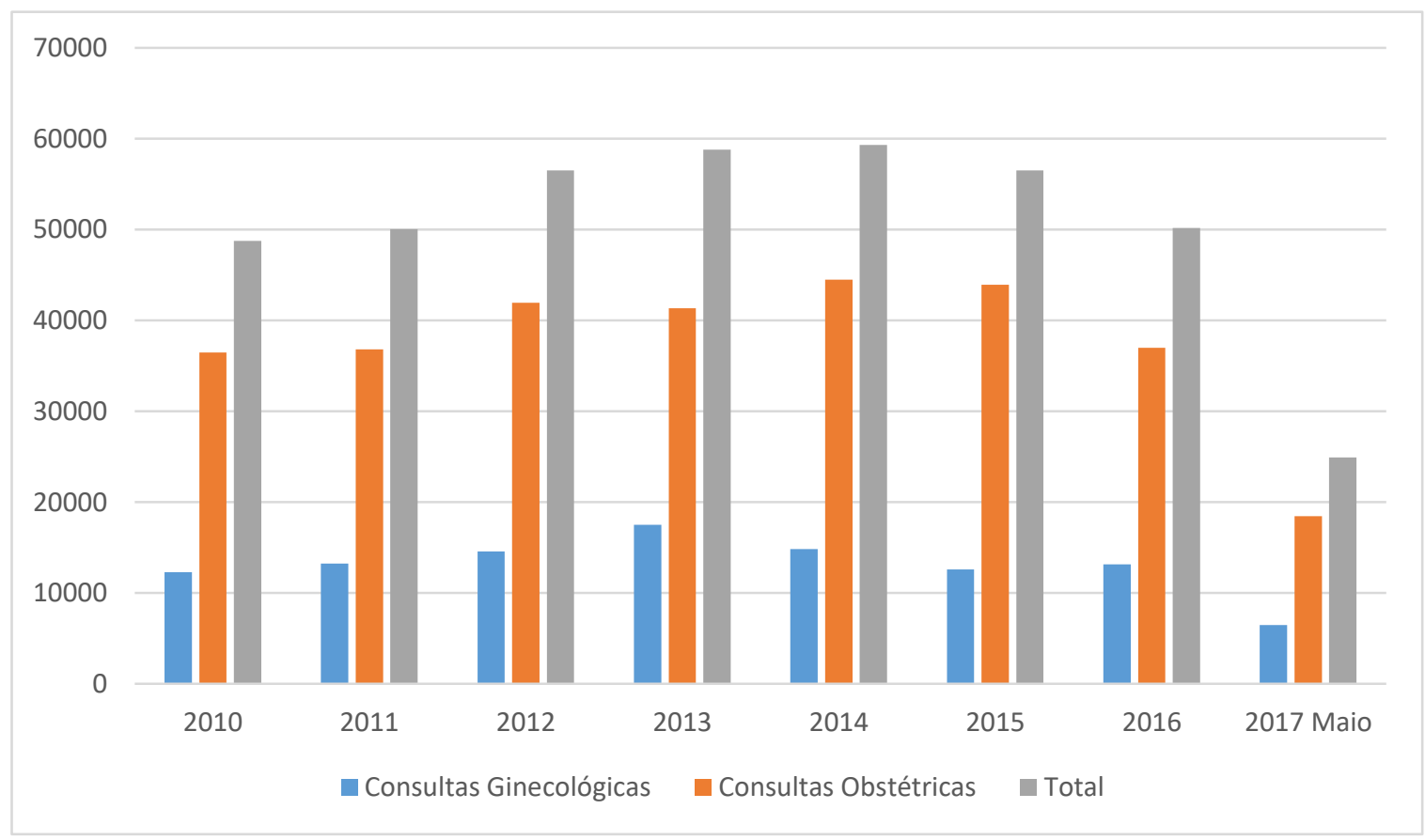

Fonte: PCSP/SMS/HMEC - Seção de Tecnologia de Informação

De acordo com o gráfico 8 , o número total de atendimentos vem crescendo ao longo dos anos. A porta de entrada para as mulheres na Maternidade, mesmo de casos 
eletivos de internação, sempre ocorre pelo Pronto Socorro, o que também contribui para o alto número de atendimentos.

\subsubsection{Ambulatório da Maternidade Cachoeirinha}

O Ambulatório da Maternidade Cachoeirinha tem como planta física um enorme corredor localizado no térreo, constituído por recepção, sala de abertura de prontuários, sanitários para pacientes e funcionários, salas da administração, da regulação de vagas, de reunião, de guarda de material médico, de arquivo de impressos, de enfermagem, de expurgo, depósito de materiais de limpeza (DML), 13 consultórios médicos (11 consultórios com banheiro, sendo um adaptado para pessoas portadoras de necessidades especiais), 01 consultório para a nutricionista, 01 para fisioterapia, 01 para o serviço social e outro para a saúde mental.

Os recursos humanos do ambulatório são compostos por equipe multiprofissional que desempenha diversos tipos de atendimento às mulheres, tanto nas questões ginecológicas, pré-natal de alto risco, violência sexual, quanto aos cuidados ao recémnascido prematuro, que necessita de acompanhamento até dois anos de idade e a homens que desejam realizar a vasectomia. Todos os atendimentos são realizados mediante agendamento prévio, nas vagas disponibilizadas no SIGA.

Os pacientes recebem a data e o horário da consulta e a orientação de se apresentarem no Ambulatório munidos de cartão SUS, RG e guia de encaminhamento médico, que deverá descrever o motivo do encaminhamento, exames realizados e condutas terapêuticas até então adotadas (Anexo 2). Ao serem atendidos no ambulatório, a ficha de Referência e Contrarreferência é arquivada no prontuário do paciente, para segundo os profissionais da Maternidade, comprovar que a gestante foi atendida após ser referenciada. Portanto, a ficha não retorna à unidade de origem, com dados referentes ao atendimento, impossibilitando o fluxo de contrarreferência.

No caso de violência sexual, a paciente é primeiramente atendida no Pronto Socorro, onde se inicia o protocolo de Vítima de Violência Sexual, com a administração de medicamentos, solicitação de exames e notificação da violência, logo após, é encaminhada para abertura de prontuário e acompanhamento no ambulatório por equipe multiprofissional a cada 45 dias, por seis meses.

O ambulatório funciona de segunda a sexta-feira das 07:00 às 19:00h e quando necessário realiza campanhas e atendimentos aos sábados. Conta com o trabalho de 75 
médicos divididos nas seguintes especialidades: Cirurgia Geral, Cirurgia Plástica, Clínica Médica, Vascular, Proctologia, Homeopatia, Anestesiologia, Endocrinologia, Psiquiatria, Planejamento Familiar (Vídeo Laqueadura, laqueadura, DIU, Implanom, Vasectomia), Neonatologia, Oftalmologia RN, Cardiologia RN, Cirurgia Geral Ginecológica, ISTs, Violência Sexual, Colposcopia, Video/Endoscopia Ginecológica, Uroginecologia, Urologia feminina, Oncologia pélvica, Pré-natal, Puerpério e Mastologia.

A equipe multiprofissional é formada por seis psicólogos, seis assistentes sociais, duas nutricionistas e sete fisioterapeutas. A equipe de enfermagem trabalha em sua maioria em regime de $12 \times 36$ horas, sendo composta por sete enfermeiros (01 supervisor para cada plantão e 04 enfermeiros assistenciais), além de 01 enfermeiro com carga horária de seis horas, 02 técnicos de enfermagem (um em cada plantão), 17 auxiliares de enfermagem (01 que trabalha diariamente com carga horária de seis horas, 09 em um plantão e 07 no outro), conta também com 01 técnico de Eletrocardiograma (ECG).

$\mathrm{O}$ atendimento de pré-natal das gestantes de alto-risco é realizado por médicos obstetras especialistas, que contam com o suporte das demais especialidades. As consultas são agendadas de acordo com a gravidade da patologia e estado de saúde e são aceitas as gestantes até a $34^{a}$ semana de gestação. Por ser uma maternidade escola, participam do atendimento internos e residentes sempre supervisionados por seus preceptores. Após o nascimento dos bebês, as consultas para a puérpera e RN são agendadas na UBS de origem, com o prazo máximo de 15 dias, porém, após o $10^{\circ}$ dia de vida, há um retorno dos RN na Maternidade para a participação no Grupo do Umbigo (orientações sobre aleitamento materno e cuidados com o RN) e consulta com o neonatologista. Bebês prematuros permanecem em acompanhamento até os dois anos de vida.

Os enfermeiros realizam a Sistematização da Assistência de Enfermagem (SAE) para as pacientes de pré-natal, cirurgia ginecológica e vítimas de violência sexual, orientam as gestantes sobre seus direitos dentro da Rede Cegonha (a presença do acompanhante durante toda a sua estadia, vale-transporte para a realização de consultas e exames e ganho do enxoval para aquelas que cumprirem o número mínimo de sete consultas), além de realizarem a coleta de colpocitologia oncótica de pacientes ginecológicas, supervisão da aplicação da vacina palivizumabe para prematuros, coordenação e orientação no Grupo do Umbigo, que reforça a importância do aleitamento materno e cuidado adequado ao coto umbilical, realização de curativos e retirada de pontos após cirurgia. Os técnicos e auxiliares de enfermagem realizam a reposição do 
material nos consultórios médicos, vacinação, acompanham as consultas médicas, participam no Grupo do Umbigo, administram medicações prescritas pelos médicos, entregam resultados de exames, realizam a limpeza e desinfecção de materiais utilizados em procedimentos e o controle de sinais vitais das pacientes.

Embora exista um impresso próprio para ser preenchido durante a primeira consulta médica de pré-natal de alto risco, assinalando a patologia que gerou a motivação para o encaminhamento, há uma baixa adesão da equipe médica no preenchimento desse impresso, impedindo que o Ambulatório acompanhe e monitore as principais causas patológicas e/ou sociais do pré-natal de alto risco.

Além disso, não há um monitoramento dos encaminhamentos realizados para certificar-se se a grade de referência pactuada é respeitada. Como indicadores ambulatoriais registrados estão o número de atendimentos médicos e multiprofissionais, de colpocitologia oncótica, curativos, fissuras mamilares detectadas no grupo do Umbigo e vacinas Palivizumabe aplicadas. No ano passado, deixou de ser coletado o indicador da idade gestacional, com que as gestantes chegavam no pré-natal de alto risco, o que seria de suma importância para correlacionar com as principais patologias e auxiliar no delineamento do perfil epidemiológico da população atendida.

Além das patologias classificatórias para uma gestação de alto risco, utilizadas nos impressos das UBS (Quadro 2), são atendidas na Maternidade as seguintes patologias (PREFEITURA MUNICIPAL DE SÃO PAULO, 2013):

- Doença cardíaca hipertensiva pré-existente, complicando a gravidez, o parto e puerpério;

- Doença renal hipertensiva pré-existente, complicando a gravidez, o parto e o puerpério;

- Hipertensão pré-existente não especificada, complicando a gravidez, o parto e o puerpério;

- Edema e proteinúria gestacionais (induzidas pela gravidez), sem hipertensão;

- Hipertensão gestacional (induzida pela gravidez), sem proteinúria significativa;

- Pré-eclâmpsia não especificada;

- Hipertensão materna não especificada;

- Tromboflebite superficial na gravidez;

- Flebotrombose profunda na gravidez;

- Diabetes mellitus pré-existente insulino dependente;

- Diabetes mellitus pré-existente, não insulino dependente; 
- Diabetes mellitus que surge durante a gravidez;

- Assistência à gravidez por motivo de abortamento habitual;

- Gestação múltipla, não especificada;

- Assistência prestada à mãe por incompetência cervical;

- Assistência prestada à mãe por outras anormalidades dos órgãos pélvicos;

- Assistência prestada à mãe por isoimunização Rh;

- Assistência prestada à mãe por insuficiência de crescimento fetal;

- Outros transtornos especificados do líquido amniótico e das membranas;

- Placenta prévia;

- Descolamento prematuro de placenta;

- Trabalho de parto pré-termo sem parto;

- Anemia complicando a gravidez, o parto e o puerpério;

- Doenças endócrinas, nutricionais, metabólicas complicando a gravidez o parto e

o puerpério;

- Transtornos mentais e doenças do sistema nervoso complicando a gravidez, o parto e o puerpério;

- Doenças do aparelho respiratório complicando a gravidez, o parto e o puerpério;

- Doenças do aparelho digestório complicando a gravidez, o parto e o puerpério;

- Toxoplasmose não especificada;

- Hipotireoidismo não especificado;

- Tireotoxicose não especificada;

- Supervisão de primigesta muito jovem;

- Gestação com HIV.

\subsubsection{UBS Dra . Ilza Weltman Hutzler}

Fundada em 13 de abril de 1994 e há nove anos administrada pela OSS Associação Saúde da Família (ASF) que foi criada em 11/07/2007(ASF, 2017).

Atualmente, a Associação Saúde da Família administra 31 UBSs na Região Sul, 06 UBS na Região Oeste e 19 na Região Norte, totalizando 56 unidades. A UBS Dra. Ilza é caracterizada como ESF formada por sete equipes, todas com o quadro de profissionais completos (01 enfermeiro, 01 médico generalista, 02 auxiliares de enfermagem, 06 agentes comunitários de saúde). Além disso, possuem no quadro de funcionários, como parte integrante da equipe, 03 cirurgiões dentistas, 03 auxiliares de 
consultório bucal, 02 técnicos de saúde bucal, 01 gerente, 01 farmacêutico, 02 auxiliares de farmácia, 14 auxiliares administrativos, 03 auxiliares de limpeza, 01 vigilante, totalizando 100 funcionários.

A equipe do Núcleo de Assistência à Saúde da Família (NASF) presta serviços há mais uma unidade da região (UBS Santa Maria) e possui no seu quadro de profissionais, 02 terapeutas ocupacionais, 01 fisioterapeuta, 01 nutricionista, 01 fonoaudiólogo e 01 psiquiatra. No momento, o NASF não possui assistente social e o profissional educador físico não compõe a equipe, devido o contrato estabelecido entre a OSS e a Prefeitura de São Paulo. Casos que necessitem do apoio do assistente social são encaminhados ao Centro de Referência de Assitência Social (CRAS) da região.

A filtração da água é observada em 5.580 domicílios (83,15\%), seguido de cloração em 920 domicílios (13,71\%), sem tratamento 193 (2,88\%) e fervura $18(0,27)$. Com relação ao abastecimento de água e sistema de esgoto 6.709 (99,97\%) contam com a rede pública e $6.693(99,73 \%)$ domicílios são de tijolos, $14(0,21 \%)$ de madeira e o restante $4(0,05 \%)$ de taipa ou taipa revestida. Com relação ao destino do lixo, 6.710 famílias $(99,99 \%)$ contam com a coleta pública de lixo e somente uma família $(0,01 \%)$ queima ou enterra seus resíduos (SIAB, 2017).

Com isso, a UBS Dra. Ilza encontra-se em uma região privilegiada, do bairro Vila Nova Cachoeirinha, não possuindo em sua área adscrita comunidades com graves problemas sociais. O número de pessoas alfabetizadas com 15 anos ou mais corresponde a 98,78\% (17.536) e 86,55\% das crianças entre 7 e 14 anos estão na escola. Somente 1,21\% (81 famílias) recebem Bolsa Família e 1,15\% (77) estão inscritas no CAD-Único, instrumento utilizado pelo Governo Federal para cadastrar e conhecer famílias que possuem renda mensal inferior a meio salário mínimo por pessoa. Tal cadastro tem o intuito de acompanhar e analisar as principais necessidades das famílias inscritas, verificar quais benefícios são recebidos e orientar a gestão desses benefícios para as famílias necessitadas (BRASIL, 2001).

De acordo com o Sistema de Informação da Atenção Básica (SIAB), de junho de 2017, a ESF possui uma população cadastrada de 21.024 pessoas, sendo um total de 6.711 famílias. Possuem cobertura de plano de saúde 4.502 pessoas, representando 21, $41 \%$ do total cadastrado. É caracterizada por ser uma população em sua maioria jovem, na faixa etária de 20 a 39 anos, portanto economicamente ativa, representando 6.551 pessoas, seguidos da faixa etária maior de 60 anos, com 4.511 pessoas. O total de gestantes da ESF corresponde a 112, sendo 96 entre 15 anos e mais e 16 com até 14 anos. Contudo, esse 
número envolve gestantes que realizam acompanhamento na UBS e no convênio, mas que recebem a visita do ACS. Para o alto risco no mês citado, nenhuma gestante havia sido encaminhada. Contudo, desde janeiro de 2017, 15 gestantes foram encaminhadas para o pré-natal de alto-risco na Maternidade Cachoeirinha, entretanto, os motivos dos encaminhamentos não foram fornecidos pelo fato da unidade não os contabilizar como indicadores.

Conforme o protocolo do Município de São Paulo para as gestantes de risco habitual, as consultas devem ocorrer mensalmente, intercaladas entre enfermeiros e médicos (sendo a primeira consulta com enfermeiro para solicitação de exames e preenchimento da ficha gestante) até a $27^{\mathrm{a}}$ semana de gestação. Da $28^{\mathrm{a}}$ a $36^{\mathrm{a}}$ semanas gestacionais, as consultas deverão ser quinzenais, devido o risco de pré-eclâmpsia, também intercaladas entre médicos e enfermeiros e da $37^{\mathrm{a}}$ a $41^{\mathrm{a}}$ semanas gestacionais, as consultas deverão ser semanais, com o profissional médico. Após a $41^{\text {a }}$ semana, as gestantes são encaminhadas para acompanhamento a cada dois dias na maternidade de referência. Diferentemente do preconizado no protocolo da Prefeitura do Município de São Paulo, os profissionais médicos e enfermeiros da ESF Dra. Ilza, preferem atender em conjunto as gestantes, desde a primeira consulta, alegando que de forma integrada o risco é menor de erros e a tomada de decisões é mais rápida, já que ambos os profissionais estão no mesmo consultório com a mesma paciente (PREFEITURA MUNICIPAL DE SÃO PAULO, 2013).

O Hospital das Clínicas da Faculdade de Medicina da USP (HCFMUSP) também oferta vagas para gestação de alto risco, seguindo os mesmos critérios de seleção da Maternidade Cachoeirinha, entretanto, devido à distância, a maioria das mulheres prefere ser acompanhada próximo à região de moradia. Todavia, uma gestante foi encaminhada para acompanhamento no HCFMUSP devido ao diagnóstico de HIV positivo e não querer ser acompanhada por um serviço próximo à sua região de moradia.

\subsubsection{UBS Vila Dionísia}

Fundada há 20 anos no bairro de Vila Nova Cachoeirinha é uma unidade mista, ou seja, coexistem na mesma unidade uma ESF e uma UBS tradicional, ambas administradas pela OSS Associação Saúde da Família.

A ESF é formada por nove equipes todas com o quadro de profissionais completos (01 enfermeiro, 01 médico generalista, 02 auxiliares de enfermagem, 06 agentes 
comunitários de saúde). A equipe da UBS tradicional conta com 5 médicos generalistas, 02 pediatras, 02 ginecologistas, 01 psiquiatra, 02 enfermeiras e 01 auxiliar de enfermagem.

Além disso, possuem no quadro de funcionários como parte integrante da equipe 02 cirurgiões dentistas, 02 auxiliares de consultório bucal, 01 técnico de saúde bucal, 01 gerente, 01 farmacêutico, 03 auxiliares de farmácia, 15 auxiliares administrativos, 04 auxiliares de limpeza, 01 viglilante, totalizando 132 funcionários.

A equipe do NASF presta serviços a mais uma unidade da região (UBS Vila Dionísia II) e possui no seu quadro de profissionais, 01fisioterapeuta, 01 nutricionista, 01 fonoaudiólogo, 01 psiquiatra e 01 assistente social. No momento, o NASF não possui terapeuta ocupacional.

A água é filtrada em 5.228 domicílios (59,78\%), seguido de consumo de água sem tratamento em 2.413 domicílios (27,59\%), com cloração em 1.056 (12,08\%) e fervura em $48(0,55)$. Com relação ao abastecimento de água e sistema de esgoto 8.735 $(99,89 \%)$ e $8.592(98,25 \%)$ respectivamente, contam com a rede pública, $128(1,46 \%)$ das residências têm o destino de fezes e urina a céu aberto e 25 (0,29\%) possuem o sistema de fossa. Com relação a construção de moradias, $8.695(99,43 \%)$ dos domicílios são de tijolos, $20(0,23 \%)$ de madeira, $19(0,22 \%)$ de taipa ou taipa revestida e $11(0,13 \%)$ de material aproveitado. Para o destino do lixo, 8.734 famílias (99,87\%), contam com a coleta pública de lixo, 08 famílias $(0,09 \%)$ queimam ou enterram seus resíduos e 3 $(0,03 \%)$ deixam o lixo à céu aberto.

O número de pessoas alfabetizadas com 15 anos ou mais corresponde a 98,00\% (21.849) e 92,85\% (3.273) das crianças entre 7 e 14 anos estão na escola. O Bolsa Família é recebido por 10,37\% (907 famílias) e 6,43\% (562) estão inscritas no CAD-Único.

É importante ressaltar, que todos os dados citados são referentes às informações contidas no SIAB, como a maior parcela da população utiliza a modalidade tradicional da UBS Vila Dionísia, grande parte das informações sócio econômicas não estão disponíveis.

Com relação à área adscrita pela ESF e em consulta ao SIAB, em junho de 2017, a população cadastrada é de 28.609 habitantes, sendo um total de 8.745 famílias. Possuem cobertura de plano de saúde 2.901 pessoas, representando $10,14 \%$ do total cadastrado. É caracterizada por ser uma população em sua maioria jovem, na faixa etária de 20 a 39 anos, portanto economicamente ativa, representando 9.835 pessoas, seguidas da faixa etária de 40 a 49 anos, com 3.843 pessoas. O total de gestantes da ESF corresponde à 304, 
sendo 263 entre 15 anos e mais e 41 com até 14 anos. Contudo, esse número envolve gestantes que acompanham na unidade e no convênio, mas que recebem a visita do ACS.

A UBS contabiliza as gestantes encaminhadas ao Ambulatório do Pré - Natal de Alto Risco da Maternidade Cachoeirinha, somente as gestantes pertencentes a ESF. Desde janeiro até junho de 2017, 22 gestantes haviam sido encaminhadas para acompanhamento na Maternidade Cachoeirinha, com os seguintes CIDs:

Quadro 4 - Gestantes encaminhadas ao alto risco da UBS Vila Dionísia.

\begin{tabular}{|l|c|c|}
\hline $\begin{array}{c}\text { Número de } \\
\text { Gestantes }\end{array}$ & CID & PATOLOGIAS \\
\hline 01 & E039 & Hipotireoidismo não especificado \\
\hline 01 & O418 & Outros transtornos especificados do líquido amniótico e das membranas \\
\hline 01 & $\begin{array}{l}\text { B199, } \\
\text { A51 }\end{array}$ & Hepatite Viral, Não Especificada; Sífilis Precoce \\
\hline 01 & O100 & Hipertensão Essencial Pré-existente Complicando a Gravidez, o Parto e o \\
Puerpério
\end{tabular}

Fonte: UBS Vila Dionísia Junho/ 2017.

As consultas de pré-natal na ESF acontecem de forma intercalada entre médicos e enfermeiros, seguindo o que é preconizado pelo protocolo à Gestante de Risco habitual do Município de São Paulo (PREFEITURA MUNICIPAL DE SÃO PAULO, 2013).

A UBS tradicional atende à uma população de cerca de 40.000 mil pessoas. Devido ao grande número de usuários e à ausência de ACS para as visitas domiciliárias, o controle das gestantes ocorre através de um livro existente na UBS, sendo realizado pela auxiliar de enfermagem, sob supervisão das enfermeiras. Ao iniciar o pré-natal na 
unidade, a gestante é agendada com o médico ginecologista e após consulta o prontuário é entregue para a auxliar de enfermagem que coloca o nome, endereço e telefone da gestante no livro controle e anota a data do retorno na consulta médica e quais exames foram solicitados. Assim, a auxiliar checa se a gestante compareceu na consulta de retorno e se realizou os exames. Caso ocorra ausência em um dos momentos citados, ocorre a busca ativa por telefone, ou visita domiciliária com auxiliar ou enfermeira.

Por não ser ESF, a enfermeira não realiza consulta de pré-natal. Para controle da UBS tradicional é utilizado o sitema Business Intelligence (BI) implantando em São Paulo para controle de indicadores como Rede Cegonha, Remédio em Casa, entre outros programas da Atenção Primária sem ESF. De acordo com o Bi-Saúde de junho de 2017, a UBS tradicional conta com 125 gestantes ativas, porém não fornece o número de gestantes encaminhadas para o alto-risco.

Comparativamente à UBS Dra. Ilza, a UBS Vila Dionísia possui uma população mais jovem, com maiores problemas sociais e maior vulnerabilidade. A região é cercada por uma área de invasão, cujos moradores utilizam a UBS tradicional e segundo informações dos próprios funcionários, tal território é caracterizado por ser uma área de tráfico e consumo de drogas, com um expressivo número de adolescentes grávidas e moradias precárias, feitas de madeira e lona.

\subsection{PARTICIPANTES DA PESQUISA}

O critério que norteou a definição dos participantes que comporiam a amostra, esteve vinculado fundamentalmente à participação dos mesmos nas consultas de prénatal, na detecção do risco gestacional e no encaminhamento das gestantes para acompanhamento na Maternidade Cachoeirinha.

Definiu-se como critério de inclusão na população do presente estudo, ser profissional médico ou enfermeiro e que realizasse consulta de pré-natal das gestantes nas UBSs participantes.

Sendo assim, a enfermeira da UBS Vila Dionísia, na modalidade tradicional, não participou da pesquisa, por não realizar consulta de pré-natal, ficando essa função somente para os ginecologistas da unidade. 
Dessa maneira, foram eleitos como participantes dessa pesquisa, 07 médicos generalistas e 07 enfermeiros da UBS Dra. Ilza e 09 médicos generalistas e 09 enfermeiros da modalidade ESF e 02 ginecologistas da modalidade tradicional da UBS Vila Dionísia.

\subsection{DESCRIÇÃO DOS INSTRUMENTOS DE COLETA DE} DADOS

Na presente pesquisa, foram utilizadas técnicas de coletas de dados usualmente aliadas à pesquisa qualitativa e ao estudo de caso, ou seja, entrevista semiestruturada e a análise de documentos.

Os documentos analisados foram fornecidos pelas unidades estudadas (Maternidade Cachoeirinha, UBS Vila Dra. Ilza e UBS Vila Dionísia), tratam-se de dados de produção e de gestão das unidades. Esses documentos foram utilizados no sentido de caracterizar a situação vivenciada pelos profissionais envolvidos na pesquisa e para contextualizar as unidades estudadas.

O debate entre as diferentes formas metodológicas deve superar o nível superficial e preservar as questões de fato adequadas à pesquisa (GAMBOA, 1989).

Dessa forma, em qualquer formatação metodológica escolhida, o pesquisador deixará manifestar sua visão de mundo, ou seja, a sua experiência de vida e sua relação com o objeto pretendido (GOMES, 2001).

A pesquisa qualitativa não segue uma forma inflexível de coleta de dados, sendo, a utilização da entrevista semi-estruturada a ferramenta mais adequada para o método em questão, pois, favorece a presença do investigador e oferta todas as probabilidades para que o informante alcance a liberdade e a originalidade necessárias para engrandecer a investigação (TRIVIÑOS, 2010).

A entrevista é uma junção entre duas pessoas a fim de que uma delas consiga informações sobre um determinado tema, por meio de uma conversação de âmago profissional. Caracteriza-se no desenvolvimento de exatidão, focalização, autenticidade e licitude de um certo ato social como o diálogo (MARCONI; LAKATOS, 2007).

\subsection{REALIZAÇÃO DAS ENTREVISTAS}

O projeto foi submetido aos Comitês de Ética em Pesquisa da Escola de Enfermagem da Universidade de São Paulo, da Prefeitura Municipal de São Paulo e da 
Maternidade Cachoeirinha e a partir da aprovação em todas essas instâncias, iniciou-se os procedimentos metodológicas relativos à realização das entrevistas (Anexo 3).

Em fevereiro de 2017, com o objetivo de verificar a adequação e a validade do roteiro elaborado para a entrevista semi-estruturada, foi realizado teste piloto, pela própria pesquisadora, com três enfermeiros da ESF de São Paulo. Os entrevistados consideraram o roteiro adequado.

As entrevistas foram realizadas nos meses de junho e julho de 2017. Participaram das entrevistas, 7 enfermeiras e 4 médicos da UBS Dra. Ilza. Da UBS Vila Dionísia, 7 enfermeiros e 5 médicos. Devido a saturação dos dados encontrados, a pesquisadora não sentiu a necessidade de prosseguir com as demais entrevistas.

Para não atrapalhar a dinâmica da unidade e não prejudicar o atendimento dos pacientes, as entrevistas foram agendadas previamente com os entrevistados, respeitandose sempre a data, o local e o horário por eles escolhidos, sendo, neste momento, prestados esclarecimentos sobre os objetivos da pesquisa e da entrevista.

No início de cada entrevista, a pesquisadora procurava criar um clima de leveza com o entrevistado, deixando-o à vontade e aproveitava o momento para fortalecer o objetivo da pesquisa. Nessa altura, era entregue ao entrevistado o Termo de Consentimento Livre e Esclarecido (TCLE), (Apêndice A), reafirmando o caráter totalmente voluntário e sigiloso desta participação.

Após obter o consentimento do entrevistado, requisitava-se então, a permissão para a gravação da entrevista, utilizando-se um roteiro com perguntas norteadoras (Apêndice B). As perguntas eram efetuadas de maneira informal, possibilitando que o entrevistado discorresse livremente sobre as questões apresentadas, e sobre questões que aparecessem no decorrer da entrevista.

Ao final da entrevista a pesquisadora anotava suas impressões a respeito do entrevistado, assim como qualquer eventualidade ou outras questões que por um acaso surgissem e que pudessem colaborar na assimilação dos depoimentos, ou influenciar na análise dos discursos. O mesmo roteiro foi utilizado para médicos e enfermeiros, entendendo que ambos possuem papel semelhante na assistência ao pré-natal realizado nas UBSs.

As entrevistas foram transcritas, o mais prematuramente possível, pela própria pesquisadora e assim iniciou-se a análise dos dados. 


\subsection{ANÁLISE DE DADOS}

A análise dos dados tem como objetivo interpretar os dados coletados considerando os aspectos sociais, históricos e filosóficos no momento da coleta e anteriores a ela. Além disso, procura amplificar o conhecimento adquirido sobre o tema estudado (MINAYO, 2010).

Como as entrevistas foram gravadas, seguiu-se a orientação de Lüdke e André (1986); Triviños (1987), na intenção de transcrevê-las o mais brevemente possível, para tentar ao máximo preservar a veracidade e a totalidade dos discursos, incorporando também a linguagem utilizada pelos participantes da pesquisa.

Os dados primários e secundários foram avaliados pela técnica de análise de conteúdo descrita por BARDIN (2007, p.9) que a define como:

"Um conjunto de instrumentos metodológicos cada vez mais sutis em constante aperfeiçoamento, que se aplicam a "discursos" (conteúdos e continentes) extremamente diversificados (...) é uma hermenêutica controlada, baseada na dedução: a inferência”.

De acordo com Lüdke e André (1986), o processo de análise do conteúdo passa por uma primeira etapa de classificação e organização dos dados, em um processo exaustivo de leitura e releitura do material coletado, para então, adentrar a uma segunda fase que é denominada teorização. Esta fase, é muito sutil pois, o pesquisador não deve se focar apenas ao que foi descrito nas unidades temáticas encontradas e sim seguir com um processo de alheamento para encontrar novas explicações.

No presente estudo, as unidades temáticas intencionais serviram de ferramenta para a análise do conteúdo e foram amparadas pelo referencial teórico escolhido, que consequentemente permitiu a compreensão do objeto.

De acordo com Minayo (2010, p.94), as unidades temáticas intencionais se caracterizam por serem:

"Aquelas que retêm historicamente as relações sociais fundamentais e podem ser consideradas balizas para o conhecimento do objeto nos seus aspectos gerais (...)comportam vários graus de abstração, generalização e de aproximação".

As unidades temáticas intencionais se relacionam de forma peculiar e com isso aparecem dos discursos dos participantes enfermeiros e médicos, as denominadas subunidades temáticas empíricas. Caracteriza-se como subunidades temáticas empíricas àquelas elaboradas com intenção operacional, tencionando o trabalho de campo. Elas 
possuem a particularidade de colher os determinantes e as circunstâncias que se definem na realidade empírica (MINAYO, 2004).

Sendo assim, realizadas as devidas reflexões sobre as unidades temáticas intencionais e as subunidades temáticas empíricas, pode-se dizer que ambas são essenciais para a realização da análise de conteúdo, conforme as orientações descritas por BARDIN (2007). O enfoque da análise de conteúdo é compreender de forma crítica a essência dos discursos, seu conteúdo exibido ou oculto, aos significados explícitos ou reprimidos (CHIZOTTI, 2010).

Ocorreu um processo laborioso e repetitivo de leitura e releitura das entrevistas, para que elas se tornassem cada vez mais conhecidas e assimiladas e dessa forma, pudessem ser analisadas pela pesquisadora.

Após ter-se desenvolvido um panorama geral dos discursos dos entrevistados, segui-se coma segregação das unidades de registro e codificação dos dados ainda não lapidados do texto. Esta técnica, realizada com o objetivo de demonstração da veracidade, englobou as etapas de recorte, classificação e junção do conteúdo, pretendendo-se a codificação do mesmo e a elaboração das unidades.

A codificação foi construída por frases, sendo que cada frase retratava uma unidade de registro/sentido, referente a uma das unidades temáticas intencionais. Essa metodologia foi realizada em cada uma das entrevistas, verificando que muitas frases tinham o mesmo significado. Após essa etapa, as frases foram organizadas em um quadro geral analítico, para a avaliação do conteúdo das entrevistas e a compreensão de que os dados já possuíam significado.

Neste processo de análise, foi importante permutar tanto o processo que trazia o fluxo de dados, como o que trazia os fundamentos teóricos, para que de forma conjunta compusessem o trabalho final. 


\section{RESULTADOS E DISCUSSÃO}

\subsection{CARACTERIZAÇÃO DA POPULAÇÃO}

Antes de iniciar a análise dos discursos dos participantes é importante caracterizar a população entrevistada nesse estudo.

Essa população foi constituída por dois grupos, o primeiro grupo formado por médicos e enfermeiros da UBS Dr ${ }^{\mathrm{a}}$.IIza Hutzler, totalmente ESF e o segundo formado por médicos e enfermeiros da UBS Vila Dionísia, com o modelo misto, ou seja, uma parte com ESF e outra tradicional.

Todos os trabalhadores são contratados pela OSS Associação Saúde da Família, com vínculo empregatício através da CLT, possuem carga horária de 40 horas semanais, sendo facultado aos médicos um dia da semana de folga, denominado day off.

Os entrevistados E1 a E11 corresponde à UBS Dra. Ilza e do E12 ao E23 corresponde à UBS Vila Dionísia. Devido a saturação de dados obtidos durante o processo das entrevistas, a entrevistadora considerou oportuno interrompê-las e iniciar a análise com os dados coletados.

Quadro 5 - Perfil dos Trabalhadores entrevistados no estudo, SMS- São Paulo, 2017.

\begin{tabular}{|l|l|l|l|l|l|}
\hline $\begin{array}{l}\text { TRABAL } \\
\text { HADOR }\end{array}$ & IDADE & SEXO & PROFISSÃO & $\begin{array}{l}\text { TEMPO NA } \\
\text { APS }\end{array}$ & ESCOLARIDADE \\
\hline E1 & 42 & F & Enfermeiro & 12 anos & $\begin{array}{l}\text { Mestre em Educação de Sistemas } \\
\text { de Saúde }\end{array}$ \\
\hline E2 & 29 & F & Enfermeiro & 06 anos & Graduação em Enfermagem \\
\hline E3 & 42 & F & Enfermeiro & 15 anos & $\begin{array}{l}\text { Pós-graduação em Saúde da } \\
\text { Família }\end{array}$ \\
\hline E4 & 30 & F & Enfermeiro & 04 anos & $\begin{array}{l}\text { Pós-graduação em Saúde Coletiva } \\
\text { e doutorando na Faculdade de } \\
\text { Medicina da USP }\end{array}$ \\
\hline E5 & 33 & F & Enfermeiro & 05 anos & $\begin{array}{l}\text { Pós-graduação em Saúde da } \\
\text { Família e cursando pós-graduação } \\
\text { em cuidados em pré-natal. }\end{array}$ \\
\hline E6 & 31 & F & Enfermeiro & 1 ano 2 meses & Graduação em Enfermagem \\
\hline
\end{tabular}




\begin{tabular}{|c|c|c|c|c|c|}
\hline E7 & 56 & $\mathrm{~F}$ & Enfermeiro & 35 anos & $\begin{array}{l}\text { Pós-graduação em Enfermagem } \\
\text { Obstétrica, Saúde Pública, } \\
\text { Pneumotisiologia e Saúde da } \\
\text { Família }\end{array}$ \\
\hline E8 & 33 & $\mathrm{~F}$ & Médico & 9 anos & $\begin{array}{l}\text { Pós-graduação em Saúde da } \\
\text { Família e Endocrinologia }\end{array}$ \\
\hline E9 & 30 & $\mathrm{~F}$ & Médico & 1 ano 8 meses & Graduação em Medicina \\
\hline E10 & 31 & $\mathrm{M}$ & Médico & 3 anos & Graduação em Medicina \\
\hline E11 & 27 & $\mathrm{M}$ & Médico & 3 meses & Graduação em Medicina \\
\hline E12 & 29 & $\mathrm{~F}$ & Enfermeiro & 5 anos & Graduação em Enfermagem \\
\hline E13 & 38 & $\mathrm{~F}$ & Enfermeiro & 13 anos & $\begin{array}{l}\text { Pós-graduação em Neonatologia e } \\
\text { Saúde Pública }\end{array}$ \\
\hline E14 & 39 & $\mathrm{~F}$ & Enfermeiro & 5 anos & Graduação em Enfermagem \\
\hline E15 & 34 & $\mathrm{~F}$ & Enfermeiro & 9 anos & Residência em Radiologia \\
\hline E16 & 36 & $\mathrm{~F}$ & Enfermeiro & 15 anos & $\begin{array}{l}\text { Pós-graduação em Saúde da } \\
\text { Família, Oncologia e Informática }\end{array}$ \\
\hline E17 & 38 & $\mathrm{~F}$ & Enfermeiro & 7 anos & Graduação em Enfermagem \\
\hline E18 & 40 & $\mathrm{~F}$ & Enfermeiro & 10 anos & Graduação em Enfermagem \\
\hline E19 & 52 & M & Médico & 17 anos & $\begin{array}{l}\text { Pós-graduação em Pediatria e } \\
\text { Homeopatia }\end{array}$ \\
\hline E20 & 24 & $\mathrm{~F}$ & $\begin{array}{l}\text { Médico } \\
\text { (Programa } \\
\text { Mais } \\
\text { Médicos) }\end{array}$ & $\begin{array}{l}1 \text { ano Sáude } \\
\text { Pública Peru } \\
1 \text { ano APS } \\
\text { Brasil }\end{array}$ & Graduação em Medicina \\
\hline E21 & 70 & $\mathrm{~F}$ & Médico & 41 anos & Graduação em Medicina \\
\hline E22 & 31 & $\mathrm{M}$ & Médico & 1 ano & Graduação em Medicina \\
\hline E23 & 29 & $\mathrm{M}$ & Médico & $\begin{array}{l}2 \text { anos Saúde } \\
\text { Pública Peru } \\
1 \text { ano APS } \\
\text { Brasil }\end{array}$ & Graduação em Medicina \\
\hline
\end{tabular}


Características do grupo, constituído por 14 enfermeiros e 9 médicos:

- $18(78,26 \%)$ pertencem ao sexo feminino e $5(21,73 \%)$ pertencem ao sexo masculino;

- 12 (52,17\%) pertencem à faixa etária de 25 a 35 anos, 04 (17,39\%) de 36 a 39 anos, $03(13,04 \%)$ de 40 a 49 anos, $03(13,04 \%)$ de 50 anos a mais e $1(4,34 \%)$ pertence a faixa etária de menores de 24 anos;

- 13 (56,52\%) possuem somente graduação, 8 (34,78\%) possuem pós-graduação lato sensu ou residência e desses 6 (75\%) possuem pós-graduação na área de APS, como Saúde Coletiva ou Saúde da Família e 2 (8,69\%) possuem pós-graduação stricto sensu;

- 11 (47,82\%) possuem até 05 anos de trabalho na APS, 9 (39,13\%) de 6 a 15 anos e $3(13,04 \%)$ possuem mais de 16 anos na APS.

De acordo com os dados, pode-se dizer que a população entrevistada é majoritariamente feminina, jovem (faixa etária entre 25 a 35 anos), possuem somente curso de graduação em sua área de formação, com um período na APS, de até 5 anos.

Nos últimos anos, observou-se um aumento expressivo e permanente da presença das mulheres na força de trabalho, como parte essencial da população economicamente ativa, contribuindo com a movimentação da economia, ainda que em desvantagem, quando comparada aos homens na execução das mesmas funções: ganham menores salários, possuem piores condições de trabalho, sofrem com assédio sexual e moral (WERMELINGER et al, 2010).

No Brasil, dados censitários mostram crescimento da força de trabalho, com o aumento da taxa bruta de participação feminina de 13,6\% em 1950, para 26,9\% em 1980, atingindo 59,1\% em 2016. A participação feminina, ainda se concentra primordialmente, nos serviços domésticos, administrativos, na área social, na educação e na saúde em geral. No setor de saúde, a participação feminina chega a quase $70 \%$ do total, com $62 \%$ da força de trabalho com nível superior, chegando a $74 \%$ nas categorias profissionais com nível médio e fundamental. A profissão mais feminizada é a das nutricionistas, na qual as mulheres representam praticamente $95 \%$ dos profissionais. Contudo, é apropriado registrar que profissões, essencialmente masculinas, como medicina, odontologia e medicina veterinária estão cada vez mais aumentando o número de profissionais do sexo feminino. É fundamental reforçar, que o aumento da participação do sexo feminino no setor saúde, não é uma exclusividade do Brasil e sim uma tendência mundial, como ocorre nos Estados Unidos (43,3\%), Canadá (42,8\%), Brasil (33,5\%), Argentina (26,9\%) entre outros (BRASIL, 2017). 
Em pesquisa realizada em 2015 pela Faculdade de Medicina da Universidade de São Paulo, o Brasil possuía um total de 399.692 médicos. Considerando os médicos em atividade no ano de 2014, 229.862 (59\%) possuem título de especialista e 159.341 profissionais $(41 \%)$, não possuem especialidade ou residência médica, sendo considerados generalistas. No grupo dos mais jovens (20 - 30 anos), os generalistas são majoritários, representando $73,7 \%$, contra $26,2 \%$ dos especialistas. Uma conjectura a ser considerada, é o fato de serem formados há poucos anos, dessa forma não tiveram tempo de concluir a Residência Médica e nem de prestar prova de título em sociedade de especialidade. Como não há vagas de Residência Médica para todos os recém-formados, uma parte permanecerá sem título de especialista (SCHEFFER, 2015).

A construção social do trabalho qualificado tem como estrutura as etapas de distinção entre os tipos de tarefa e os trabalhadores que os executam. Esses processos é que estabelecem as identidades profissionais, e estas são, ao mesmo tempo, identidades sexuadas e de posições de condecoração na comunidade (WERMELINGER et al., 2010).

Como exemplo, evidencia-se a visão social entre a medicina e a enfermagem, ambas feminilizadas, porém vistas de forma diferenciada. A enfermagem é preterida de uma representação de tecnicidade e vinculada a um universo de trabalho com competências intrísecas à natureza feminina, apesar, dos serviços realizados por enfermeiros, impulsionarem, além de competências técnicas, competências pessoais elaboradas e difíceis de quantificar, adquiridas tanto pela experiência e interação com usuários e demais profissionais como em formações cada vez mais estruturadas. (DAUNE-RICHARD, 2003).

A profissão de enfermeiro é atribuída principalmente às atividades de cuidado no seu aspecto mais humano e menos técnico, embora, exija cada vez mais o conhecimento e o domínio de novas tecnologias no campo médico, administrativo, social e psicológico, promovendo cada vez mais a especialização em busca de maiores conhecimentos e com a intenção de uma maior valorização profissional e monetária. Sendo assim, é oportuno detalhar a análise sobre os processos praticados, com a intenção de que sejam introduzidas e/ou reafirmadas as tecnologias leves e leves-duras nas ações de saúde, principalmente na Atenção Primária à Saúde, com o intuito de unir as representações existentes ao saber técnico-profissional para a valorização de todas as categorias (MERHY, 2002). 


\subsection{AS UNIDADES TEMÁTICAS INTENCIONAIS DO ESTUDO}

O presente estudo teve como objetivo entender como ocorre a contrarreferência da Maternidade Cachoeirinha para as UBS Vila Dionísia e Dra. Ilza Hutzler, para tanto, tomou-se como unidades temáticas intencionais desse estudo:

- O sistema de saúde;

- O funcionamento do sistema de referência e contrarrefrência;

- Fatores estruturais das Unidades Básicas de Saúde.

Tendo como norteadoras as unidades temáticas intencionais, construíram-se as subunidades temáticas empíricas, através da análise das falas dos profissionais enfermeiros e médicos, cujos discursos expuseram a maneira como eles vivenciaram, sentiram e compreenderam a política de contrarreferência que ocorre no Município de São Paulo.

\subsubsection{O Sistema de Saúde}

Com relação à primeira unidade temática intencional, o sistema de saúde, a partir dos discursos dos participantes, emergiram três subunidades temáticas empíricas, a saber:

- Resolubilidade;

- Integralidade;

- Lógica adotada pelos usuários do Sistema Único de Saúde.

\subsubsection{Resolubilidade}

A resolubilidade dos problemas de saúde da população, não permite ignorar a importância da relação usuário/profissional, através do processo de comunicação que está envolto no cuidar e nas orientações que deverão ser repassadas de forma que o receptor, no caso o usuário, compreenda e modifique em ações que objetivam a melhoria de sua sáude, seja através de atividades preventivas ou até mesmo reabilitadoras. Para tanto, é fundamental que os trabalhadores sejam devidamente capacitados, para perceber a estrutura e funcionamento do SUS, assim como a sua relação com o usuário (DIAS, 2010).

$\mathrm{O}$ atendimento realizado na APS deve focar na resolubilidade dos problemas do usuário, podendo o mesmo ser encaminhado para um nível de maior complexidade, caso 
seja oportuno o uso de tecnologias mais complexas e que não se apresentam dispostas no setor primário. Contudo, para que o sistema de saúde engrene, considerando suas diferenças tecnológicas, é fundamental que cada nível de complexidade, seja acertivo. Dessa forma, os níveis de saúde (primário, secundário e terciário) devem estar capacitados em todos os pontos de acesso, respondendo aos princípios da resolubilidade e da integralidade (CAPOTE, 1990).

Observando que o trabalho humano, tal como se orienta nos tempos atuais, só é possível o seu funcionamento por meio das tecnologias que se delineiam, torna-se fundamental pensar sobre a conexão que se estabelece entre as tecnologias, o mundo, a ciência e o homem, em todos os sentidos e locais. As tecnologias em saúde são classificadas em três categorias: tecnologia dura, relacionada a equipamentos tecnológicos, normas, rotinas e estruturas organizacionais; leve-dura, que representa todos os saberes fundamentados no processo de saúde, ou seja, o modo como se cria necessidades e a forma de executá-las, e a leve, que condiz com às tecnologias de relações, de produção, de comunicação, acolhimento e vínculo. Apesar dessas três categorias se comunicarem, o ser humano procura principalmente, a tecnologia das relações, explicitada pelo vínculo entre profissional e usuário, e tão representativo da APS. Historicamente, as tecnologias leve-duras e duras estiveram ligadas à produção de um modelo voltado à consulta médica, onde o conhecimento médico direciona e determina o trabalho dos demais profissionais, muito vivenciado nos níveis secundário e terciário (MERHY; FRANCO, 2003)

Essa percepção é bastante clara, como pode ser observado pelos discursos abaixo:

"Porque lá eles fazem ultrassom, eles fazem cardiotoco, essas coisas, aqui a gente não faz. Então pelo menos esses exames diferenciais que eles fazem lá eu gostaria de saber, porque a gente não tem contato nenhum aqui, então eu queria que viesse pelo menos um resuminho, alguma coisa assim. " (E4)

"Até o início eu fazia assim, eu tentava controlar com medicamento e só encaminhava se eu não conseguia, hoje eu já tô encaminhando de qualquer forma, entendeu? Começou a ter pressão alta eu já encaminho. A gente faz o controle da glicemia, tudo direitinho, deu alguma alteração eu já peço prá ir pra lá. Porque é como eu tô te falando, como eu sou nova e não tenho muita experiência, fico com medo de acontecer algum problema e eu não saber conduzir direito, então eu geralmente encaminho pra lá" (E9)

Uma maior resolubilidade da APS poderia proporcionar a efetividade dos atendimentos e minimizar a fila de espera por consultas com especialistas e exames, 
especialmente os de maior complexidade, reservando os recursos da atenção terciária para procedimentos verdadeiramente necessários (FRANCO; MAGALHÃES, 2004). Para tanto, a introdução do SUS nos currículos de graduação e a capacitação dos profissionais tanto da APS, quanto dos demais níveis de atenção é fundamental para que se atinja o resultado esperado.

Na XII Conferência Nacional de Saúde, realizada em 2000, a discussão da educação na área de saúde, antes repelida a segundo plano, foi fortemente ressaltada. Como conclusão, entendeu-se que não se tratava apenas em formar pessoal capacitado tecnicamente, mas profissionais que fizessem uma ponderação sobre o acesso universal, a qualidade e a humanização na Atenção à Saúde, em junção com o controle social. O Ministério da Educação precisaria ajustar o currículo de graduação das escolas voltadas para a formação de profissionais da área de saúde, incluindo como prioridade as ações de atenção primária. Os profissionais, atualmente são formados para o uso exorbitante e abusivo das tecnologias duras e para a especialização, o que não é necessariamente adequado para o SUS. Essa conduta, estimula o abuso do diagnóstico baseado em exames laboratoriais e de imagem, em prejuízo da avaliação clínica do paciente, propiciando um número enorme de exames subsidiários para fins diagnósticos, piorando a busca e a espera dos pacientes, dificultando o acesso e utilização do sistema (BRASIL, 2000).

Nota-se que a introdução das temáticas relativas ao SUS, primordialmente no que se refere à questão da resolubilidade e da referência e contrarreferência, nas grades curriculares dos cursos de graduação na área da saúde, ainda permanece arcaica e distante do desejado, para a formação de profissionais que independentemente do setor de atuação (primário, secundário e terciário) compreendam seus princípios e diretrizes e corroborem para o seu funcionamento como preconizado. Observa-se que a maioria dos respondentes, apresenta uma resposta negativa, sobre o conhecimento do que seja os conceitos de referência e contrarreferência:

"Nenhuma, não lembro de ter tido isso na faculdade, pré-natal sim, mas de referência e contra referência não”. (E15)

"Durante a graduação? Não teve uma abordagem, na graduação não de referência e contrarrferência, essas coisas de SUS. Temática de pré-natal foi abordada dentro de uma disciplina especifica". (E16)

"De referência e contra-referência, não. Na parte nossa de atenção primária não, não tive nada disso". (E2)

"Pré-natal a gente aprende, referência e contra-referência não. Não porque a gente fez, faz muitos anos atrás né, na minha época. ” (E3) 
"Eu me formei na USP né, então eu fazia parte já do pré-natal tanto do Hospital das Clínicas, quanto no Hospital Universitário. Então eu conseguia ver os dois lados já né, tanto o pré-natal de risco que era no HC, quanto no risco habitual no Hospital Universitário. Então eu já sabia os dois lados. Mas não teve referência $e$ contrarreferência, não, não teve”. (E10)

"A graduação do São Camilo ela fala muito sobre Saúde Pública... dessa questão de comunicação entre os serviços, até então quando você está na graduação você acha que tudo que é te passado da mesma forma que deveria acontecer quando se tem uma reestruturação, eles falam da reestruturação da assistência né, onde você tem primário, secundário e terciário né, acho que ele consegue te passar o script do que deveria ser né, ele passa exatamente isso onde você tem, vai na atenção primária, a atenção primária passa pra terciária e a terciária cuidou, resolveu, volta pra atenção primária. Mas sempre se conversando". (E17)

Percebe-se, que muitas informações sobre o funcionamento do SUS, são repassadas durante os estágios, porém como orientações de atendimento:

"A gente sempre foi instruído né, tanto a preencher a referência quando encaminhava e a contra-referência quando a gente tava no serviço de especialidade, pro serviço que encaminhou ter uma resposta. " (E11)

"Durante o internato que foi a parte que a gente mais teve contato, porque durante a minha matéria mesmo de ginecologia, infelizmente a minha turma de prática, não teve prática. É, teve um problema lá, então a gente não teve prática. E aí, eu só fui mesmo passar a ter contato, fazer os exames, tudo bonitinho, através do internato, que aí a gente teve que praticar mesmo, mas até então só tinha teoria. Os residentes que eram as pessoas que a gente acompanhava, eles sempre falavam que quando não dava prá atender por lá, que a gente ia pedir pra ir pro alto risco, onde tivesse de referência do hospital lá da faculdade, e que era interessante a gente receber a resposta, né”. (E2)

Muitos profissionais, buscam nos cursos de pós-graduação, o entendimento sobre o que é o SUS e seu funcionamento:

“... eu fiquei na verdade quinze anos só fazendo pediatria, então eu na realidade nem tinha mais conhecimento desse fator, na verdade de contra referência e referência, eu fiz um novo curso na verdade como Médico de Saúde da Família prá ter um novo conhecimento aí da referência”. (E19)

Mas nem todos os cursos de pós-graduação ofertam essa temática:

"Eu me formei a trinta e cinco anos atrás, então não existia SUS, né. Eu participei até, fiz passeata pelo SUS, fizemos um monte de coisas. Mas a gente sempre teve essa visão tanto na parte hospitalar e sempre na parte de profilaxia que a gente chamava na época né, e sempre existia essa ideia ambulatorial e hospitalar, né. Não tinha uma hierarquização do sistema ainda né, então, na minha graduação eu não tive essa informação, nem quando eu fiz especialização, nem nada disso, tá”. (E7)

Segundo a IX Conferência Nacional de Saúde, realizada em 1992, é imprescendível para a implementação do SUS uma política nacional de recursos humanos 
efetiva, que acrescente ações como a qualificação e/ou formação permanente de seus trabalhadores, cuja evolução na carreira conte com o alicerce de escolas de formação nas Secretarias de Saúde; ou mediante conexão com Secretarias de Educação, universidades e outras instituições públicas de ensino superior (BRASIL, 1993).

Nas falas abaixo verifica-se que os profissionais aqui ouvidos tiveram pouco acesso a treinamentos em seus locais de trabalho:

"Quando eu entrei, acho que pelo fato de eu ser recém-formada, eu passei acho que uns quinze a vinte dias acompanhando a Dra. ..., que é uma das médicas mais velhas daqui, né. E aí eu fiquei acompanhando uns vinte dias, só não pude fazer um mês direitinho, porque o médico da minha equipe tinha saído, acho que ia completar uns seis, sete meses. Então a minha área tava muito, tava precisando muito de médico, precisava arrumar algumas coisas e então eu fiquei um tempo menor. Que elas tinham proposto no início, era um mês de treinamento". (E9)

“Capacitação, aqui já teve, mas há muito tempo...”. (E19)

“A minha primeira capacitação foi em 2005, de lá prá cá não tive mais”. (E1)

"Não tive capacitação de pré-natal não. De referência e contrarreferência? Não, isso a gente não tem capacitação prá entender, a gente ao longo do trabalho você vai aprendendo. .... aula não, mas impresso tem. Eles dão a gente lê". (E3)

Um outro fator relevante, quando se fala em resolubilidade, está na presença da ESF e o importante trabalho dos ACS, que inseridos na comunidade conseguem propiciar a formação de vínculo com os usuários e desta forma conhecer e auxiliar no atendimento das necessidades de saúde da população, tornando-se um elo com os demais profissionais da APS. Durante as entrevistas, foram relatadas a importância do ACS na busca ativa das gestantes faltosas, nas consultas de pré-natal, no aviso do nascimento dos recém-nascidos e no acompanhamento das visitas domiciliárias para a realização das consultas de puerpério.

"Por conta do agente comunitário que faz visita na casa e acaba sabendo informação sobre ela, e muitas não têm como vir aqui e lá por conta do emprego. Então muitas ficam só lá, mas assim a gente não deixa de ter informação, como ele passa mensalmente na casa, ele acaba sabendo como é que tá, se interna se não interna, se teve alguma complicação tudo, ele trás pra gente”. (E3)

“A gente faz a busca ativa com os agentes, tudo prá tentar achar essas gestantes”. (E2)

"E a agente de saúde quando fica sabendo, nos avisa a gente faz a visita de puerpério em casa”. (E4)

“...o agente comunitário avisa a gente, a gente também acompanha né então a gente sabe mais ou menos o período que ela tá ganhando o neném”. (E7) 
"Mas a gente tem contato com a paciente do PSF, porque na verdade ela tem a assistência da agente comunitária de saúde né”. (E19)

Quando comparada a ESF, observa-se que na UBS tradicional, os profissionais de saúde encontram dificuldades em realizar um controle próximo das gestantes, bem como de problemas decorrentes da gestação:

"Eu acho que demora muito prá chegar as comunicações de óbito, pra quem é do PSF é mais tranquilo, mas quando é da tradicional, que não tem agente comunitário, aí fica bem complicado, demora muito". (E15)

"Sim, tem dificuldade, muita, principalmente se ela for tradicional. A gente só consegue agora de um ano prá cá por que, porque a gente monitora gestante. Obvio que tem bastante dificuldade, porque os endereços são bastante dificultosos porque é viela, Gervazea, não sei se já conhece a Gervazea, Taquara Sul, é difícil achar as gestantes lá, mas enfim a gente acha, mas se tivesse ACS ajudava. " (E17)

Em um estudo realizado na cidade de São Paulo, efetuando um comparativo entre as unidades com ESF e com UBS tradicional, observou-se que nas unidades com ESF, o vínculo com os usuários era maior, assim como a resolubilidade das necessidades de saúde. Além disso, acredita-se que a ESF possibilita a construção pelo usuário, de um sentimento de pertencimento a um ideário de cuidado de saúde individualizado e detalhado (ELIAS et al., 2006).

Com a incorporação da ESF como modelo na APS, baseia-se o vínculo entre profissionais e população, favorecendo saberes e práticas para desafiar e resolver problemas ligados a uma determinada comunidade, sobre vários pontos e não somente sobre o domínio saúde. A família é compreendida a partir do ambiente onde vive e elabora suas relações, almejando dessa forma, promover a melhoria das condições de vida. A ESF possui um potencial revolucionário, articula setores da comunidade (entidades religiosas, escolas, líderes comunitários, entre outros) em benefício de atividades preventivas e de promoção à saúde (ARCE, 2014).

Enquanto característica da APS, a longitudinalidade da assistência, contribui para a relação entre profissionais e usuários/famílias. A relação é criada pela pessoa e não pela doença, como resultado, há efeitos proveitosos na comunidade: maior participação às atividades de prevenção e promoção à saúde, maior rapidez no reconhecimento de problemas do território e dessa forma, uma diminuição da utilização do serviço com ações curativas (MENDONÇA et al., 2008).

Para a ideia de longitudinalidade e continuidade do cuidado, Cunha e Giovanella (2011) legitimam o termo brasileiro de vínculo longitudinal e o caracterizam como a 
relação terapêutica combinada entre profissional e usuário, tendo como referência e utilização a UBS, como base regular de cuidado ao longo do tempo.

Conforme as autoras, podem ser discriminadas três categorias em relação ao vínculo longitudinal: a aprovação por parte da população, como sendo a UBS, a referência habitual para o cuidado em saúde; o vínculo duradouro entre paciente - profissional, no cenário de uma população pertencente a uma determinada área, ponderando confiança, responsabilidade e a experiência do usuário; e a continuidade informacional, que relaciona à qualidade dos registros de saúde, sua utilização e oferta, permitindo a aquisição de conhecimento arrojado sobre os diferentes pacientes pela equipe de saúde, o que colabora com a orientação da conduta terapêutica. Essa última categoria, elenca critérios de eficiência e responsabilidade em relação à obtenção de novas informações, e a utilização de novas tecnologias podem colaborar com tal processo (CUNHA; GIOVANELLA, 2011).

Com relação aos ACS, são considerados como de primordial importância para a vinculação dos usuários às unidades de saúde, visto que moram nas comunidades nas quais as UBS estão inseridas, conhecem a população adscrita e desenvolvem o papel de mediadores entre os saberes técnicos e populares. Uma das competências próprias dos ACSs está na possibilidade de superação da separação entre os saberes técnicos e os saberes da população, no sentido da construção de um discurso que possibilite a compreensão e vivência ampliada do conceito de saúde. Dessa forma, o ACS se realça como agente de ações e práticas libertadoras de saúde (MACIAZEKI-GOMES et al., 2016).

Sendo assim, é essencial a ampliação da ESF como modalidade de APS que com suas características, favoreça a instauração dos princípios e diretrizes do SUS. Dessa forma, as UBS tradicionais devem o mais precocemente possível abrirem espaço para as unidades com ESF (KANTORSKI et al., 2009). 


\subsubsection{Integralidade}

O conceito de integralidade rememora a conexão dos serviços por meio de redes assistenciais, admitindo a interdependência dos envolvidos e das instituições, pois nenhuma delas possui todos os recursos, tecnologias e competências necessárias para as resoluções de saúde em seus diferentes ciclos de vida. Torna-se imprescindível, a criação de mecanismos de cooperação e coordenação inerentes de uma gestão eficiente e responsável com os bens da sociedade e que tragam respostas às necessidades de saúde da população (HARTZ; CONTANDRIOPOULOS, 2004).

Para assegurar a integralidade, é fundamental realizar alterações na forma de produzir cuidado, iniciando pela APS com seguimento nos demais setores, como o secundário e o terciário. Dessa forma, a integralidade começa pela organização dos processos de trabalho na APS, na qual a assistência deve ser baseada na multidisciplinaridade, utilizando ferramentas de trabalho próprias dessa área, como o acolhimento, ausculta qualificada e a formação do vínculo, onde a equipe se imputa pelo cuidado prestado. Dessa forma, o cuidado é produzido e executado a partir das várias áreas de saberes e práticas, na qual se reunem o de vigilância à saúde, cuidados à sociedade, finalizando com os cuidados individuais (FRANCO; MAGALHÃES, 2004).

Contudo, observa-se nas falas um descomprometimento com a integralidade, sem o mérito de ser de forma intencional, ou por falta de conhecimento desse princípio:

"Se a médica do alto risco, ela pede prá paciente passar aqui e lá, a gente acompanha, se não, ela só acompanha no alto risco, isso é muito relativo. Tem obstetra e dependendo da patologia ele quer que fique aqui e lá, e tem patologias ele fala só quero que você acompanhe lá, e a gente só faz a visita domiciliar, o enfermeiro faz a visita domiciliar". (E1)

"Então a gente acaba não tentando convencer muito de ficar indo lá e vindo aqui, a não ser que eles deem alta pra ela e ela venha pra cá, mas assim, se vão três prá lá, uma fica e duas não vem pra cá." (E4)

“Algumas continuam, outras não. Preferem ficar passando só lá mesmo, não são todas que ficam passando nos dois por conta do emprego, tudo. Elas preferem ficar passando só lá mesmo e aí elas ficam só lá e pronto". (E3)

"Porque quando o paciente vem pra mim, se ele já foi pro alto risco é porque ele precisa de um cuidado específico, de um olhar mais detalhado, ele vai vim prá mim pra fazer o que?" (E17)

Seguem-se algumas falas, que evidenciam o conhecimento do princípio da integralidade e sua aplicabilidade no cuidado prestado: 
"Nós fazemos a orientação de que mesmo no alto risco a gente deve fazer o monitoramento continuar porque a gestante é nossa, a gestante não vai sair do território né, a gente tem que monitorar esse alto risco". (E16)

“A gente faz tudo prá tentar que elas fiquem aqui e lá na Cachoeirinha. Tem paciente que adere, e tem paciente que não adere. Porque trabalha, tem suas atividades e fica difícil, tanto passar lá, como passar aqui, né? Que aí vamos dizer, que se for mensal, duas consultas no mês, difícil, né? Então, depende. Mas a gente tenta ao máximo. É importante”. (E2)

"Eu peço, prá tanto continuar aqui quanto lá. Mas eu não sei o que se passa, que tem algumas que ficam aqui comigo e continuam lá, e algumas falam que não precisa continuar aqui e ficam só lá no alto risco, mas temos que acompanhar, com certeza. Temos que correr atrás da informação delas, da saúde delas, né?” (E8)

A integralidade presume uma relação coordenada e estruturada entre os diversos níveis do SUS e a mutualidade entre atores e instituições (MENDES, 2001).

Assim como em outros municípios, há na cidade de São Paulo, o Comitê de Investigação de Mortalidade Materno Infantil, que tem por objetivo investigar as causas de óbitos ocorridas nesse nível, para interferir nas causas evitáveis e dispor de dados estatísticos e epidemiológicos para amparar a criação de políticas públicas. Sendo assim, quando ocorre um óbito materno, fetal, natimorto e em mulher em idade fértil (15 a 49 anos), ocorre a necessidade de elaboração de um relatório investigativo, parte a ser preenchido pelo hospital onde ocorreu o óbito, parte a ser preenchido pela UBS à qual a paciente é vinculada. Algumas informações solicitadas à APS, são referentes ao período de internação da paciente e aos procedimentos pelos quais ela passou durante o período de internação, dessa forma, se não houver o acompanhamento do equipamento da Atenção Primária à Saúde, mesmo quando a gestante permence no alto risco, dificilmente o relatório poderá ser preenchido de forma correta e completa, para ser encaminhado ao Comitê.

“Ah sim! Porque a gente não tem os dados né” (E1)

"Dados da maternidade é muito difícil, normalmente se a gente garimpa muito a gente consegue algumas informações no SIGA e olhe lá, mas dados assim da maternidade, é muito dificil”. (E2)

"Quando eu peguei era mais difícil, mas agora o comitê tá muito melhor. Então a gente consegue quando tem reuniões do comitê essas informações. Diretamente da Maternidade a gente não tem essa relação, a gente só consegue assim, porque em algumas visitas deles, os responsáveis do comitê, é uma visita hospitalar, que não é nossa, aí através dessas visitas eles têm essas informações, e na reunião a gente discute, mas não diretamente, a gente com a Maternidade. "(E13) 
Além de estruturar a linha de cuidado, da perspectiva dos fluxos assistenciais, considera-se que a APS e mais especificamente a ESF, possui responsabilidades sobre o cuidado usuários que vivem em um determinado território, portanto, deverá acompanhálas, assegurando o acesso aos outros níveis de assistência, e garantindo seu retorno quando o atendimento nos demais níveis não for mais necessário (FRANCO; MAGALHÃES, 2004).

\subsubsection{Lógica adotada pelos usuários do Sistema Único de} Saúde

Essa subunidade temática empírica trata da lógica ainda predominante no âmbito dos serviços de saúde, onde o usuário muitas vezes se utiliza da atenção terciária, buscando a resolução de suas necessidades de saúde. Muitas vezes, ao serem encaminhadas para o alto-risco, as gestantes deixam de ser acompanhadas na atenção primária, seja através de consultas, seja através das visitas domiciliárias da equipe multiprofissional, sem saber que já no puerpério, retornarão com seus recém-nascidos, para acompanhamento durante o ciclo de vida de ambos.

“Ela prefere ficar só no alto risco. É difícil ela ficar nos dois serviços, né. Lá os exames saem rápido, tem ultrassom, tudo rápido, qualquer queixa já passa no pronto socorro e eles atendem elas. Aqui não, demora, tem que marcar, às vezes a agenda tá cheia”. (E13)

Segundo a fala dos profissionais, um outro fator corroborante, é a orientação dada às gestantes encaminhadas ao alto risco, em que a equipe profissional da atenção terciária orienta a descontinuidade do seguimento das consultas de pré-natal na APS. Considerando tais afirmações, torna-se essencial promover o contato e a integração dos profissionais dos diferentes níveis de saúde, através de capacitações conjuntas, para garantir o funcionamento do SUS. Em termos de gestão e política, a construção de hospitais e a alocação de recursos para o mesmo, têm muito mais reconhecimento por parte da população do que o investimento na APS (DIAS, 2010).

"Depende, o profissional lá na maternidade também não ajuda muito, muitas das vezes. Fala que não precisa vir a UBS, que o pré-natal lá é o suficiente”. (E2)

"Elas têm orientação, segundo elas, que o pré-natal é somente lá no alto risco e não precisa passar na unidade, então muitas acabam não vindo mais na UBS”. (E3)

"Uma das queixas que a gente tem, é que quem atende fala assim pra ela: 'Ó não precisa voltar pra unidade, só vem aqui'. "' (E7)

"Mas a grande maioria não faz aqui, a orientação pelos médicos do Cachoeirinha é fazer só lá, segundo elas né?" (E15) 
"Mas a gente tem algumas dificuldades, pois muitas vezes elas são orientadas no alto risco a não vir na atenção primária”. (E16)

"Segundo que, a própria Maternidade, isso óbvio são relatos de pacientes, a gente não sabe até onde tem veracidade, existe uma orientação de que 'Ó você não precisa ir lá no posto, você tá acompanhando aqui e teoricamente você não precisa ir lá no posto"’." (E17)

Além disso, existe a compreensão dos próprios profissionais da APS, de que seria um grande transtorno à gestante se deslocar para dois locais diferentes, no caso a UBS e a Maternidade Cachoeirinha, para uma mesma finalidade, a realização do pré-natal, outro fator, é a questão ética alegada, na qual, profissionais podem ter condutas diversas sobre uma uma determinada questão, ocasionando fatores estressantes, tanto para o profissional, quanto para a gestante.

"Também há conflitância de condutas, apesar do médico do alto risco ser mais capacitado, ser especialista na verdade pra atender a paciente gestante, as vezes tem alguns médicos que mexem em conduta de lá, eu na verdade não sou a favor de atendimento prá gestante, pode até se marcar o atendimento prá paciente, ver o que ela tá fazendo, ver o resultado dos exames, anotar tudo no prontuário mas fazer o atendimento né, dobrado com mais de um médico..." (E12)

"Que o paciente tá sendo conduzido por um profissional, onde tem uma orientação né, o que realmente né, a gente vai monitorar? A gente o médico, eu tô colocando aqui como um problema de discussão, ela vem aqui pra unidade, é outro profissional, são dois ginecologistas né, o que que ele faz? Se tiver uma conduta que ele ver como contrária? Ele vai interferir? Isso vai de alguma maneira trazer alguma dúvida prá paciente na conduta que tá sendo tomada de ambas as partes? Então assim é uma discussão né, o que que a gente quanto unidade, vai fazer prá essa paciente de alto risco”. (E17)

"Então, na verdade assim, não permanece por dois motivos. Uma porque a paciente teria que passar na verdade no alto risco prá não sei de quanto em quanto tempo, no alto risco na verdade é menor o período de consultas, e aí ela teria que passar aqui né, em consulta mensal com a gente até a 28, depois aí é quinzenal, e aí na verdade a paciente vai ficar na verdade muito atribulada, em termos de consulta. Então na realidade por isso, a gente decidiu na verdade não acompanhar a paciente dessa forma, mensalmente”. (E19)

Diante do exposto, torna-se imprescindível uma orientação, ainda que de maneira lenta, porém gradual, de orientação da população para o entendimento de que a porta de entrada do sistema de sáude deve ser a APS, deixando para os hospitais, os cuidados complexos e de urgência e emergência. O usuário e os profissionais devem estar vinculados e o acolhimento, assim como a escuta qualificada, devem fazer parte do processo de cuidar (MURRAY, 2000).

Atualmente, já está em pauta, a mudança na marcação dos agendamentos das unidades de ESF e tradicionais, no que concerne a intransigência das agendas dos 
profissionais e na flexibilização de acesso do paciente. Para enfrentar esse problema, algumas unidades fora do país e no Brasil, introduziram uma abordagem conhecida como cuidado avançado, acesso aberto ou consultas do dia. A agenda tem cerca de $65 \%$ a $75 \%$ para consultas no mesmo dia, há equilíbrio entre demanda e oferta de serviço, o tempo de espera é de um dia e sem a necessidade de reserva de vagas, diminuíndo o absenteísmo, viabilizando a longitudinalidade do cuidado e a diminuição da procura (WOLLMANN et al., 2014).

\subsubsection{O funcionamento do sistema de referência e contrarrefrência}

Com relação à segunda unidade temática intencional, o funcionamento do sistema de referência e contrarreferência, a partir dos discursos dos participantes, emergiram três subunidades temáticas empíricas, a saber:

- A visão do sistema de referência e contrarreferência;

- Desafios de comunicação entre os níveis de atenção;

- Importância da contrarreferência.

\subsubsection{A visão do sistema de referência e contrarreferência}

O município de São Paulo tem como referência para urgência e emergências (nível terciário), as unidades de pronto-atendimento e os hospitais, e para o nível secundário os ambulatórios de especialidades.

No que tange à Maternidade Escola Cachoeirinha, ela se insere nesses dois níveis de assistência; terciário, enquanto unidade hospitalar e secundário, enquanto unidade ambulatorial de especialidades.

No caso do pré-natal, quando em qualquer momento da gestação é identificado algo que a caracterize como alto risco, é preenchido o impresso de referência e contrarreferência (Anexo 2) e a paciente procura o setor administrativo da UBS, para a procura de vagas através do sistema SIGA, e o agendamento da consulta com especialistas do pré-natal de alto risco. No caso da Maternidade Escola Cachoeirinha, quando iniciado o atendimento, abre-se um prontuário para registro de todo o seguimento da paciente com a equipe multiprofissional. No primeiro atendimento, a folha de referência e contrarreferência, justificando o motivo do encaminhamento, é anexada em prontuário como forma de comprovar a efetuação da consulta e nesse momento, com o arquivamento 
dessa ficha, interrompe-se a oportunidade de uma contrarreferência. Perde-se, portanto, a oportunidade, de que informações pertinentes sobre a gestação e as condutas adotadas, sejam compartilhadas com a APS.

A outra forma das gestantes adentrarem no setor terciário, no caso na Maternidade Escola Cachoeirinha, são os encaminhamentos realizados pela UBS, após a detecção de situações críticas durante as consultas de rotina, como hipertensão, hipo ou hiperglicemia, sangramentos vaginais, dores intensas que não condizem com o início do trabalho de parto, entre tantas outras situações. Nesse caso, é solicitado uma ambulância que presta serviços para a Secretaria Municipal da Saúde e a gestante é removida tendo como porta de entrada o Pronto Socorro Obstétrico. É então, realizado o atendimento e não necessariamente a gestante permanecerá em acompanhamento com o alto-risco. Por vezes, a gestante é orientada a retornar e dar seguinmento na UBS e por vezes, a depender da gravidade, é dada alta com encaminhamento para agendar no ambulatório de alto de alto risco da Maternidade.

A última forma de contato direto com a Maternidade Escola Cachoeirinha é a procura espontânea da gestante no momento do início do trabalho de parto, situações de urgência e emergência que ocorrem fora da UBS, durante feriados e finais de semana e no período noturno.

“ O sistema de referência e contrarrefrência funciona para ajudar o paciente, né? Se tiver pressão alta, diabetes, e agora esses casos que estão vindo pra mim que nunca tinha aparecido, lúpus, epilepsia, asma eu faço o encaminhamento, se for urgente já chamo a ambulância, né?" (E2)

“ A porta de entrada é aqui, na UBS né... então a gestante sempre começa aqui. Depois que a gente atende, na verdade depois que o médico atende, se for alto risco ele encaminha porque aqui a gente não consegue cuidar. Lá eles fazem tudo e assim o sistema funciona. Por aqui que entra. " (E9)

"A gente sempre sabe prá onde mandar. Aqui é Cachoeirinha, eles informam a gente da nossa referência. Antes era o Mandaqui. Então pelo menos isso não tem como mandar errado. A gerente passa o informe" (E15)

O sistema de referência e contrarreferência funciona como um instrumento para o funcionamento do SUS. Contudo, sem uma rede de serviços organizada, que compartilhe dos mesmos interesses, e que dialogue, esse importante instrumento não funciona. Notase que os serviços acabam funcionando de forma fracionada, onde cada serviço cuida do seu próprio interesse, não ocorrendo comunicação entre os diferentes níveis (DIAS, 2010). 
A pesquisa por mecanismos facilitadores para o estabelecimento de processos de referência e contrarreferência pode ser analisada como fundamental para a realização do princípio da integralidade. Dessa forma, deve-se assegurar e fornecer nos serviços, protocolos de referência e contrarreferência, com o intuito de assegurar a assistência e o acompanhamento da paciente, entre os serviços próprios e conveniados, com predileção para os mais próximos da sua residência (FRATINI et al., 2007; BRASIL, 2008).

\subsubsection{Desafios de Comunicação entre os Níveis de Atenção}

É fundamental a oferta estruturada de assistência preventiva, curativa e de reabilitação, assegurando o funcionamento da referência e contrarreferência em uma rede articulada entre os três níveis de atenção à saúde, com fluxos e percursos demarcados e estruturados espacialmente de forma que concilie com a necessidade da população de um território adscrito em suas peculiaridades (atenção às urgências, atenção à saúde maternoinfantil e atenção à saúde do homem) designando-se para essas ações o nome de Regulação (GIOVANELLA et al., 2002).

Com isso, a regulação é caracterizada como um conjunto de ações e ferramentas para estruturar a oferta, conforme a necessidade da população elencando competências, fluxos e responsabilidades, com a intenção de facilitar o acesso com qualidade e resolubilidade em todos os níveis de atenção à saúde (BARBOSA et al., 2015).

A extensão da ação regulatória na área da saúde pública, demonstra-se no grupo de ações mediatas, que se correlacionam entre a demanda dos usuários e sua possibilidade de acesso aos serviços de saúde. Com essa denominação do termo regulação, junta-se aptidões de condução política, análise da situação, planejamento e comunicação, na estruturação e gestão dos fluxos de acesso, do desempenho dos sistemas e da qualidade da assistência (BRASIL, 2006).

O conceito de integração envolve coordenação e contribuição entre mantenedores dos serviços assistenciais, para a elaboração de um sistema de saúde, no qual o usuário pode ser atendido em diversos níveis de atenção, sem que tenha que contar a cada atendimento realizado, a sua história. Os profissionais dos diferentes níveis de atenção deveriam interagir e se comunicar para a condução de condutas terapêuticas que visem o bem-estar do paciente. Porém, são poucas as inicitaivas de comunicação existentes, dificultando demasiadamente o seguimento terapêutico e permitindo riscos à saúde do usuário (LEATT et al., 2000). 
Pesquisas demostram, que os profissionais de saúde possuem dificuldades em se comunicar para propiciar o trabalho em equipe e multidisciplinar, propiciando e garantindo a segurança do paciente (NOGUEIRA; RODRIGUES, 2015).

As lacunas de comunicação entre membros de uma equipe e entre diversos níveis de atenção à saúde, têm sido um dos principais fatores que colaboram para aumentar as estatísticas quanto a erros médicos, eventos adversos e, aumento da insatisfação por parte dos usuários do cuidado ofertado. A partir dos fatores elencados e como forma para correção dos mesmos, diversas instituições têm elaborado protocolos de comunicação, fundamentados em reuniões de equipe, essenciais para diminuir lacunas na comunicação entre os profissionais (SANTOS et al., 2015).

Diante dos fatos apontados, convém o empenho árduo das organizações de saúde e seus gestores, em propiciar estratégias de comunicação entre os diversos níveis de atenção, para entender e diminuir dificuldades enfrentadas pelas equipes na assistência direta, com a intenção de emergir canais efetivos de comunicação. Dessa forma, quando surge uma cultura institucional de diálogo, as necessidades e os erros são mais amplamente divulgados pelos profissionais e a instituição consegue ingerir nos processos de trabalho e na capacitação permanente, fornecendo uma estrutura que conceda uma integração entre diversos profissionais e setores e como consequência uma assistência mais segura (PAESE; DAL SASSO, 2013).

Durante a elaboracão do presente trabalho, observou-se que tanto os processos regulatórios, como o de comunicação entre os profissionais da atenção primária e terciária, encontram-se desconectados da teoria.

Como exemplo, constata-se a dificuldade de comunicação existente entre os profissionais da UBS e os profissionais da Maternidade, seja por e-mail, telefone, formulários, reuniões de equipe, entre outros, dificultando o esclarecimento de dúvidas e integralidade do cuidado.

"Acho que é inelegível às vezes, porque vem carbonado então a gente fica um pouco sem entender, acho que só isso. Os dados básicos a gente consegue ter”. (E5)

"A gente não tem o contato deles lá, sabe, de quem faz o pré-natal de alto risco, não tem prá quem ligar para tirar dúvida da paciente, entendeu? Então a gente, assim, a gente se perde nas coisas" (E11)

"Minha gestante que faz alto risco também disse que tem o whats da médica. Você acredita nisso? Não tenho como saber como a gestante está, aqui é tudo no papel, falta comunicação e o papel, nossa, às vezes, é dado na mão delas, mas elas perdem, rasgam, sei lá, não volta, coisa de doido, viu! ” (E22) 
"Podia né ter reunião entre a gente, assim a gente se conversava e se resolvia. Tipo um matriciamento sabe, onde a gente se conversa e a gente se entende e se explica. As pacientes ganham e nós também. ”(E15)

"Porque às vezes a gente não tem essa informação e o paciente também não tem, porque por exemplo os exames que eu faço aqui, que a gente faz aqui a gente anota, mas da pro paciente, e isso não acontece na Maternidade, fica com a Maternidade, então a gente não tem esse, fica um hiato né, fica uma abertura. Então eu não sei né, principalmente sorologia que a gente faz três vezes, duas vezes né, não tem essa informação às vezes, então a gente perde a sequência mesmo né, do acompanhamento. ” (E7)

"Os exames que as pacientes fazem lá a gente não consegue ver por aqui, e a Maternidade não lança no SIGA, nada, nenhum dado. Tem espaço para eles fazerem isso e ai entendeu? A gente pegava o resultado do exame delas" (E2)

"Há dificuldade prá gestante de alto risco de qualquer coisa que você precise, até mesmo os exames, que elas fizeram a gente não consegue pegar porque eles não dão, as consultas prá ver quais são os parâmetros prá poder colocar no pré-natal, eles também não dão, então a dificuldade é muito grande, não tem essa referência $e$ contrarreferência". (E4)

Outro fator importante é o agendamento dos RNs, que nas UBSs acontece na chamada reserva técnica, ou seja, através do sistema SIGA a Maternidade agenda as consultas de puericultura e puerpério nas UBSs de origem. Contudo, as vagas abertas não são identificadas por área de cadastramento e o agendamento ocorre na primeira vaga disponível. Com isso, muitas vezes, a puérpera e o RN são agendados com uma equipe com a qual não há vínculo e o pré-natal não foi acompanhado. Quando possível, a consulta é desmarcada e remarcada com a equipe de referência, quando não, mãe e criança passam em consulta para o fechamento do puerpério e uma nova consulta é agendada para seguimento.

Tal fato não precisaria ocorrer, se a Maternidade ao invés do sistema SIGA utilizasse o telefone para o agendamento das consultas, permitindo que as cadastradas passassem com sua equipe de referência, ou fosse adicionado ao SIGA a identificação das vagas às equipes das unidades. É importante ressaltar que por ser o sistema SIGA uma plataforma municipal, somente as unidades da prefeitura têm acesso. Quando são hospitais estaduais, filantrópicos ou privados as puérperas são orientadas a procurar a UBS de origem para marcação de consulta de puerpério. A falta de um sistema integrado de agendamento, funciona como mais um entrave na referência e contrarreferência do usuário dentro do sistema e como uma deficiência ao funcionamento do processo regulatório. 
"Quando ela sai de alta, o agente comunitário realiza a visita, na realidade ela já sai até com consulta do hospital, dependendo se é o Cachoeirinha, se é um hospital municipal, se é um hospital estadual não consegue sair com consulta de lá pra cá”.(E1)

"Mas já sai da maternidade com a consulta marcada com o médico da unidade, não especificamente o médico da equipe. Isso dificulta muito prá gente, porque até conseguir se organizar, ir até a casa da gestante, da puérpera, ela já veio aqui. Aí muita das vezes, quando tem a complicação da reserva técnica, que aí já é outro problema que a gente tem, mas que não vem ao caso agora. Mas dificulta muito nosso processo de contato, de atuação com esse binômio, bebê e puérpera, porque sai de casa, aí a gente já não consegue fazer as orientações domiciliares que é a nossa proposta". (E2)

"Eles geralmente, a Maternidade agenda com o médico que tá disponível, não com o médico de referência da unidade, deveriam perguntar qual que é o médico que acompanhou o pré-natal pra agendar com esse médico, aí a gente acaba até modificando as consultas, vai fazer o puerpério na casa a gente vê com qual medico foi agendado, cancela, e agenda com o médico de referência na unidade”. (E6)

"Atualmente elas são agendadas pela Maternidade, só que tem algumas gestantes ainda que tem algumas maternidades que não agendam essa consulta, da Maternidade Cachoeirinha a gente não tem problema nenhum, todas as gestantes são marcadas lá no dia da alta. Agora outras maternidades, algumas vezes não tem marcação, aí a gente tem que sair correndo atrás pra captar". (E19)

Em junho de 2017, o Ministério da Saúde anunciou chamada pública para a informatização da APS de todo o país. A informatização das UBS é uma das principais ações do DIGISUS, um projeto que deve digitalizar todas as informações dos usuários do SUS, favorecendo o acesso aos dados do cidadão em qualquer unidade de saúde do Brasil. A nova estratégia trará vantagens na qualidade da assistência para todos os usuários que utilizam a APS, uma vez que permite, em curto prazo, acessar todos os dados de pacientes do SUS por uma única plataforma, por meio da biometria do usuário, evitando assim, a repetição de exames e encaminhamentos desnecessários para a atenção especializada, propiciando a resolutividade no âmbito da APS. Parte do projeto, será financiado pelo Ministério da Saúde e parte deverá contar com o subsídio das prefeituras (BRASIL, 2017).

Atualmente, o Brasil possui 42.488 UBSs em funcionamento. Desde total, 15.158 (35,7\%) das UBSs enviam dados por meio do prontuário eletrônico, dessas, 6.373 (42\%) utilizam o e-SUS AB, prontuário fornecido gratuitamente pelo MS. Hoje, 27.330 (64,3\%) das UBSs não utilizam prontuário eletrônico. Com a plataforma digital, todos os serviços de saúde da cidade poderão acompanhar o histórico, os dados e resultados de exames dos 
pacientes, verificar em tempo real a disponibilidade de medicamentos, ou mesmo registrar as visitas dos ACSs, melhorando o atendimento ao cidadão (BRASIL, 2017).

Apesar da iniciativa extremamente positiva, existem alguns entraves a serem vencidos: como os municípios devem custear parte da implantação do sistema, tal medida dificilmente acontecerá em um tempo curto, visto o grande número de municípios enfrentando grave crise financeira. Um outro fator, é a provisão de recursos tecnológicos, como cabeamento de internet, computadores e impressoras em comunidades carentes e a forma para evitar o furto rotineiro desses equipamentos, impedindo a continuidade da assistência. Além disso, poderá ocorrer demora na digitalização dos prontuários físicos existentes, e finalmente, se a integração não ocorrer com todos os hospitais do país, o nível terciário ficará impossibilitado de obter informações e fornecê-las inviabilizando a integralidade da assistência.

\subsubsection{Importância da Contrarreferência}

Considera-se contrarreferência o encaminhamento do usuário ao estabelecimento de origem (unidade que referiu), após a resolução do problema que motivou a referência (BRASIL, 1987).

Com relação a esta subunidade temática intencional, pode-se colocar que a contrarreferência é muito importante para a continuidade da assistência e do tratamento quando puérpera e recém-nascido retornam para a unidade, seja ela, ESF ou tradicional, pois os profissionais da APS saberão o que ocorreu durante o atendimento na atenção terciária, as possíveis intercorrências e as orientações para o prosseguimento do acompanhamento. No entanto, percebe-se com as falas que o relatório de puerpério encaminhado para a APS é suficiente quando a gestação é de risco habitual, porém, é insuficiente se ocorrer qualquer tipo de intercorrência que fuja do extritamente do normal.

"Eles escrevem o básico né, então assim se gestante não tem nenhuma intercorrência, ótimo, agora se tem alguma intercorrência, eu acho que é muito pouquinho né, poderia vir mais explicado. " (E8)

"Porque eu acho que as que não tem nenhuma complicação, que tem um parto sem nenhuma intercorrência, nessas a gente consegue dar continuidade, a não ser que aconteça alguma coisa, sei lá um sangramento, aí sim. Mas nessas de alto risco eu acho que seria interessante, sei lá um guia, alguma coisa pra gente poder dar continuidade ao tratamento, entendeu?" (E9) 
"Os dados necessários que a gente precisa existe, mas a gente tem dificuldade por exemplo, de sífilis, né, quando existe o tratamento de sífilis, a caracterização, se é sífilis congênita ou não, se deu andamento, se ele já tá no ambulatório de vocês de acompanhamento, isso falta prá gente. Que aí dificulta a gente dar continuidade aqui, né. Se já foi aplicado certinho a penicilina, então, por exemplo, um parto fórceps que deslocou o ombro, também muita das vezes a gente não sabe o que que aconteceu depois do parto, quais que foram as condutas. Se vai voltar em retorno lá ou se é com a gente, então essas coisas de feedback de especialidade, prá gente é complicado, porque a gente acaba fazendo os dois trabalhos, ou a gente acha que a maternidade fez e não fez e não deu assistência, entendeu? " (E2)

"Bom, às vezes só pela caderneta da gestante né, porque às vezes preenchem, os que fizeram acompanhamento lá no hospital, as vezes não preenchem. Não tenho nenhum relatório tenho que perguntar prá paciente 'aconteceu alguma coisa? Teve alguma intercorrência durante o parto? Teve sangramento? Não teve sangramento? ' Às vezes a paciente esquece também de perguntar, de falar "não doutor, estou tomando sulfato ferroso" já quase por exemplo no final da consulta, "'ah não doutor, estou tomando sulfato ferroso porque teve sangramento, durante o parto" então, onde encontro os dados, não tenho né”. (E20)

"Tem o relatório de alta do momento do parto, da hora que chegou na unidade, do momento do parto, dados do neonato e tudo mais. Mas relatórios do alto risco não, o que ela teve antes do parto não. Eu acho que essa parte do resumo do pré-natal de alto risco seria importante prá gente prá fazer o acompanhamento”. (E23)

O relatório da Conferência Internacional sobre cuidados primários de saúde reforça que o encaminhamento é um método que deve se desenvolver em dois sentidos e que a retenção do usuário numa instituição de maior tecnologia deve ser o mais rápido possível. Assim que seu estado de saúde melhore ou sua condição se torne favorável para deixar a atenção secundária ou terciária, o usuário deve retornar para a APS, com informações claras sobre as constatações clínicas e o tratamento aplicado, assim como a atenção adicional solicitada (OMS, 1978).

Assim como o presente trabalho, que constatou falhas na realização da contrarreferência, diversos trabalhos têm abordado o mesmo tema; um trabalho desenvolvido em 2013, na cidade de Botucatu, no interior de São Paulo, constatou problemas semelhantes com a contrarreferência, demonstrando que tal acontecimento não está restrito à uma determinada região (MENOZZI, 2013).

Vale ressaltar, que a questão da dificuldade na realização da contrarreferência é uma questão antiga, que antecede a implantação do SUS, permanecendo até a atualidade. Dessa forma, cabe a conscientização dos serviços especializados sobre a importância da contrarreferência, não somente para as equipes engendradas nos diversos níveis de atenção, mas também ao usuário, como forma de orientá-lo de seus direitos e deveres, 
para que ele possa requerer com os profissionais envolvidos no seu atendimento, em realizar uma ação tão importante para a manutenção dos princípios do SUS: a contrarreferência.

\subsubsection{Fatores Estruturais das Unidades Básicas de Saúde}

Com relação a terceira unidade temática intencional, fatores estruturais das Unidades Básicas de Saúde, a partir dos discursos dos participantes, emergiu uma subunidade temática empírica, a saber:

\subsubsection{Organização dos Serviços}

As unidades de saúde no município de São Paulo estão sendo administradas majoritariamente por OSSs. Das 451 UBS existentes, 205 são administradas por OSS, 176 pelo setor público e 70 são mistas. A cada dia, mais unidades de saúde são entregues para a administração indireta e com isso, um maior número de funcionários públicos é realocado em outros setores (PREFEITURA MUNICIPAL DE SÃO PAULO, 2017).

Dentro do município de São Paulo de acordo com a região geográfica, ocorre o predomínio de uma OSS. Na região Sul, por exemplo, a maior parte das UBSs é gerida pelo Hospital Israelita Albert Einstein e Sírio Libanês, na região Leste, Hospital Santa Marcelina, na região Norte, Associação Saúde da Família, IABAS, entre tantas outras. Dessa forma, as OSS, admistram as UBS atribuindo-lhes características peculiares, por vezes, descaracterizando-as.

Ambas unidades do presente estudo, são administradas pela OSS Associação Saúde da Família, sendo a UBS Dra. Ilza Hutzler uma unidade de ESF e a UBS Vila Dionísia uma unidade mista, ou seja, parte ESF e parte tradicional. Contudo, ao realizar um comparativo de ambas as unidades, no que cabe à assistência na lógica da ESF, no quesito da assistência ao pré-natal, nota-se fluxos internos distintos. Na UBS Dra. Ilza Hutzler, não há o intercalamento das consultas de pré-natal, entre médicos e enfermeiros, no sendo a paciente atendida ao mesmo tempo pelos dois profissionais, ou então, somente pelo médico. Com isso, ocorre uma ocupação dupla da agenda de dois profissionais, que poderiam ampliar o seu atendimento. Abaixo, seguem algumas falas que apontam o descrito: 
"É um modelo um pouco diferente a minha, a abertura eu faço sempre sozinha, só que a minha médica optou por atender a gestante junto comigo, então a gente atende, claro tá na agenda dela e tá na minha e a gente vai atendendo junto, uma vai registrando a outra vai examinando, depende com quem ela tá agendada”. (E5)

“Assim a minha equipe atende junto médico e enfermeiro, mas sempre tem um médico". (E6)

"A gente costuma atender junto, na maioria das vezes, mas tem vezes que eu atendo sozinho, aqui também vem aluno da graduação da Uninove também, então a gente acaba atendendo junto". (E11)

"O acompanhamento acaba sendo semanal né, e atende eu e minha Enfermeira, hoje foi dia inclusive”. (E10)

"A primeira consulta é sempre com a enfermeira, depois elas passam comigo. Já falaram assim ai, faz uma com a enfermeira, uma com a médica. Eu sempre peço prá voltar comigo, a não ser que eu não esteja, como no caso quando eu tava de férias, que aí passou com a enfermeira. Mas geralmente elas sempre voltam comigo, só na primeira consulta mesmo, por causa daquela papelada que tem que preencher, do prontuário delas, aí primeiro é com a enfermeira". (E9)

Na UBS Dra. Ilza as planilhas de dados sobre os motivos dos encaminhamentos das gestantes de alto risco, são elaboradas por cada equipe, não possuindo um consolidado geral da unidade. Na UBS Vila Dionísia, há a realização de planilhas da área da ESF com nome, idade e motivo do encaminhamento para o alto-risco e que são consolidadas para uma melhor visualização do território, contudo, a parte tradicional da unidade, não dispõe de tais dados, sendo a área com o maior número de gestantes e por não possuir o acompanhamento do ACS, aumenta ainda mais a dificuldade de acompanhamento dessas gestantes.

Além disso, membros de uma mesma equipe quando questionados sobre a elaboração e controle de planilhas de encaminhamentos das gestantes de alto risco, possuíam respostas divergentes, demostrando uma falta de integração entre os mesmos, dificultando a construção e discussão de dados para nortear projetos terapêuticos singulares.

"Olha, eu tenho uma lista de gestantes, mas só da minha área tá. Mas elas vão tendo o bebê e a gente vai tirando, né. Mas no momento que ela tá no alto risco eu sei quantas eu tenho". (E3)

"Sim. A minha equipe a gente tem, as outras eu não sei como faz. Tem esse controle e eu só tenho uma gestante de alto risco". (E5)

“Não. Sei da minha equipe mais ou menos quantas foram, mas no geral não”. (E10)

"Da minha área sim”. (E16) 
"Sim. O setor da regulação quando ele manda, ele planilha teoricamente essas gestantes que vão pro alto risco, então quando a gente precisa, ou mesmo a equipe de mãe paulistana, ela consegue ter uma margem de quem é esse alto risco ou não, a gente identifica geralmente, né? Mas só da ESF, da tradicional não, são muitas"..(E17)

"Não, não tenho. Não tenhos esses dados. Talvez a enfermeira tenha. Você pode tentar falar com ela. ” (E20)

"Estatístico da minha equipe? Não tenho isso anotado, sabe, mas não são tantas né, da minha área não são tantas”. (E22)

\subsection{FLUXOGRAMA E INSTRUMENTO DE REFERÊNCIA E CONTRARREFERÊNCIA}

Indo ao encontro da proposta do Mestrado Profissional, que é o desenvolvimento de um produto a ser utilizado no âmbito do trabalho no qual o pesquisador está inserido, e considerando os resultados obtidos na presente pesquisa, surgiu a ideia da construção de um fluxograma e de um formulário com as principais informações referentes ao prénatal de alto risco, como exames laboratoriais, de imagem, medicamentos utilizados, descrição de consultas com especialistas e condutas terapêuticas adotadas, além de um espaço próprio para descrever o motivo e condutas estabelecidas durante internações ocorridas no período da gestação.

Caso, nehuma nova rotina tenha sido estabelecida de um mês para o outro, bastará o envio do formulário descrevendo que não houve alterações nos dados citados, sem que haja a necessidade do profissional copiar novamente as informações já enviadas.

Para identificação da UBS a qual a gestante pertence, será necessário a solicitação durante a primeira consulta no pré-natal de alto risco, do cartão de identificação da UBS, no qual consta o nome da unidade e o número de prontuário.

O preenchimento do impresso poderá ser realizado pelo médico responsável pelo pré-natal, ou por outro profissional designado pela chefia do ambulatório e ocorrerá de forma mensal, com o posterior envio via mala direta para a UBS de origem da gestante. Dessa forma, a responsabilidade pelo repasse das informações sobre o seu estado de saúde, não recairá sobre a gestante, que por diversos motivos como extravio ou rasura, poderia não entregar o formulário na UBS.

O correto preenchimento e encaminhamento do formulário, propiciará o acompanhamento das condições do pré-natal de alto risco pela atenção primária e como consequência, uma maior integração entre os níveis de atenção à saúde. Como exemplo, 
dentre muitas situações possíveis, poderá ocorrer o envio do formulário informando a ausência da gestante em consulta de pré-natal na Maternidade Cachoeirinha, motivando uma busca ativa da UBS, para saber o motivo da falta e sua posterior informação para o alto-risco, que poderá remarcar a consulta, fazendo com que a vaga não seja perdida.

Esse formulário, poderá ser o início de uma abertura para discussões clínicas e interação entre os diveros profissionais envolvidos durante o pré-natal, propiciando que os princípios do SUS, sejam verdadeiramente aplicados. Por não ser um formulário estático, poderá sofrer alterações em seu conteúdo e forma de preenchimento, à medida que novas ideias surjam a partir dos profissionais envolvidos. A integração entre a UBS e a Maternidade é fundamental para a integralidade e continuidade da assistência e poderá servir de modelo para que outros hospitais iniciem o trabalho conjunto em prol da saúde da gestante e seu RN, minimizando riscos de abandono e agravos à saúde. 
FLUXOGRAMA PARA INTEGRAÇÃO ENTRE MATERNIDADE E UBS

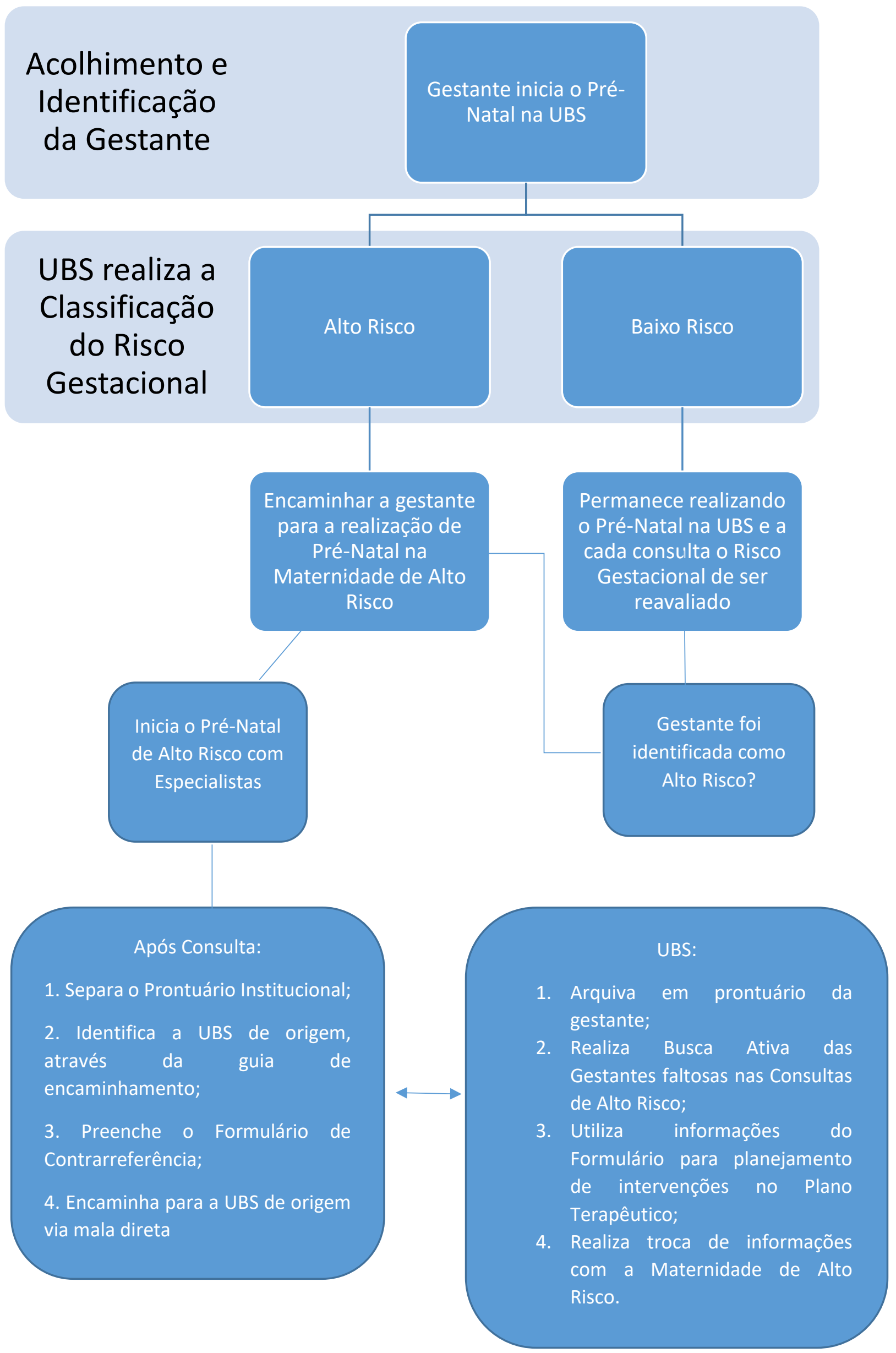




\section{Sugestão de Formulário de Contrarreferência de Maternidades que}

\section{Atendem Gestantes de Alto Risco, à Atenção Primária à Saúde}

Prontuário $\mathrm{n}^{\mathrm{o}}$ :

UBS:

Matrícula na UBS:

Nome:

DN:

Data da Consulta: Médico Responsável:

Realizou exames? ( ) Sim ( ) Não Data da coleta:

\begin{tabular}{|l|l|l|l|l|l|}
\hline EXAMES & RESULTADOS & EXAMES & RESULTADOS & EXAMES & RESULTADOS \\
\hline $\mathrm{Hb}$ & & Bilirrubina T: & & TPPA & \\
\hline $\mathrm{Ht}$ & & Bilirubina D: & & TS & \\
\hline Leucócitos & & Bilirrubina I: & & TC & \\
\hline Plaquetas & & HIV & & ABO & \\
\hline Sódio & & AgHbs & & Rh & \\
\hline Potássio & & Anti- Hbs & & Glicemia & \\
\hline Amilase & Anti-Hbc total & & $\begin{array}{l}\text { Hemoglobina } \\
\text { glicada }\end{array}$ & \\
\hline Uréia & & Hep C & & Urina I & \\
\hline Creatinina & & PCR & & Urocultura & \\
\hline TSH & & VHS & & PPF & \\
\hline T4 & & TP & & & \\
\hline
\end{tabular}

Realizou USG desde a última consulta? ( ) Sim ( ) Não TVG ( ) Obst ( ) Obst c/ doppler ( ) PBF ( )

Resultado:

BCF: ILA: Peso Fetal Estimado:

Ocorreram alterações na prescrição das medicações com relação as consultas anteriores? ( ) Sim ( ) Não Quais? Por qual motivo? 
Medicações prescritas:

\begin{tabular}{|c|c|c|c|c|}
\hline Medicamento & Dose & Via & Horário & Tempo \\
\hline & & & & \\
\hline & & & & \\
\hline & & & & \\
\hline & & & & \\
\hline & & & & \\
\hline
\end{tabular}

Obs: se as medicações prescritas permanecerem as mesmas desde a última consulta, não há a necessidade de preenchimento.

Paciente teve alguma intercorrência no período entre consultas?

( ) $\operatorname{Sim}($ ) Não

Passou em consulta com especialista?

( ) Sim Qual: ( ) Não

Precisou internar? Sim ( ) Não( ) Período de internção: à

Relato:

Responsável pelo Preenchimento 


\section{CONCLUSÕES}




\section{CONCLUSÕES}

Observando os achados do estudo em pauta, à luz do quadro teórico adotado, entende-se que o objetivo geral foi respondido, na medida em que limites e potencialidades do sistema de referência e contrarreferência no acompanhamento de gestantes de alto risco encaminhadas para a Maternidade Cachoeirinha foram analisados.

A partir do recorte viabilizado pelas unidades temáticas intencionais, emergiram através dos discursos dos participantes, subunidades temáticas empíricas, que possibilitaram uma maior aproximação com o objeto e uma maior compreensão sobre o mesmo.

Os resultados das entrevistas e os dados levantados sobre o ciclo gravídicopuerperal, refletem lacunas no processo de contrarreferência. Após a detecção de risco gestacional durante a consulta de pré-natal na Atenção Primária à Saúde, as gestantes são referenciadas para o alto-risco, no caso a Maternidade Cachoeirina. Contudo, após o início do pré-natal de alto risco, as gestantes, em sua maioria, acabam se desvinculando da UBS e a Maternidade Escola Cachoeirinha acaba não enviando dados que poderiam permitir esse acompanhamento.

Os princípios da hierarquização e integralidade encontram-se fragilizados, desenhados de forma empírica e em níveis dependentes de definições territoriais e, como consequência, deve-se avaliar melhor as necessidades de saúde da população, e a partir de então, a oferta e a demanda, justificando a política de referência e contrarreferência. Tal fato foi observado nas unidades de saúde tradicionais, que sem contarem com a presença do ACS e de uma equipe que pudesse favorecer a formação do vínculo, vivenciaram a dificuldade de acompanhamento e de intervenção oportuna nos agravos que podem ocorrer durante a gestação.

Os mecanismos de referência e contrarreferência existentes na rede hierarquizada, não se mostraram suficientes para garantir a fluidez aos processos de assistência e gerência. Esses processos funcionam se houver integração, compromisso e interesse entre gestores de ambos os níveis de assistência. A introdução das OSS, principalmente na APS, não deve ser garantia de "lucro" aos cofres públicos e sim garantia de que os princípios do SUS sejam aplicados no atendimento da população.

O grau de incorporação tecnológica é um outro fator que deve ser considerado, para garantir a integralidade do sistema em uma rede hierarquizada e deve ser utilizado 
com responsabilidade para que o setor terciário não se isole dentro de sua capacidade resolutiva e continue se integrando aos demais níveis de assistência, respeitando a hierarquização. É importante ressaltar que a capacitação nos cursos de graduação em saúde, para o trabalho no SUS em todos os níveis da assistência é fundamental para que modelos hospitalocêntricos e médico centrados não se perpetuem.

Os protocolos assistenciais de pré-natal, parto e puerpério estão consolidados e devem ser desenvolvidos pela rede e executados por parceiros, como OSS e funcionários públicos. A absorção e execução plena desses protocolos, depende não somente do grupo de profissionais, mas, de todo um contexto social, sendo, portanto, fundamental um espaço periódico de discussões para alterações que beneficiem a todos, usuários e profissionais.

Com a organização dos Distritos de Saúde, há a necessidade de desenvolver um sistema de documentação e registro assistencial, viabilizando a troca de informações através do uso de tecnologias como prontuário eletrônico, permitindo o acesso ao histórico de saúde do paciente em qualquer nível de atenção, auxiliando na tomada de decisões e diminuindo custos com condutas repetitivas.

A qualidade de atenção, sobretudo, na atenção primária à saúde, emerge sinalizando a necessidade de investimento em recursos humanos que deve ocorrer de forma integrada, tanto para a administração direta, quanto para as OSS, visto que o resultado final será o atendimento de uma mesma população.

A Maternidade Cachoeirinha é um hospital escola de atenção terciária e referência para toda a região Norte da cidade de São Paulo. Diariamente, novos estudos e técnicas são introduzidos no campo multiprofissional, como forma de prestar assistência de qualidade na área de saúde da mulher e da criança. Possui um excelente reconhecimento por parte dos usuários e comumente é indicado, por profissionais da APS, para que pacientes, mesmo não o tendo como referência, o procurem para resolução dos seus problemas. Além disso, consegue ser referência para uma ampla rede de UBSs e absorver pacientes de outras instituições hospitalares, que enfrentam problemas com a contratação de recursos humanos, sem que isso prejudique a assistência, mesmo com o aumento da demanda.

Outra questão a ser considerada, é o déficit de recursos humanos, na Maternidade Escola Cachoeirinha, o que tem dificultado a realização de ações como: a alimentação de dados do sistema SIGA, com resultados de exames; ligações para marcações de consultas diretamente na UBS; busca ativa de gestantes faltosas no pré-natal de alto-risco, entre 
outras. Os funcionários existentes, são colocados para a assistência direta, relegando a segundo plano as funções administrativas que também são fundamentais para a qualidade do cuidado.

Como sugestão para permitir uma melhor avaliação epidemiológica da população atendida e melhorar a qualidade da assistência, sugere-se a introdução de três novos indicadores ambulatoriais: o registro do motivo do encaminhamento ao alto risco e a unidade que realizou o encaminhamento, a fim de se verificar se o sistema de referência está sendo devidamente respeitado, caso contrário, haveria a necessidade de novas pactuações, e o cruzamento de dados entre a data em que a gestante foi referenciada para a consulta de alto risco e a data em que a consulta efetivamente ocorreu. Esse último indicador, visa identificar, se a gestante teve acesso em tempo hábil à avaliação do alto risco.

Outra sugestão seria a de mudar o sistema de marcação de consultas das puérperas e RNs, considerando a equipe na qual a mesma está cadastrada na APS, e não apenas realizando uma reserva técnica, para mostrar ao sistema que a consulta foi agendada. Futuramente, poderiam ser implementadas alterações no sistema SIGA, que permitissem a marcação da consulta identificando a equipe da ESF à qual a paciente está vinculada.

Com relação às UBSs, a ampliação da ESF, a normatização do atendimento e a adesão aos protocolos do município, favoreceriam a qualidade da assistência prestada, ampliando a capacidade de atendimento. As diversas organizações sociais deveriam convergir para um único modelo assistencial. As UBSs que compuseram o presente estudo, deveriam promover a elaboração de indicadores sobre o motivo do encaminhamento ao alto risco e deveriam checar se houve comparecimento às consultas programadas na Maternidade Escola Cachoeirinha. Dessa forma, para o primeiro indicador, poderia-se visualizar o perfil epidemiológico dessa população, elaborando estratégias de intervenção de promoção e prevenção à saúde e para o segundo indicador, acompanhar a assiduidade das gestantes às consultas e realizar a busca ativa quando necessário, comunicando à Maternidade Escola Cachoeirinha o motivo da falta, promovendo a integralidade entre os níveis de atenção.

Essas sugestões poderão colaborar para a troca de informações entre os diversos níveis de atenção, além de aprimorar o preenchimento de formulários solicitados pelo Comitê de Mortalidade Materno-Infantil, propiciando um trabalho em equipe e uma alimentação de dados mais precisa. 
7 CONSIDERAÇÕES FINAIS 


\section{CONSIDERAÇÕES FINAIS}

Observa-se que o sistema de referência é executado na maioria das vezes a contento, permitindo que as gestantes classificadas como de alto risco sejam atendidas pelo nível terciário.

No que se refere ao sistema de contrarreferência, este é precário, sendo encaminhadas poucas informações para a APS, sobre as gestantes que passaram pelo atendimento de alto risco, dificultando a assistência que será prestada para essas mulheres e seus filhos na UBS.

Percebe-se a necessidade de uma formação pedagógica, para graduandos e profissionais da área da saúde, sobre a importância da referência e contrarreferência no SUS.

Sem a contrarreferência é provável que exista perda na qualidade dos serviços ofertados, havendo prejuízo para a integralidade da assistência. Contudo, apesar do funcionamento fragmentado dos serviços de saúde no que se refere a referência e contrarreferência, verificou-se através dos depoimentos dos entrevistados, o desejo de melhorar a comunicação e a interação entre os serviços.

Espera-se que em um futuro próximo, as unidades tradicionais de saúde cedam lugar para as ESFs, que devido à sua estruturação, conseguem realizar um acompanhamento mais próximo das demandas e necessidades de saúde individuais e da comunidade, podendo contribuir para a melhora dos indicadores de saúde da população.

Outra expectativa importante, é a de que o sistema de informação em saúde seja distribuído de forma equânime para todo o município, integrando todas as unidades de saúde, contribuindo para a integração e troca de informações entre os profissionais, permitindo também, que o paciente se sinta acompanhado de forma integral, sem a necessidade de recontar sua história de saúde a cada atendimento.

Este estudo sugere que o atual modelo de referência e contrarreferência necessita de uma profunda reflexão e de definição (ou redefinição) de seu papel no SUS. Esperase que o formulário aqui sugerido, que permite a integração das informações, seja um instrumento que possa qualificar a assistência às gestantes de alto risco.

As razões pelas quais ocorre a desvinculação da APS, por parte das gestantes, não foram investigadas nesse estudo, contudo podem ser objeto para futuras discussões sobre a temática em pauta. 
Espera-se que os resultados desse trabalho possam ser divulgados junto aos gestores locais e dessa forma venham a contribuir para a efetivação de uma política pública municipal de referência e contrarreferência que vislumbre a integralidade da assistência. 


\section{REFERÊNCIAS}

AESE, Fernanda; SASSO, Grace Teresinha Marcon Dal. Cultura da segurança do paciente na atenção primária à saúde. Texto \& Contexto Enfermagem, Florianópolis, v. 22, n. 2, p. 302-310, jun. 2013.

ALMEIDA C, Macinko J. Validação de uma metodologia de avaliação rápida das características organizacionais e do desempenho dos serviços de atenção básica do Sistema Único de Saúde (SUS) em nível local. Série técnica desenvolvimento de sistemas e serviços de saúde v.10, p.215, 2006.

ALMEIDA, C. M. As reformas sanitárias nos anos 80: crise ou transição? 1995. Tese (Doutorado). Escola Nacional de Saúde Pública Fundação Oswaldo Cruz, Rio de Janeiro, 1995.

ALMEIDA, E. S. A. et al. Distritos Sanitários: Concepção e Organização. São Paulo: Editora Fundação Peirópolis, 1998.

ANDRADE, L. O. M.; BARRETO, Ivana C. H. C.; BEZERRA, Roberto C. Atenção primária à saúde e estratégia saúde da família. São Paulo: Editora Hucitec, 2006.

ANDRADE, Sônia Maria Oliveira de.Representações sociais das enfermeiras sobre a integralidade na assistência à saúde da mulher na rede básica. Ciênc. Saúde Coletiva, v. 13, n. 1, p. 61-70, 2008. Disponível em: <http://dx.doi.org/10.1590/S141381232008000100011>. Acesso em: 06 fev. 2017.

ANDRE, M.E.D.A. Estudo de caso: seu potencial na educação. Cadernos de Pesquisa, p. $51-54,1984$.

ANDREUCCI, C. B.; CECATTI, J. G. Desempenho de indicadores de processo do Programa de Humanização do Pré-Natal e Nascimento no Brasil: uma revisão sistemática. Cadernos de Saúde Pública, 2010. Disponível em: <https://www.scielosp.org/article/csp/2014.v30suppl1/S85-S100/>. Acesso em:06 fev 2017.

ANSILIERO, Graziela. Histórico e evolução recente da concessão de saláriosmaternidade no Brasil. Informe da Previdência Social, Brasília, v. 19, n. 2, p. 1-9, fev. 2007.

ANVERSA, Elenir Terezinha Rizzetti et al. Qualidade do processo da assistência prénatal: unidades básicas de saúde e unidades de Estratégia Saúde da Família em município no Sul do Brasil. Cadernos de Saúde Pública, v. 28, n. 4, p. 789-800, apr. 2012.

AQUINO, T.; SOUTO B.G.A. Problemas gestacionais de alto risco comuns na atenção primária. Rev. méd. Minas Gerais, v. 25, p. 9, 2015. Disponível em: <http://www.rmmg.org/exportar-pdf/1873/v25n4a16.pdf>. Acesso em: 15 set. 2017.

ARCE, Vladimir Andrei Rodrigues; SOUSA, Maria Fátima de. Práticas de longitudinalidade no âmbito da Estratégia Saúde da Família no Distrito Federal. Caderno Saúde Coletiva, Rio de Janeiro, v. 22, n. 1, p. 62-68, mar. 2014. 
BAPTISTA, T. W. F. Análise das portarias ministeriais da saúde e reflexões sobre a condução nacional da política de saúde. Cadernos de Saúde Pública, p. 615-626, 2007.

BARBOSA, Dayse Vieira Santos; BARBOSA, Nelson Bezerra; NAJBERG, Estela. Regulação em Saúde: desafios à governança do SUS. Cadernos Saúde Coletiva, v. 24, n. 1, p. 49-54, 2015.

BARDIN, L. Análise de conteúdo: A visão de Laurence Bardin. Lisboa: Edições 70, 2011.

BIRMAN, J. A. Physis da Saúde Coletiva. Physis Rev Saúde Coletiva 1: 16, 1991.

BOBBIO, N; MATTEUCI, N. \& PASQUINO, G. Dicionário de Política. Brasília: Editora Universidade de Brasília, 1995.

BORGES, Fabrício Quadros. Gestão da Informação no Sistema Único de Saúde. Revista de Administração FACES Journal, v. 13, n. 2, p. 83-98, abr./jun. 2014.

BRAGA, A. A gestão da informação. Disponível em: <www.arquivar.com.br/espaco_profissional/sala_leitura/artigos/Gestao_da_Informacao. pdf>. Acesso em: 06 dez. 2016.

BRASIL, Ministério da Saúde. Manual de implantação de complexos reguladores. Brasília, 2006a. Folder.

BRASIL, Ministério do Trabalho. Pesquisa sobre a participação das mulheres no mercado de trabalho, 2017. Disponível em: $<$ https://www.agenciabrasilia.df.gov.br/2017/03/07/governo-divulga-pesquisa-sobreparticipacao-feminina-no-mercado-de-trabalho/>. Acesso em: 08 set. 2017.

BRASIL, São Paulo, Secretaria da Saúde. Atenção à gestante e a puérpera no SUS SP: Manual técnico do pré-natal e puerpério. São Paulo, 2010. Folder.

BRASIL. Associação Saúde da Família. História e Funcionamento. Disponível em: <www.saudedafamilia.org>. Acesso em: 06 mai. 2017.

BRASIL. Conselho Nacional de Secretários de Saúde. Para entender a gestão do SUS. CONASS, Brasília, 2003.

BRASIL. Constituição (1988). Constituição da República Federativa do Brasil. Brasília: Senado, 1988.

BRASIL. Lei no 11770, de 09 de setembro de 2008. Cria o Programa Empresa Cidadã, destinado à prorrogação da licença-maternidade mediante concessão de incentivo fiscal, e altera a Lei no 8.212, de 24 de julho de 1991. Diário Oficial da União, Brasília, 10 set. 2008, Seção 1, p. 1.

BRASIL. Lei $\mathrm{n}^{\circ}$ 8.080, de 19 de setembro de 1990. Dispõe sobre as condições para a promoção, proteção e recuperação da saúde, a organização e o funcionamento dos 
serviços correspondentes e dá outras providências. Diário Oficial da União, Brasília, 20 set. 1990, Seção 1, p. 18055.

BRASIL. Lei ${ }^{\circ}$ 8.213, de 14 de julho de 1991. Dispõe sobre os planos de benefícios da previdência social. Brasília, 1991. Diário Oficial da União, Brasília, 25 jul. 1991, Seção 1, p. 14809.

BRASIL. M. K et al. Contribuições da rede cegonha para o acompanhamento do pré-natal por enfermeiras da atenção básica. Revista Cesumar v. 18, n. 1, p. 73-80, 2013. Disponível em: <http://apps.cofen.gov.br/cbcenf/sistemainscricoes/arquivosTrabalhos/I45350.E11.T862 9.D7AP.pdf>. Acesso em: 07 abr.2017.

BRASIL. Ministério da Saúde, 2017. A informatização da Atenção Básica. Brasília, 2013-2018. Disponível em: <http://portalsaude.saude.gov.br/index.php/cidadao/principal/agencia-saude/28956ministerio-da-saude-anuncia-chamada-publica-para-informatizacao-de-ubs>. Acesso em: 12 jun. 2017.

BRASIL. Ministério da Saúde, Portaria nº 1459 de 24 de junho de 2011. Institui no âmbito do Sistema Único de Saúde - SUS - a Rede Cegonha. Brasília, 2011. Diário Oficial da União, Brasília, 24 jun. 2011, Seção 1, p. 109.

BRASIL. Ministério da Saúde. 11 ${ }^{a}$ Conferencia Nacional de Saúde, 2001. Disponível em: 〈http://conselho.saude.gov.br/biblioteca/relatorios/relatorio_11.pdf>. Acesso em: 04 mar. 2017.

BRASIL. Ministério da Saúde. ABC do SUS: doutrinas e princípios. Disponível em: <http://www.pbh.gov.br/smsa/bibliografia/abc_do_sus_doutrinas_e_principios.pdf>. Acesso em: 02 abr. 2017

BRASIL. Ministério da Saúde. Cadernos RH Saúde. Brasília: Ministério da Saúde, 1993.

BRASIL. Ministério da Saúde. Diretrizes de Atenção à gestante: Operação Cesariana. Disponível em: <http://conitec.gov.br/images/Consultas/Relatorios/2015/Relatorio_PCDTCesariana_CP .pdf>. Acesso em: 02 abr. 2017

BRASIL. Ministério da Saúde. Diretrizes operacionais dos Pactos pela Vida, em Defesa do SUS e de Gestão. Brasília, 2006. Folder.

BRASIL. Ministério da Saúde. Gravidez, parto e nascimento com saúde, qualidade de vida e bem-estar. Brasília, 2013. Folder.

BRASIL. Ministério da Saúde. Informações sobre mortalidade materna no Brasil. Boletim Epidemiológico, v. 43, n. 1, 2011. Disponível em: $<$ http://datasus.saude.gov.br/informacoes-de-saude/business-intelligence-

bi/informacoes-de-mortalidade>. Acesso em: 15 set. 2016. 
BRASIL. Ministério da Saúde. Manual dos Comitês de Mortalidade Materna, Brasília, 2007. Disponível

em:

$<$ http://bvsms.saude.gov.br/bvs/publicacoes/manual_comites_mortalidade_materna.pdf >. Acesso em:

BRASIL. Ministério da Saúde. NOB-SUS 1996: Norma Operacional Básica do Sistema Único de Saúde. 1997 Jan. Disponível em: <http://www.redeblh.fiocruz.br/media/nob.pdf >. Acesso em:

BRASIL. Ministério da Saúde. Normas e padrões de construções e instalações de serviços de saúde. 2. ed. Brasília: Editora Ministério da Saúde, 1987.

BRASIL. Ministério da Saúde. Parto, Aborto e puerpério: assistência humanizada à mulher. Brasília, 2001. Folder.

BRASIL. Ministério da Saúde. Política Nacional de Atenção Básica. Portaria no 648 de 28 de março de 2006. Diário Oficial da União, Brasília, 29 mar. 2006, Seção 1, p. 71.

BRASIL. Ministério da Saúde. Programa de Humanização do Pré-natal e Nascimento. Secretaria de Políticas de Saúde, 2018. Disponível em: <http://bvsms.saude.gov.br/bvs/publicacoes/parto.pdf>. Acesso em: 05 mai. 2017

BRASIL. Ministério da Saúde. Redes de atenção à saúde: a Rede Cegonha/Consuelo Penha. Manual Rede Cegonha, São Luís, p. 1-43, 2015.

BRASIL. Ministério da Saúde. Regionalização da assistência à saúde: aprofundando a descentralização com equidade no acesso. Série A. Normas e Manuais Técnicos. 2. ed. Brasília: Editora $\quad 2002.2$ Disponível em: <http://siops.datasus.gov.br/Documentacao/NOAS\%2001\%20de\%202002.pdf>. Acesso em: 30 jan. 2017

BRASIL. Ministério da Saúde. Relatório Final da $13^{\text {a }}$ Conferência Nacional de Saúde: saúde e qualidade de vida: políticas de estado e desenvolvimento. Brasília: Editora do Ministério da Saúde, 2008.

BRASIL. Ministério da Saúde. Relatório final da $8^{\text {a }}$ Conferência Nacional de Saúde. Brasília: Editora do Ministério da Saúde, 1986.

BRASIL. Ministério da Saúde. Sistema de informação sobre mortalidade. São Paulo

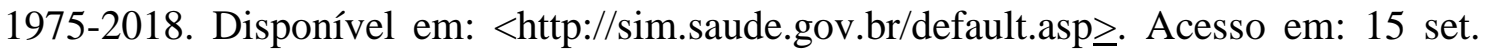
2016.

BRASIL. Ministério do Desenvolvimento Social. Informações sobre o CAD-Único. Disponível em: <http://mds.gov.br/assuntos/cadastro-unico $\geq$. Acesso em: 06 mai. 2017.

BRASIL. Portaria GM/MS no 399, de 22 de fevereiro de 2006. Divulga o Pacto pela Saúde 2006 consolidação do SUS e aprova as diretrizes operacionais do referido pacto. Diário Oficial da União, Brasília, 23 fev. 2006. Seção 1, p. 43. 
BRASIL. Portaria ${ }^{\circ}$ 1.473, de 18 de julho de 2013. Institui os Comitês Gestores, Grupos Executivos, Grupos Transversais e os Comitês de Mobilização Social e de Especialistas dos compromissos prioritários de governo organizados por meio de Redes Temáticas de Atenção à Saúde. Diário Oficial da União, Brasília, 25 jul. 2013. Seção 1, p. 27.

BRASIL. Presidência da República. Objetivos de Desenvolvimento do Milênio. Relatório Nacional de Acompanhamento, 2010. Disponível em: $<$ http://www.ipea.gov.br/portal/index.php?option=com_content $\&$ view=article $\& i d=2253$ 8>. Acesso em: 30 jan. 2017.

BRITO, Jussara Cruz de. O trabalho em saúde: olhando e experienciando o SUS no cotidiano. Cadernos de Saúde Pública, Rio de Janeiro, v. 21, n. 5, p. 1612-1614, oct. 2005.

BRITO-SILVA, Keila; BEZERRA, Adriana Falangola Benjamin; TANAKA, Oswaldo Yoshimi. Direito à saúde e integralidade: uma discussão sobre os desafios e caminhos para sua efetivação. Interface, v. 16, n. 40, p. 249-260, mar. 2012.

BUCHABQUI, Jorge Alberto; CAPP, Edison; FERREIRA, Jair. Adequação dos encaminhamentos de gestações de alto-risco na rede básica de atenção à saúde de Porto Alegre, Rio Grande do Sul, Brasil. Revista Brasileira de Saúde Materno Infantil, v. 6, n. 1, p. 23-29, mar. 2006.

CAMPOS, G. W. S. et al. Tratado de saúde coletiva. São Paulo: Editora Hucitec /Rio de Janeiro: Editora Fiocruz, 2006.

Capote MIR. Sistemas locales de salud: organización, regionalización, princípios generales: Los sistemas locales de salud: conceptos, métodos, experiências. Organización Panamericana de la Salud, Washington, D.C, p.117-35, 1990.

CAPRA F. O ponto de Mutação: o modelo biomédico. 1. ed. São Paulo: Cultrix; 1982.

CARNEIRO, R. G. Dilemas antropológicos de uma agenda de saúde pública: Programa Rede Cegonha, pessoalidade e pluralidade. Interface-Comunicação, Saúde, Educação, v. 17, n.44, p. 49-59, 2013.

CARVALHO, B. G.; PETRIS, A. J.; TURINI, B. Controle social em saúde: Bases da Saúde Coletiva. Londrina: UEL, 2001.

CASSIANO, A. C. M. et al. Saúde materno-infantil no Brasil: evolução e programas desenvolvidos pelo Ministério da Saúde. Revista do Serviço Público, Brasília, v. 65, n. 2, p. 227-244, abr./jun. 2014.

CECÍLIO, Luiz. C. O. Modelos técnico-assistenciais em saúde: da pirâmide ao círculo, uma possibilidade a ser explorada. Cadernos de Saúde Pública, Rio de Janeiro, p. 469478, jul./set. 1999.

CHEN, X.K. et al. Adequacy of prenatal care and neonatal mortality in infants born to mothers with and without antenatal highrisk conditions. Australian and New Zealand Journal of Obstetrics and Gynaecology, Australia, p. 122-127, 2007. 
CHIZZOTTI, A. Pesquisa em ciências humanas e sociais. São Paulo: Cortez, 2010.

CONILL, Eleonor Minho. Avaliação da integralidade: conferindo sentido para os pactos na programação de metas dos sistemas municipais de saúde. Cadernos de Saúde Pública, Rio de Janeiro, v. 20, n. 5, p. 1417-1423, oct. 2004.

CORRÊA, Áurea Christina de Paula; Dói, Helga Yuri. Contrarreferência de mulheres que vivenciaram gestação de risco a unidades de saúde da família em cuiabá. Ciência, Cuidado Saúde, p. 104-110, jan./mar. 2014.

CRUZ, Rachel. Aspectos históricos, conceituais e organizativos do pré-natal Revista brasileira de ciências da saúde, v.18, n. 1, p. 87 - 94, 2014.

CUNHA, Elenice Machado da; GIOVANELLA, Ligia. Longitudinalidade/continuidade do cuidado: identificando dimensões e variáveis para a avaliação da Atenção Primária no contexto do sistema público de saúde brasileiro. Ciência \& saúde coletiva, Rio de Janeiro, v. 16, p. 1029-1042, 2011.

DA SILVA, L. M. V. et al. Análise da implantação da gestão descentralizada em saúde: estudo comparado de cinco casos na Bahia, Brasil. Cadernos de Saúde Pública, Rio de Janeiro, v. 23, n. 2, p. 355-370, 2007.

DALPLAZ, A. K; STEDLLE, N. L. R. V Jornada Internacional de Políticas Públicas. São Luís do Maranhão, 2011.

DAUNE-RICHARD, Anne-Marie. Qualificações e representações sociais. São Paulo: Editora Senac, 2003.

DI GIOVANNI, Miriam. Rede Cegonha: da Concepção à Implantação: Monografia apresentada ao Curso de Especialização em Gestão Pública da Escola Nacional de Administração Pública - ENAP, 2013.

Dias C.F. O Sistema de referência e contrarreferência na estratégia saúde da família no município de bauru: perspectiva dos gestores. 2010. Dissertação (Mestrado) Faculdade de Medicina, Universidade de São Paulo, São Paulo.

DIAS, Camila Faria. O sistema de referência e contra-referência na estratégia saúde da família no município de Bauru: perspectiva dos gestores. 2010.

Dissertação (mestrado) - Faculdade de Medicina de Botucatu, Universidade Estadual Paulista, São Paulo.

DUARTE, Ligia Schiavon et al. Regionalização da saúde no Brasil: uma perspectiva de análise. Saude soc., São Paulo, v. 24, n. 2, p. 472-485, jun. 2015. 
ELIAS, P. E. Estado e saúde: os desafios do Brasil Contemporâneo, São Paulo Perspec. São Paulo, v.18, n.3, jul./sep. 2004.

ELIAS, Paulo Eduardo et al. Atenção Básica em Saúde: comparação entre PSF e UBS por estrato de exclusão social no município de São Paulo. Ciência saúde coletiva, Rio de Janeiro, v. 11, n. 3, p. 633-641, 2006.

ESCOREL, S. Reviravolta na saúde: origem e articulação do Movimento Sanitário. Rio de Janeiro: Editora Fiocruz, 1998.

FRATINI J. R. G.; SAUPE R.; MASSAROLI A. Avaliação de um programa de alta especial: um estudo preliminar de referência e contra-referência. Itajaí: Univali, 2007.

FEBRASGO. Assistência Pré-natal. Manual de Orientação, 2000. Disponível em: <http://www.abenforj.com.br/site/arquivos/manuais/304_Manual_Pre_natal_25SET.pdf . Acesso em: 02 fev. 2017

FLEURY, S. M. T.; OUVERNEY, A. M. Gestão de Redes: a estratégia de regionalização da política de saúde. Rio de Janeiro: Editora FGV, 2007.

FRANCO, T. B.; MAGALHÃES, J. H. Integralidade na assistência à saúde: a organização das linhas do cuidado, 2004. Disponível em: <http://www1.saude.rs.gov.br/dados/1311947118612INTEGRALIDADE\%20NA\%20A SSIST\%CANCIA $\% 20 \%$ C0\%20SA\%DADE\%20-\%20T\%FAlio.pdf $>$. Acesso em: 05 nov. 2016

GAMBOA, S. A. S. A dialética na pesquisa em educação: elementos de Contexto. Metodologia da pesquisa educacional. São Paulo: Cortez, 1989.

GIL, A. C. Como elaborar projetos de pesquisa. 4. ed. São Paulo: Atlas, 2009.

GIOVANELLA L, et al. Saúde da família: limites e possibilidades para uma abordagem integral de atenção primária à saúde no Brasil. Ciência saúde coletiva, p. 783-794, 2009.

GIOVANELLA L. et al. Sistemas municipais de saúde e a diretriz da integralidade da atenção: critérios para avaliação. Saúde Debate, p. 37-61, 2002.

GOMES, A.A. Considerações sobre a pesquisa científica: em busca de caminhos para a pesquisa científica. Revista Intertemas, Presidente Prudente, p. 61-81, 2001.

GONCALVES, Carla Vitola; et al. Qualidade e eqüidade na assistência à gestante: um estudo de base populacional no Sul do Brasil. Cadernos de Saúde Pública, Rio de Janeiro, v. 25, n. 11, p. 2507-2516, nov. 2009.

GRYSCHEK, Anna Luiza de Fátima Pinho. A política de qualificação da força de trabalho em enfermagem no programa municipal de doenças sexualmente transmissíveis e AIDS de São Paulo: um desafio contínuo. 2001. Tese (Doutorado) Programa de Pós-graduação da Escola de Enfermagem, Universidade de São Paulo. 
GUERRA, C. G.; RODRIGUES, P. H. A.; Avaliação da referência e contrarreferência no Programa Saúde da Família na Região Metropolitana do Rio de Janeiro (RJ, Brasil), 2010. Ciênc. Saúde Coletiva, Rio de Janeiro, v.15, 2010.

GUIMARÃES L.; GIOVANELLA L. Entre a cooperação e a competição: percursos da descentralização do setor saúde no Brasil. Rev Panam Salud Pública, v.16, p. 283 -288, 2004.

HALBE, H. Tratado de Ginecologia. 3. ed. São Paulo: Rocca, 2000.

HALPERN, Ricardo et al. Atenção pré-natal em Pelotas, Rio Grande do Sul, Brasil, 1993. Cadernos de Saúde Pública, Rio de Janeiro, v. 14, n. 3, p. 487-492, jul. 1998.

HARTZ, Zulmira M. de Araújo; CONTANDRIOPOULOS, André-Pierre. Integralidade da atenção e integração de serviços de saúde: desafios para avaliar a implantação de um "sistema sem muros". Cadernos de Saúde Pública, Rio de Janeiro, v. 20, p. 331-336, 2004.

LEATT P.; PINK G.; GUERRIERE M. Towards a canadian model of integrated healthcare. HealthcarePapers, p. 13-55, 2000.

IBAÑEZ, N.; BITTAR, O. J. N. V.; SÁ, E. N. C.; YAMAMOTO, E. K.; ALMEIDA, M. F.; CASTRO, G. J.; Organizações Sociais de Saúde: o modelo do Estado de São Paulo. Ciênc. Saúde Coletiva, São Paulo, v.6, n.2, 2001.

IBGE. Painel Histórico dos Distritos de Saúde de São Paulo, 2010. Disponível em: <http://www.cidades.ibge.gov.br/painel/historico.php?codmun=355030>. Acesso em: 08 fev. 2017. Acesso em: 02 abr. 2017

IBGE. Taxas de mortalidade infantil, 2013. Disponível em: <http://brasilemsintese.ibge.gov.br/populacao/taxas-de-mortalidade-infantil.html.> Acesso em: 06 out. 2016.

IUNES, Roberto F. Demanda e demanda em saúde: Conceito e contribuição para a gestão da saúde. IPEA, p. $99 \quad-122, \quad$ 1995. Disponível em: <http://www.ipea.gov.br/portal/index.php?option=com_content\&view=article\&id= 5329>. Acesso em: 01 nov. 2016

KASSAR, S. B. et al. Determinants of neonatal death with emphasis on health care during pregnancy, childbirth and reproductive history. J Pediatr, v. 89, n. 3, p. 269-277, 2013.

KASSAR, S.B et al. Determinants of neonatal death with emphasis on health care during pregnancy, childbirth and reproductive history. J Pediatr, 2013. Disponível em: <http://periodicos.ufpb.br/index.php/rbcs/article/download/15780/11722>. Acesso em: 01 nov. de 2016

LAVRAS, Carmen. Atenção primária à saúde e a organização de redes regionais de atenção à saúde no Brasil. Saude soc., São Paulo, v. 20, n. 4, p. 867-874, dez. 2011. 
LIMA, João Paulo Cavalcante. Estudos de caso e sua aplicação: proposta de um esquema teórico para pesquisas no campo da contabilidade. Revista de Contabilidade e Organizações, v. 6, n. 14, p. 127-144, 2012.

LIMA, L. D. \& BAPTISTA, T. W. F. Política e gestão da saúde no Brasil: desafios para a VISA. Rio de Janeiro: Fiocruz, 2003.

LÜDKE, M.; ANDRÉ, E. D. A. Pesquisa em Educação: abordagens qualitativas. São Paulo: EPU, 1986.

MACHADO M. H. et al. Análise da força de trabalho do setor saúde no Brasil: focalizando a feminização. Fundação Oswaldo Cruz, Rio de Janeiro, 2006.

MACIAZEKI-GOMES, Rita de Cássia et al. O trabalho do agente comunitário de saúde na perspectiva da educação popular em saúde: possibilidades e desafios. Ciência \& Saúde Coletiva, Rio de Janeiro, v. 21, n. 5, p. 1637-1646, 2016.

MARCONI, M. A.; LAKATOS, E. M. Técnicas de Pesquisa. São Paulo: Editora Atlas, 2007.

MATTA, Gustavo Corrêa. Políticas de Saúde: organização e operacionalização do sistema único de saúde. Rio de Janeiro: Fiocruz, 2007.

MEDEIROS JÚNIOR, A.; RONCALli, A. G. LIMA, K. C. Políticas de saúde no Brasil. Saúde bucal coletiva: conhecer para atuar. EDUFRN, p. 249-259, Natal, 2004.

MENDES, E. V. Distrito Sanitário: o processo social de mudança das práticas sanitárias do Sistema Único de Saúde. São Paulo: Hucitec, 1993.

MENDES, Eugênio Vilaça. Os grandes dilemas do SUS. Salvador: Casa da Qualidade, 2001.

MENDONÇA, M. H. M; VASCONCELLOS, M. M.; VIANA, A. L. A. Atenção primária à saúde no Brasil. Cadernos de Saúde Pública, 2008.

MENOZZI, Karen Aline Batista da Silva. O sistema de referência e contrareferência no contexto da equipe multiprofissional de saúde. 2013. Dissertação (mestrado) Faculdade de Medicina de Botucatu, Universidade Estadual Paulista, São Paulo.

MERHY, E. E. Saúde: a cartografia do trabalho vivo. São Paulo: HUCITEC, 2002.

MERHY, Emerson Elias; FRANCO, Túlio Batista. Por uma Composição Técnica do Trabalho centrada no campo relacional e nas tecnologias leves. Ano XXVII, Rio de Janeiro, v. 27, n. 65, set./dez. 2003.

MERRHY; Emerson Elias. O trabalho em saúde: olhando e experienciando o sus no cotidiano. São Paulo: HUCITEC, 2007. 
MINAYO, M. C. S. \& SANCHES, O. Quantitative and Qualitative Methods: Opposition or Complementarity? Cadernos de Saúde Pública, Rio de Janeiro, p. 239-262, jul./sep. 1993.

MINAYO, M. C. S. et al. Pesquisa Social: Teoria, Método, e Criatividade. Petrópolis: Vozes, 2004.

MINAYO, M.C. S. O desafio do conhecimento: Pesquisa Qualitativa em Saúde. 12. ed. São Paulo: Hucitec, 2010.

MODESTO, P. Reforma administrativa e marco legal das organizações sociais no Brasil: As dúvidas dos juristas sobre o modelo das organizações Sociais. Revista de informação legislativa, v. 34, n. 136, out./dez. 1997.

MOURA, V.A.; FEITOSA, F.E.L. Avaliação de Cesáreas na Maternidade Escola Assis Chateaubriand utilizando o Sistema de Classificação de Robson em dez grupos. Revista Médica UFC. Rio Grande do Sul, v. 57, n. 1, p.25-29, 2017.

MURRAY M.; TANTAU C. Same-day appointments: exploding the access paradigm. Family Practice Management, p. 45-50, 2000.

NOGUEIRA, J. W. S.; RODRIGUES, M. C. S. Comunicação efetiva no trabalho em equipe em saúde: desafio para a segurança do paciente*. Cogitare Enfermagem, p. 636640, jul./set. 2015.

NOVAES, H. M; CAPOTE Myr. Sistemas locales de salud - um médio para la regionalización de los servicios de salud. Organización Panamericana de La Salud, p. $147-58,1990$.

OLIVEIRA, A. Gênero, Saúde Reprodutiva e Trabalho: formas subjetivas de viver e resistir às condições de trabalho (Dissertação de Mestrado) - Fundação Oswaldo Cruz. Rio de Janeiro, p. 167, 2001.

ORGANIZAÇÃO MUNDIAL DA SAÚDE. Boletim Epidemiológico sobre mortalidade materna no Brasil. Disponível em: $<$ http://portalsaude.saude.gov.br/index.php/profissional-e-gestor/vigilancia/noticiasvigilancia/7525-nova-edicao-do-boletim-epidemiologico-aborda-mortalidade-maternaaids-dengue-e-tuberculose>. Acesso em: 06 out. 2016.

ORGANIZAÇÃO MUNDIAL DA SAÚDE. Cuidados primários de saúde: relatório da conferência internacional sobre cuidados primários de saúde, Alma Ata. Brasília: UNICEF; 1978.

Organização Mundial da Saúde. Ensaio clínico aleatorizado de controle do pré-natal da OMS. Manual para a prática de um novo modelo de assistência pré-natal, 2012. Disponível em: <http://who.int/reproductive-health/rhl-pg.09>. Acesso em: 07 out. 2016.

PAIM, J. S. A reorganização das práticas de saúde em distritos sanitários: Distrito Sanitário: o processo social de mudança das práticas sanitárias do Sistema Único de Saúde. São Paulo: Hucitec, 1995. 
PAIM, J.; TRAVESSOS, C.; ALMEIDA, C.; BAHIA L.; MACINKO, J. O sistema de saúde brasileiro: história, avanços e desafios. Lancet, 1778-1797, 2011.

PAIM, Jairnilson Silva. O que é o SUS. Rio de Janeiro: Editora Fiocruz, 2009.

PEGO, R. A.; ALMEIDA, C. M. Teoria y práctica de las reformas de los sistemas de salud: los casos de Brasil y Mexico. Cad Saúde Pública v. 4, p. 971-978, 2002.

PEREIRA, Laïs de Toledo Krücken; GODOY, Dalva Maria Alves; TERCARIOL, Denise. Estudo de caso como procedimento de pesquisa científica: reflexão a partir da clínica fonoaudiológica. Psicol. Reflex. Crit., Porto Alegre, v. 22, n. 3, p. 422-429, 2009.

Perrot M. Os Silêncios do Corpo da Mulher: O Corpo Feminino em Debate. $1^{\text {a }}$ ed. São Paulo: UNESP; 2003.

PESSOTO, U. C. A regionalização do Sistema Único de Saúde SUS no fim dos anos 1990: um discurso conservador. 2010. Tese (doutorado em Geografia) - Faculdade de Ciências e Tecnologia da Universidade Estadual Paulista, Presidente Prudente.

PREFEITURA DO MUNICÍPIO DE SÃO PAULO. Manual Técnico - Normatização das rotinas e procedimentos de Enfermagem nas Unidades Básicas de Saúde. São Paulo, 2013. Disponível em: <http://www.prefeitura.sp.gov.br/cidade/secretarias/saude/atencao_basica/enfermagem/i ndex.php?p=8835>. Acesso em: 08 mai. 2017.

Prefeitura Municipal de Guarulhos. Distritos e Regiões de Saúde do Município de São Paulo 2017. Disponível em: <http://www.prefeitura.sp.gov.br/cidade/secretarias/saude/organizacao/index.php?p=54 06 2 . Acesso em: 20 jan. 2017.

PREFEITURA MUNICIPAL DE SÃO PAULO. Distribuição das unidades básicas de saúde. São Paulo: Prefeitura de São Paulo, 2017.

PREFEITURA MUNICIPAL DE SÃO PAULO. Hospital Maternidade Escola Cachoeirinha. Número de Atendimentos e Procedimentos realizados nos anos de 2016 até maio de 2017. São Paulo 2008-2018. Disponível em: <tabnet.datasus.gov.br/>. Acesso em: 06 jun. 2017.

PROTASIO, Ane Polline Lacerda et al. Avaliação do sistema de referência e contrarreferência do estado da Paraíba segundo os profissionais da Atenção Básica no contexto do $1^{\circ}$ ciclo de Avaliação Externa do PMAQ-AB. Saúde debate, Rio de Janeiro, v. 38, p. 209-220, Oct. 2014.

QUINELLATO, L. V. A DIRETRIZ DE HIERARQUIZAÇÃO DO SUS: mudando a antiga perspectiva do modelo médico assistencial privatista. Dissertação (Mestrado International Management) - International Management, Fundação Getúlio Vargas, 2009.

SELLTIZ, C.; WRIGHTSMAN, L. S.; COOK, S. W. Métodos de pesquisa das 
relações sociais. São Paulo: Herder, 1965.

RIBEIRO E. et al. Risk factors for Inadequate prenatal care use in the metropolitan area of Aracaju, Northeast Brazil. BMC Pregnancy Childbirth, p. 9- 31, 2009.

ROUQUAYROL, M. Z.; FILHO, N. A. Epidemiologia \& Saúde. 6.ed. Rio de Janeiro: MEDSI, 2003.

SANTIAGO, R. F. et al. Quality of care in the family healthcare units in the city of Recife: user perception. Ciência \& Saúde Coletiva, v. 18, n. 1, p. 35-44, jan. 2013.

SANTOS M.C. et al. Comunicação em saúde e a segurança do doente: problemas e desafios. Revista Portuguesa de Saúde Pública. Disponível em:<https://goo.gl/bJEhu1>. Acesso em: 10 jul. 2017

SÃO PAULO, Secretaria da Saúde. Atenção à gestante e a puérpera no SUS. Manual técnico do pré-natal e puerpério, São Paulo, 2010. Disponível em: <http://www.saude.sp.gov.br/resources/ses/perfil/gestor/destaques/atencao-a-gestante-ea-puerpera-no-sus-sp/manual-tecnico-do-pre-natal-e-puerperio/manual_tecnicoii.pdf.

Acesso em: 06 dez. 2016

SIMEÃO, E.; MENDONÇA, A.V.M. Comunicação da Informação em Saúde no Brasil: Aspectos de Qualidade e Desafios. Brasília, p. 85-93, 2007.

SILVA; Suzana R.; A representação social dos princípios do Sistema Único de Saúde pelos seus usuários. 2007. Dissertação (Mestrado em Enfermagem) -Faculdade de Enfermagem, Universidade do Estado do Rio de Janeiro, Rio de Janeiro.

SAY, Lale et al. Global causes of maternal death: a WHO systematic analysis. Lancet Glob Health, v. 2, p. 323-333, 2014. Disponível em: http://goo.gl/S6dO8D. Acesso em: 14 set. 2016.

SCHEFFER, M. et al. Demografia Médica no Brasil 2015, 2015. Disponível em: <https://www.usp.br/agen/wp-content/uploads/DemografiaMedica30nov2015.pdf>.

Acesso em: 08 mai. 2017

SERRA, Carlos Gonçalves; RODRIGUES, Paulo Henrique de Almeida. Avaliação da referência e contrarreferência no Programa Saúde da Família na Região Metropolitana do Rio de Janeiro (RJ, Brasil). Ciência saúde coletiva, Rio de Janeiro, v. 15, supl. 3, p. 3579-3586, 2010.

SIAB. Sistema de Informações da Atenção Básica, UBS Vila Dionísia e UBS Dra. Ilza Hutzler. São Paulo, Disponível em: <http://datasus.saude.gov.br/sistemas-eaplicativos/epidemiologicos/siab>. Acesso em: 6 jun. 2017.

SILVA, Fabiane Carmo Santos. O princípio da integralidade e os desafios da saúde coletiva. Revista Saúde e Desenvolvimento, v. 7, n.4, jan./dez. 2015. 
SILVA, L M. V. et al. District Allocation and Utilization of Health Care Services in Pau da Lima, Salvador, Bahia, Brazil. Cad. Saúde Pública, Rio de Janeiro 11 p. 72-84, jan./mar. 1995.

SILVA, R. V. G. O.; RAMOS F. R. S. Integralidade em saúde: revisão de literatura. Ciência Cuidado e Saúde, p. 593-601, jul./set. 2010.

SILVA, Vanessa Costa; RIVERA, Francisco Javier Uribe; HORTALE, Virginia Alonso. Projeto Integrar: avaliação da implantação de serviços integrados de saúde no Município de Vitória, Espírito Santo, Brasil. Cadernos de Saúde Pública, Rio de Janeiro, p.14051414, jun. 2007.

SINASC. Sistema de Informações de Nascidos Vivos. Disponível em: $<$ http://datasus.saude.gov.br/sistemas-e-aplicativos/eventos-v/sinasc-sistema-deinformacoes-de-nascidos-vivos>. Acesso em: 15 set. 2016.

SIOPS. Sistemas de Informações sobre Orçamento Público em Saúde, 2016. Disponível em: <http://www.datasus.gov.br/DATASUS/index.php?area=060402>. Acesso em: 06 out. 2016.

SOUSA, Rafael da Cruz; BATISTA, Francisco Eduardo Bastos. Política Pública de Saúde no Brasil: História e Perpesctivas do Sistema Único de Saúde - SUS. Artigo apresentado no VII Congresso Norte Nordeste de Pesquisa e Inovação, Palmas Tocantins 2012.

SOUZA, Georgia Costa de Araújo; COSTA, Iris do Céu Clara. O SUS nos seus 20 anos: reflexões num contexto de mudanças. Saúde e sociedade, vol.19, n.3, p.509-517, 2010 .

SOUZA, Georgia Costa de Araújo; COSTA, Iris do Céu Clara. O SUS nos seus 20 anos: reflexões num contexto de mudanças. Saude soc., São Paulo, v. 19, n. 3, p. 509$517,2010$.

SPEDO, Sandra Maria; TANAKA, Oswaldo Yoshimi; PINTO, Nicanor Rodrigues da Silva. O desafio da descentralização do Sistema Único de Saúde em município de grande porte: o caso de São Paulo, Brasil. Cadernos de Saúde Pública, Rio de Janeiro, v. 25, n. 8, p. 1781-1790, 2009.

STARFIELD, Barbara. Atenção Primária: equilíbrio entre necessidades de saúde, serviços tecnologia. D Disponível em: <http://bvsms.saude.gov.br/bvs/publicacoes/atencao_primaria_p2.pdf >. Acesso em: 24 fev. 2017.

SUGUIHIRO, Vera Lucia Tieko. A ação investigativa na prática cotidiana do Assistente Social. Serviço Social e Sociedade. Londrina, v. 2, n. 1, p. 1-153, jul./dez. 1999.

TANAKA, Ana Cristina d'Andretta; SIQUEIRA, Arnaldo Augusto Franco de; BAFILE, Paulo Nogueira. Situação de saúde materna e perinatal no Estado de São Paulo, Brasil.Rev. Cadernos de Saúde Pública, São Paulo, v. 23, n. 1, p. 67-75, feb. 1989. 
TANAKA, Sayuri Maeda. Gestão da referência e contrarreferência na Atenção ao Ciclo gravídico - puerperal: a realidade do Distrito do Butantã. 2002. Tese (Doutorado) - Escola de Enfermagem da USP, São Paulo.

TEIXEIRA, S. M. F., O dilema reformista na reforma sanitária brasileira. Rev Adm Pública, Rio de Janeiro, v. 21, n. 4: 94-115, 1987.

TRAVASSOS, Claudia; MARTINS, Mônica. Uma revisão sobre os conceitos de acesso e utilização de serviços de saúde. Cadernos de Saúde Pública, v. 20, p. 190-198, 2004.

TRIVIÑOS, A. N. S. Introdução à pesquisa em ciências sociais: a pesquisa qualitativa em educação. 1. ed. São Paulo: Atlas, 2010.

TURATO, E. R. Métodos qualitativos e quantitativos na área da saúde: definições, diferenças e seus objetos de pesquisa. Revista de Saúde Pública, p. 507-514, 2005.

UNQUEIRA, Luciano A. Prates. Gerência dos serviços de saúde. Cadernos de Saúde Pública, Rio de Janeiro, v. 6, n. 3, p. 247-259, set. 1990.

VELHO, G. Observando o Familiar: A Aventura Sociológica. Rio de Janeiro: Zahar. 1978.

VENTURA, D. F. L.; ARANHA, M. I. Direito Institucional Sanitário. Direito sanitário e saúde pública: coletânea de textos. Brasília, DF: Ministério da Saúde, v. 1, p. 261-299, 2003.

VIEGAS, Selma Maria da Fonseca; PENNA, Cláudia Maria de Mattos. O SUS é universal, mas vivemos de cotas. Ciênc. saúde coletiva, Rio de Janeiro, v. 18, n. 1, p. 181-190, jan. 2013.

WILLCOX, S. et al. Measuring and reducing waiting times: a cross-national comparison of strategies. Health Affairs, Bethesda, v. 26, n. 4, p. 1078-1087, 2007.

WOLLMANN, Adriane. Novas possibilidades de organizar o acesso e a agenda na atenção primária à $2014 . \quad$ Daúde, 2 isponível em: <http://arquivos.leonardof.med.br/SaudeCuritiba_CartilhaAcessoAvancado_201406-05.pdf>. Acesso em: 06 de abril 2017

WORLD HEALTH ORGANIZATION. Expert committee on information support for new public health action at district level. WHO Technical Report Series, Geneva, 1993. 


\section{ANEXO 1 - QUADRO COM AS UNIDADES DE SAÚDE E SUAS RESPECTIVAS REFERÊNCIAS PARA MATERNIDADE DE BAIXO E ALTO RISCO NA REGIÃO NORTE DO MUNICÍPIO DE SÃO PAULO}

\begin{tabular}{|c|c|c|}
\hline UnidadesdeSaúde & $\begin{array}{c}\text { Maternidade de Referência } \\
\text { Risco } \\
\text { habitual }\end{array}$ & $\begin{array}{c}\text { Maternidade de Referência } \\
\text { Alto Risco }\end{array}$ \\
\hline UBS Jardim Rosinha & \multirow{3}{*}{ H. José Soares Hungria } & \multirow{3}{*}{ H.Mat.V. Nova Cachoeirinha } \\
\hline UBS Morada doSol & & \\
\hline UBS Morro Doce & & \\
\hline UBS Caiuba & \multirow{3}{*}{ H. Geral deTaipas } & \multirow{3}{*}{ H.Mat.V. Nova Cachoeirinha } \\
\hline UBS Perus & & \\
\hline UBS Recantodos Humildes & & \\
\hline UBS ChácaraInglesa & \multirow{6}{*}{ H. José Soares Hungria } & \multirow{6}{*}{ H.Mat.V. Nova Cachoeirinha } \\
\hline UBS Aldeia Indígena & & \\
\hline UBS Vila Pirituba & & \\
\hline UBS Anhanguera & & \\
\hline UBS VilaMangalot & & \\
\hline UBS Santo Elias & & \\
\hline UBS Dr.AugustoL. A. Galvão & \multirow{21}{*}{ H.Mat.V. No } & \multirow{21}{*}{ Cachoeirinha } \\
\hline UBS Jardim Ladeira Rosa & & \\
\hline UBS JardimPaulistano & & \\
\hline UBS Nova Esperança & & \\
\hline UBS JardimVista Alegre & & \\
\hline $\begin{array}{l}\text { UBS SilmaraRejaneMarcolino } \\
\text { deSouza }\end{array}$ & & \\
\hline UBS Vila Ramos & & \\
\hline UBS Vila Terezinha & & \\
\hline UBS Vila Palmeiras & & \\
\hline UBS Vila Progresso & & \\
\hline UBS Dra. Ilza Hutzler & & \\
\hline UBS Vila Dionísia & & \\
\hline UBS CasaVerde & & \\
\hline UBS CasaVerdeAlta & & \\
\hline UBS Dr.WalterElias & & \\
\hline UBS ParquePeruche & & \\
\hline UBS Sítio doMandaqui & & \\
\hline UBS Dona AdelaideLopes & & \\
\hline UBS Vila Barbosa & & \\
\hline UBS Vila Espanhola & & \\
\hline UBS Vila Santa Maria & & \\
\hline
\end{tabular}

Fonte: PMSP - 2017 


\section{ANEXO 2 - FICHA DE REFERÊNCIA E CONTRARREFERÊNCIA DA PMSP}

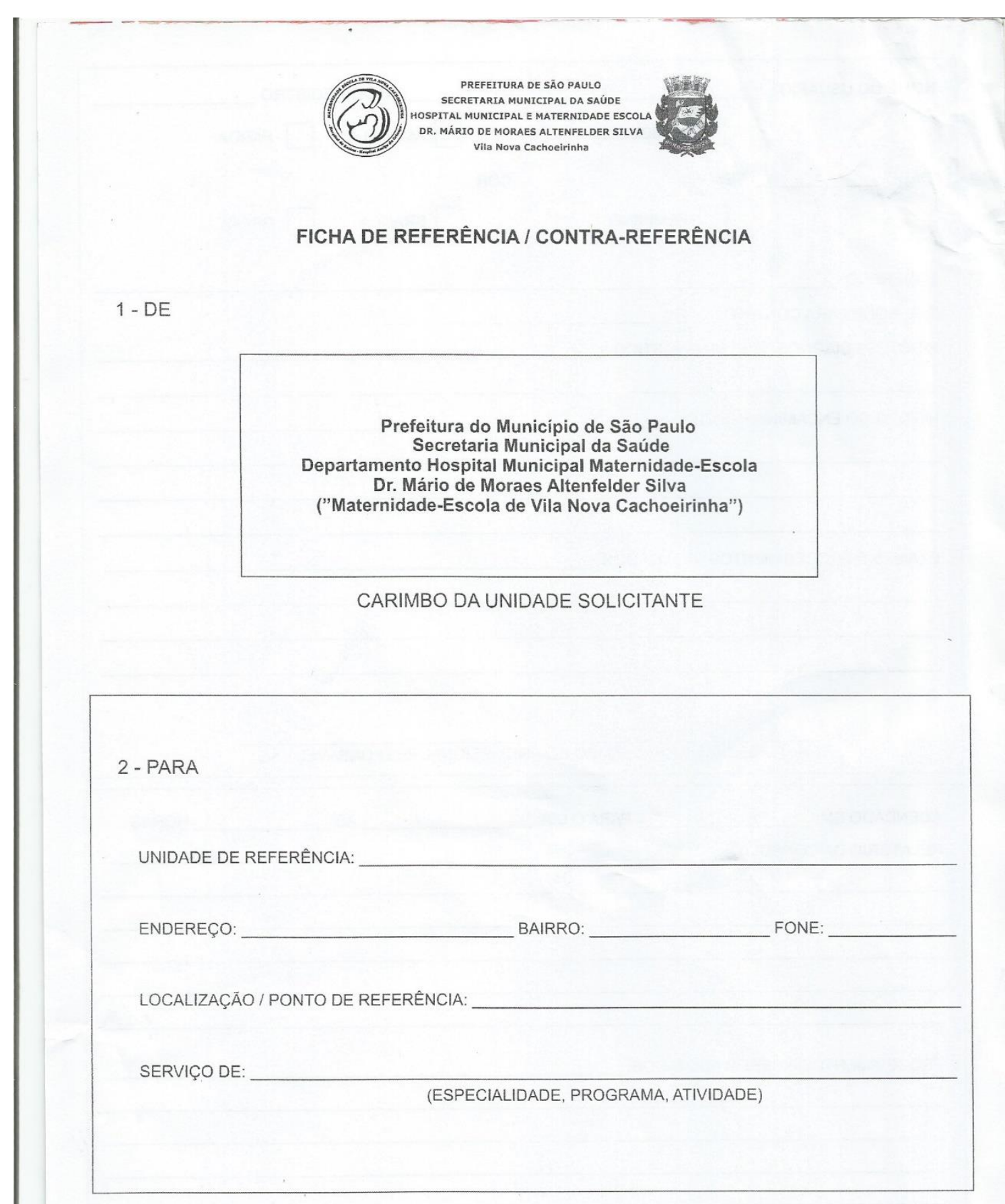




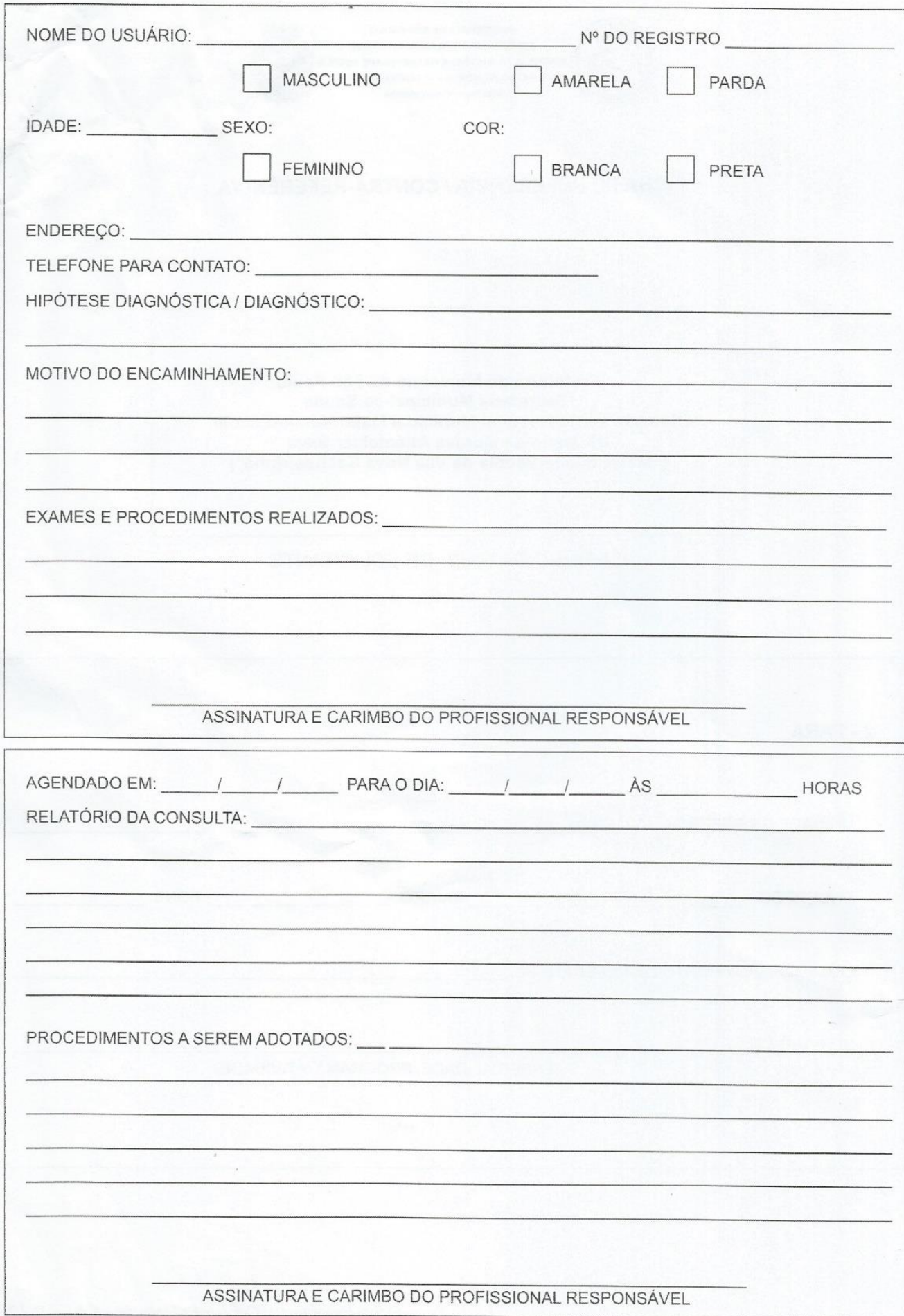




\section{ANEXO 3 - APROVAÇÃO NOS COMITÊS DE ÉTICA DA ESCOLA DE ENFERMAGEM DA USP, SECRETARIA DA SAÚDE DA PMSP E DA MATERNIDADE ESCOLA CACHOEIRINHA}

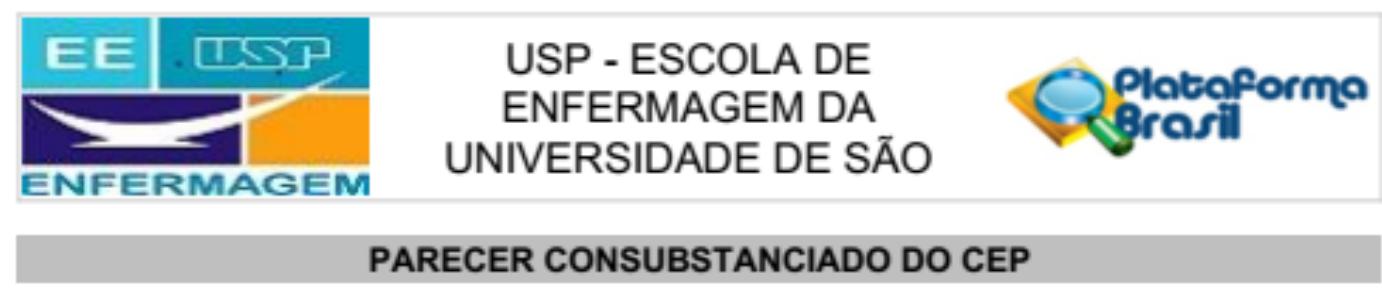

\section{DADOS DO PROJETO DE PESQUISA}

Título da Pesquisa: Acompanhamento de Gestantes no Pré-Natal de Alto Risco da Maternidade Cachoerinha: Contra Referência na Atenção Primária à Saúde

Pesquisador: ANA CAROLINA BRITO DE OLIVEIRA

Área Temática:

Versão: 2

CAAE: 63999417.7 .0000 .5392

Instituiçāo Proponente: Escola de Enfermagem da USP

Patrocinador Principal: Financiamento Próprio

DADOS DO PARECER

Número do Parecer: 1.969 .834

Apresentação do Projeto:

Trata-se do projeto de pesquisa para Exame de Qualificação para obtençāo do título de Mestre do Programa de Pós-Graduação em Enfermagem (PPGE) da EEUSP. Será uma pesquisa qualitativa que realizará entrevista semiestruturada com médicos, enfermeiros e gerentes de Unidades Básicas de Saúde, para verificar o encaminhamento para a referência maternidade Cachoerinha e posterior acompanhamento das mães e crianças na Atenção Básica (contra-referência).

Objetivo da Pesquisa:

Diagnosticar as dificuldades enfrentadas pelas equipes da APS no acompanhamento das gestantes referenciadas para a Maternidade Cachoerinha durante e após a realização do pré-natal de alto risco e elaborar formulário de acompanhamento das gestantes que realizam pré-natal de alto risco na Maternidade Cachoerinha e encaminhar as UBS de origem para controle, compartilhamento de informaçōes e de corresponsabilidade do cuidado prestado.

Avaliaçāo dos Riscos e Beneficios:

Não há riscos ou desconfortos previstos. Como beneficios, deve haver melhor acompanhamento de mães que realizaram pré-natal de alto risco na Maternidade Cachoeirinha, uma vez que haverá maior integração e troca de informaçōes entre as Unidades Básicas de Saúde e a maternidade.

\footnotetext{
Endereço: Av. Dr. Enéas de Carvalho Aguiar, 419

Bairro: Cerqueira Cesar CEP: $05.403-000$

UF: SP Municipio: SAOPAULO

Telefone: (11)3061-8858

E-mail: cepeegusp.br
} 


\section{EE USP USP - ESCOLA DE

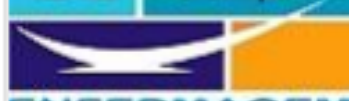 \\ ENFERMAGEM DA UNIVERSIDADE DE SÃO

\section{Comentários e Consideraçōes sobre a Pesquisa:}

O projeto justifica adequadamente a necessidade do trabalho para melhorar o sistema de informaçāo entre a referéncia para pré-natal de alto risco (Maternidade Cachoeirinha) e os serviços de Atenção Básica, que devem dar seguimento para o atendimento da mãe e da criança, após o parto e nascimento. Será realizada entrevista semi-estruturada com médicos, enfermeiros e gerentes de Unidades Básicas de Saúde da Zona Norte de Sāo Paulo, do Distrito Cachoerinha: UBS Dra. Ilza Hutzler e UBS Vila Dionisia.

\section{Consideraçōes sobre os Termos de apresentação obrigatória:}

-O Termo de Consentimento Livre e Esclarecido contempla as recomendaçōes da Resolução 466 de 2012 do Conselho Nacional de Saúde. Será assinado por pacientes localizados por ligação telefônica. - O cronograma é exequivel e propōe o inicio da coleta de dados em junho de 2017. - O orçamento é de RS 726,30 .

- Não apresenta autorização das gerências das Unidades Básicas de Saúde

\section{Recomendações:}

Corrigir o resumo (Nos métodos, o estudo é qualitativo, no resumo é quali-quantitativo)

Conclusōes ou Pendências e Lista de Inadequaçōes:

A autora passou a descrever a pesquisa como qualitava. É necessário corrigir o resumo.

\section{Consideraçōes Finais a critério do CEP:}

- Este CEP informa a necessidade de registro dos resultados parciais e finais na Plataforma Brasil;

- Esta aprovação não substitui a autorização da instituição coparticipante, antes do inicio da coleta de dados.

Este parecer foi elaborado baseado nos documentos abaixo relacionados:

\begin{tabular}{|l|l|c|l|c|}
\hline \multicolumn{1}{|c|}{ Tipo Documento } & \multicolumn{1}{|c|}{ Arquivo } & Postagem & Autor & Situaçāo \\
\hline $\begin{array}{l}\text { Informaçōes Básicas } \\
\text { do Projeto }\end{array}$ & PB_INFORMAČES_BÁSICAS_DO_P & $\begin{array}{c}23 / 02 / 2017 \\
17: 42: 23\end{array}$ & & Aceito \\
\hline $\begin{array}{l}\text { Projeto Detalhado / } \\
\text { Rrochura }\end{array}$ & Trabalho_f54214.pdf & $23 / 02 / 2017$ \\
Investigador.docx & $17: 41: 38$ & $\begin{array}{l}\text { ANA CAROLINA } \\
\text { BRITO DE OLIVEIRA }\end{array}$ & Aceito \\
\hline TCLE / Termos de & $\begin{array}{l}\text { Termo_de_Consentimento_Livre_e_Esci } \\
\text { assentimento / }\end{array}$ & $\begin{array}{c}23 / 01 / 2017 \\
12: 30: 47\end{array}$ & $\begin{array}{l}\text { ANA CAROLINA } \\
\text { BRITO DE OLIVEIRA }\end{array}$ & Aceito \\
\hline
\end{tabular}

Endereço: Av. Dr. Enéas de Carvalho Aguiar, 419

Bairro: Cerqueira Cesar CEP: $06.403-000$

UF: SP Municipio: SAOPAULO

Telefone: (11)3061-8858

E-mail: cepeegusp.br 


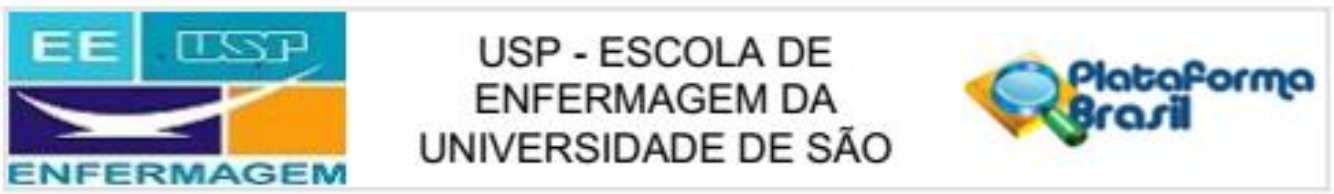

Contnusaçao do Parecer: 1969.834

\begin{tabular}{|l|l|c|l|c|}
\hline $\begin{array}{l}\text { Justificativa de } \\
\text { Ausência }\end{array}$ & $\begin{array}{l}\text { Termo_de_Consentimento_Livre_e_Esci } \\
\text { arecido.docx }\end{array}$ & $\begin{array}{c}23 / 01 / 2017 \\
12: 30: 47\end{array}$ & $\begin{array}{l}\text { ANA CAROLINA } \\
\text { BRITO DE OLIVEIRA }\end{array}$ & Aceito \\
\hline Folha de Rosto & digitalizar0001.pdf & $\begin{array}{c}22 / 01 / 2017 \\
11: 32: 14\end{array}$ & $\begin{array}{l}\text { ANA CAROLINA } \\
\text { BRITO DE OLIVEIRA }\end{array}$ & Aceito \\
\hline
\end{tabular}

Situação do Parecer:

Aprovado

Necessita Apreciação da CONEP:

Não

SAO PAULO, 17 de Março de 2017

Assinado por:

Lisabelle Mariano Rossato

(Coordenador)

Endereço: Av. Dr. Enéas de Carvalho Aguiar, 419

Bairro: Cerqueira Cesar

CEP: $05.403-000$

UF: SP

Municipio: SAO PAULO

Telefone: (11)3061-8858

E-mail: cepeeBusp.br 


\begin{tabular}{|c|c|}
\hline EM PESQUISA - SMS & $\begin{array}{c}\text { SECRETARIA MUNICIPAL DA } \\
\text { SAÚDE DE SÃO PAULO - } \\
\text { SMS/SP }\end{array}$ \\
\hline
\end{tabular}

\section{PARECER CONSUBSTANCIADO DO CEP}

Elaborado pela Instituiçăo Coparticipante

\section{DADOS DO PROJETO DE PESQUISA}

Titulo da Pesquisa: Acompanhamento de Gestantes no Pré-Natal de Alto Risco da Maternidade Cachoerinha: Contra Referência na Atençăo Primária à Saúde

Pesquisador: ANA CAROLINA BRITO DE OLIVEIRA

Área Temática:

Versăo: 1

CAAE: 63999417.7.3001.0086

Instituiçăo Proponente: Escola de Enfermagem da USP

Patrocinador Principal: Financlamento Proprio

\section{DADOS DO PARECER}

Número do Parecer: 2.021 .723

\section{Apresentaçăo do Projeto:}

Trata-se de projeto de pesquisa para obtençáo do titulo de Mestre em Ciéncias pelo Programa de Pósgraduaçăo em Enfermagem na Atençăo Primária em Saúde no Sistema Único de Saúde, da Escola de Enfermagem da Universidade de Så Paulo.

É uma pesquisa qualitativa descritiva, em que se utilizará, para a coleta dos dados, a entrevista semiestruturada com os profissionais de duas UBSs que têm como referêncla a Maternidade Cachoeirinha para a realizaçăo do pré-natal de alto risco.

A pesquisadora é enfermeira, funcionária pública da Maternidade Cachoeirinha, e por conta de seu trabalho tem percebido falhas no processo de acompanhamento das gestantes de alto risco, encaminhadas ao referido hospital.

As unidades que terăo a equipe multidisciplinar (médicos, enfermeiros e gerentes das unidades) entrevistada serăo a UBS Dra. IIza Hutzler e a UBS Vila Dionisia, ambas pertencentes ao Distrito Cachoeirinha da Regiaso Norte de Săo Paulo e ao território da Maternidade, sendo administradas por Organizaçбes Sociais (OS) e que possuem ESF na sua composiçăo.

Os dados colhidos nas entrevistas semlestruturadas seráo analisados pelo método de análise do discurso do sujeito.

Endereço: Rua General Jardim, $36-1^{\circ}$ andar
Balro: CENTRO CEP: $01.223-010$
$\begin{aligned} & \text { UF: SP } \quad \text { Municiplo: SAO PAULO } \\ & \text { Telefone: (11)3397-2464 E-mail: smecepggmall com }\end{aligned}$




\begin{tabular}{|c|c|}
\hline EM PESQUISA-SMS & $\begin{array}{c}\text { SECRETARIA MUNICIPAL DA } \\
\text { SAÚDE DE SÃO PAULO - } \\
\text { SMS/SP }\end{array}$ \\
\hline
\end{tabular}

Conthaçalo do Paseoer: 2021.72

Objetivo da Pesquisa:

Primário:

Diagnosticar as dificuldades enfrentadas pelas equipes da APS no acompanhamento das gestantes referenciadas para a Maternidade Cachoerinha durante e apos a realizaçăo do pré-natal de alto risco. Secundário:

Elaborar formulário de acompanhamento das gestantes que realizam pré-natal de alto risco na Maternidade Cachoerinha e encaminhar as UBS de origem para controle, compartilhamento de informaçōes e de corresponsabilidade do cuidado prestado.

\section{Avaliação dos Riscos e Beneficios:}

Nào há riscos, para além de possivel desconforto que algumas pessoas sentem ao terem que participar de entrevistas.

Pode haver beneficios, pois como a identificaçăo das dificuldades no acompanhamento das gestantes de alto risco, pela equipe das UBS, após seu encaminhamento para o hospital de referéncia, podera propiciar a proposiçăo de estratégias para superaçăo das dificuldades identificadas. Como a pesquisa também tem como objetivo elaborar formulário de acompanhamento, isto pode favorecer o atendimento do estabelecido como mais eficaz, que é o acompanhamento pala equipe da UBS de toda a fase gestacional, puerperal de de acompanhamento das crianças.

\section{Comentários e Consideraçōes sobre a Pesquisa:}

Pesquisa relevante que poderá trazer beneficios para o processo de trabalho preconizado para o eficaz atendimento e acompanhamento das gestantes de alto risco, puérperas e crianças fruto destas gestaçסes. A metodologia descrita está adequada aos objetivo propostos.

Consideraçōes sobre os Termos de apresentaçăo obrigatória:

A Folha de Rosto está corretamente preenchida, foram identificadas instituiçăa proponente $e$

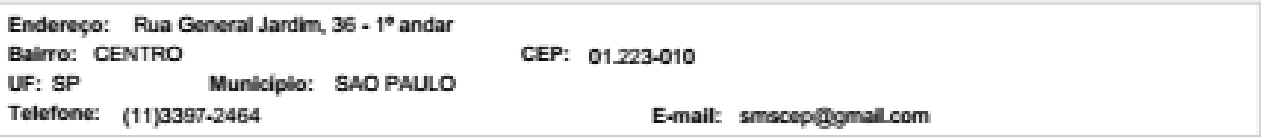




\section{SECRETARIA MUNICIPAL DA SAÚDE DE SÃO PAULO - SMS/SP}

Conthuaglo do Pascour: 2021.723

coparticipante. Fol apresentado documento de autorizaçăo da CRS Norte para realizaçăo do estudo. O estudo também inclui o Hospital Cachoeirinha que sera analisado também por aquele CEP.

TCLE, Cronograma, orçamento detalhado e fonte financladora estäo adequados.

Conclusōes ou Pendências e Lista de Inadequaçőes:

Sem pendências ou inadequaçōes.

Consideraçōes Finais a critério do CEP:

Para inicio da coleta dos dados, o pesquisador deverá se apresentar na mesma instância que autorizou a realizaçăo do estudo (Coordenadoria, Supervisăo, SMS/Gab, etc).

Se o projeto prever aplicaçăo de TCLE, todas as páginas do documento deverăo ser rubricadas pelo pesquisador e pelo voluntário e a última página assinada por ambos, conforme Carta Circular no 003/2011 da CONEPICNS.

Salientamos que o pesquisador deve desenvolver a pesquisa conforme delineada no protocolo aprovado. Eventuals modificaçōes ou emendas ao protocolo devem ser apresentadas ao CEP de forma clara e sucinta, identificando a parte do protocolo a ser modificada e suas justificativas. Lembramos que esta modificaçăo necessitará de aprovaçăo ética do CEP antes de ser implementada.

De acordo com a Res. CNS 466/12, o pesquisador deve apresentar os relatórios parcials e final através da Plataforma Brasil, icone Notificaçăo. Uma cópia digital (CD/DVD) do projeto finalizado deverá ser enviada a instância que autorizou a realizaçăo do estudo, via correio ou entregue pessoalmente, logo que o mesmo estiver concluido.

Este parecer fol elaborado baseado nos documentos abaixo relacionados:

\begin{tabular}{|c|c|c|c|c|}
\hline Tipo Documento & Arquivo & Postagem & Autor & Situaçäo \\
\hline $\begin{array}{l}\text { Projeto Detalhado / } \\
\text { Brochura } \\
\text { Investigador } \\
\end{array}$ & Trabalho_final.docx & $\begin{array}{c}23 / 02 / 2017 \\
17: 41: 38\end{array}$ & \begin{tabular}{|l|} 
ANA CAROLINA \\
BRITO DE OLIVEIRA
\end{tabular} & Acelto \\
\hline $\begin{array}{l}\text { Informaçōes Básicas } \\
\text { do Projeto }\end{array}$ & $\begin{array}{l}\text { PB_INFORMACCOES_BÁSICAS_DO_P } \\
\text { RO_JETO 854214.pdf }\end{array}$ & $\begin{array}{c}23 / 01 / 2017 \\
21: 29: 11 \\
\end{array}$ & & Acelto \\
\hline $\begin{array}{l}\text { Projeto Detalhado I } \\
\text { Brochura } \\
\text { Investioador }\end{array}$ & Trabalho_final.docx & $\begin{array}{c}23 / 01 / 2017 \\
21: 28: 46\end{array}$ & \begin{tabular}{|l|} 
ANA CAROLINA \\
BRITO DE OLIVEIRA
\end{tabular} & Acelto \\
\hline Informaçōes & PB_INFORMACCOES_BASICAS_DO_P & $23 / 01 / 2017$ & & Acelio \\
\hline
\end{tabular}

Endereço: Rua General Jardim, $35 \cdot 1^{\circ}$ andar BalrTo: CENTRO

UF: SP

CEP: $01.223-010$

Telefone: (11)3397-2464

E-mail: smecepthomallcom 


\section{SECRETARIA MUNICIPAL DA SAÚDE DE SÃO PAULO - SMS/SP}

Conthuaclo do Parcoer: 2021.72

\begin{tabular}{|c|c|c|c|c|}
\hline Básicas do Projeto & ETO_854214.pdf & $12: 31: 34$ & & Aceilo \\
\hline $\begin{array}{l}\text { TCLE / Termos de } \\
\text { Assentimento / } \\
\text { Justificativa de } \\
\text { Ausência }\end{array}$ & $\begin{array}{l}\text { Termo_de_Consentimento_Lvire_e_Esc } \\
\text { arecido.docx }\end{array}$ & $\begin{array}{c}23 / 01 / 2017 \\
12: 30: 47\end{array}$ & $\begin{array}{l}\text { ANA CAROLINA } \\
\text { BRITO DE OLIVEIRA }\end{array}$ & Acelito \\
\hline $\begin{array}{l}\text { Informaçōes Básicas } \\
\text { do Projeto }\end{array}$ & $\begin{array}{l}\text { PB_INFORMAÇOES_BASICAS_DO_P } \\
\text { RO_JETO 854214.pdf }\end{array}$ & $\begin{array}{c}22 / 01 / 2017 \\
18: 21: 10 \\
\end{array}$ & & Acelito \\
\hline Folha de Rosto & digitalizar0001.pdf & $\begin{array}{c}22 / 01 / 2017 \\
11: 32: 14\end{array}$ & $\begin{array}{l}\text { ANA CAROLINA } \\
\text { BRITO DE OLIVEIRA }\end{array}$ & Acelito \\
\hline
\end{tabular}

Situaçăo do Parecer:

Aprovado

Necessita Apreciaçẵo da CONEP:

Năo

SAO PAULO, 19 de Abril de 2017

Assinado por:

SIMONE MONGELLI DE FANTINI

(Coordenador) 


\section{HOSPITAL MUNICIPAL E MATERNIDADE-ESCOLA DR. MÁRIO DE MORAES}

\section{PARECER CONSUBSTANCIADO DO CEP}

Elaborado pela Instituiçāo Coparticipante

\section{DADOS DO PROJETO DE PESQUISA}

Título da Pesquisa: Acompanhamento de Gestantes no Pré-Natal de Alto Risco da Maternidade Cachoerinha: Contra Referência na Atenção Primária à Saúde

Pesquisador: ANA CAROLINA BRITO DE OLIVEIRA

Área Temática:

Versão: 1

CAAE: 63999417.7 .3002 .5454

Instituição Proponente: Escola de Enfermagem da USP

Patrocinador Principal: Financiamento Próprio

\section{DADOS DO PARECER}

Número do Parecer: 2.103.642

\section{Apresentação do Projeto:}

Apresentação do projeto está de acordo com as exigências estabelecidas.

Objetivo da Pesquisa:

Acredito que trará contribuiçāo para os serviços de saúde.

Avaliação dos Riscos e Beneficios:

Há risco minimo.

Comentários e Consideraçōes sobre a Pesquisa:

O Método está suficientemente detalhado para permitir a compreensāo da proposta do estudo.

Consideraçōes sobre os Termos de apresentação obrigatória:

Esclarecer que o pesquisador é responsável por qualquer risco ou dano referente à pesquisa.

Conclusōes ou Pendèncias e Lista de Inadequaçōes:

O trabalho está muito bem escrito e tem condiçōes de aprovação por este Comitê.

Consideraçōes Finais a critério do CEP:

Trata-se de pesquisa cuja coleta de dados ocorrerá integralmente na rede de atenção básica (AB), não no Hospital Municipal e Maternidade-Escola Dr. Mario de Moraes Altenfelder Silva - Vila Nova Cachoeirinha (HMEC). Será realizada por meio de entrevistas a profissionais da AB. A pesquisa

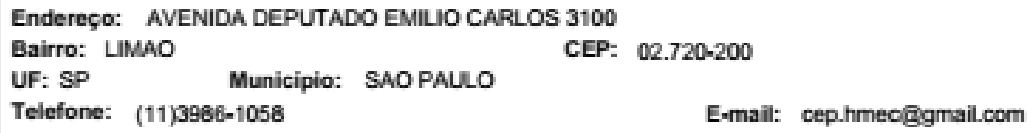




\section{HOSPITAL MUNICIPAL E MATERNIDADE-ESCOLA DR. MÁRIO DE MORAES}

Contruaçso do Parecer. 2.103.642

trará beneficios para o HMEC na medida em que os conhecimentos produzidos poderão melhorar a integração das informaçōes para qualificar o processo de referência e contra-referência na regiāo.

Este parecer foi elaborado baseado nos documentos abaixo relacionados:

\begin{tabular}{|c|c|c|c|c|}
\hline Tipo Documento & Arquivo & Postagem & Autor & Situaçāo \\
\hline $\begin{array}{l}\text { Informaçōes Básicas } \\
\text { do Projeto }\end{array}$ & $\begin{array}{l}\text { PB_INFORMAÇŌES_BÁSICAS_DO_P } \\
\text { ROJETO 854214.pdf }\end{array}$ & $\begin{array}{c}23 / 02 / 2017 \\
17: 42: 23\end{array}$ & & Aceito \\
\hline $\begin{array}{l}\text { Projeto Detalhado / } \\
\text { Brochura } \\
\text { Investigador }\end{array}$ & Trabalho_final.docx & $\begin{array}{c}23 / 02 / 2017 \\
17: 41: 38\end{array}$ & $\begin{array}{l}\text { ANA CAROLINA } \\
\text { BRITO DE OLIVEIRA }\end{array}$ & Aceito \\
\hline $\begin{array}{l}\text { Informaçōes Básicas } \\
\text { do Projeto }\end{array}$ & $\begin{array}{l}\text { PB_INFORMAÇŌES_BÁSICAS_DO_P } \\
\text { ROJETO 854214.pdf }\end{array}$ & $\begin{array}{c}23 / 01 / 2017 \\
21: 29: 11 \\
\end{array}$ & & Aceito \\
\hline $\begin{array}{l}\text { Projeto Detalhado / } \\
\text { Brochura } \\
\text { Investigador }\end{array}$ & Trabalho_final.docx & $\begin{array}{c}23 / 01 / 2017 \\
21: 28: 46\end{array}$ & $\begin{array}{l}\text { ANA CAROLINA } \\
\text { BRITO DE OLIVEIRA }\end{array}$ & Aceito \\
\hline $\begin{array}{l}\text { Informaçōes Básicas } \\
\text { do Projeto }\end{array}$ & $\begin{array}{l}\text { PB_INFORMAÇŌES_BÁSICAS_DO_P } \\
\text { ROJETO 854214.pdf }\end{array}$ & $\begin{array}{c}23 / 01 / 2017 \\
12: 31: 34 \\
\end{array}$ & & Aceito \\
\hline $\begin{array}{l}\text { TCLE / Termos de } \\
\text { Assentimento / } \\
\text { Justificativa de } \\
\text { Ausência }\end{array}$ & $\begin{array}{l}\text { Termo_de_Consentimento_Livre_e_Escl } \\
\text { arecido.docx }\end{array}$ & $\begin{array}{c}23 / 01 / 2017 \\
12: 30: 47\end{array}$ & $\begin{array}{l}\text { ANA CAROLINA } \\
\text { BRITO DE OLIVEIRA }\end{array}$ & Aceito \\
\hline $\begin{array}{l}\text { Informaçōes Básicas } \\
\text { do Projeto }\end{array}$ & $\begin{array}{l}\text { PB_INFORMAÇŌES_BÁSICAS_DO_P } \\
\text { ROJETO 854214.pdf }\end{array}$ & $\begin{array}{c}22 / 01 / 2017 \\
18: 21: 10 \\
\end{array}$ & & Aceito \\
\hline Folha de Rosto & digitalizar0001.pdf & $\begin{array}{c}22 / 01 / 2017 \\
11: 32: 14 \\
\end{array}$ & \begin{tabular}{|l|} 
ANA CAROLINA \\
BRITO DE OLIVEIRA
\end{tabular} & Aceito \\
\hline
\end{tabular}

Situaçāo do Parecer:

Aprovado

Necessita Apreciação da CONEP:

Não

SAO PAULO, 06 de Junho de 2017

Assinado por:

Renata Cereda Cordeiro

(Coordenador)

Endereç: AVENIDA DEPUTADO EMILO CARLOS 3100

Bairro: LIMAO

UF: SP

CEP: $02.720-200$

Telefone: (11)3986-1058

E-mail: cep.hmeoggmail.com 


\section{APÊNDICE A - Termo de Consentimento Livre e Esclarecido (TCLE)}

Convido o (a) Sr (a) para participar da pesquisa intitulada "Acompanhamento de Gestantes no Pré-natal de Alto Risco da Maternidade Cachoeirinha: contrarreferência na Atenção Primária à Saúde” desenvolvida pela Sr (a) Ana Carolina Brito de Oliveira.

As gestantes ao serem encaminhadas ao pré-natal de alto risco devem continuar também com seu acompanhamento nas Unidades Básicas de Saúde e deve ocorrer uma troca de informações entre as instituições que acompanham essas pacientes.

O estudo tem como objetivos:

\section{Objetivo geral:}

Investigar limites e potencialidades do sistema de referência e contrarreferência no acompanhamento de gestantes de alto risco encaminhadas para a Maternidade Cachoeirinha.

Pedirei que me conceda uma entrevista com duração aproximadamente de 45 minutos para conversarmos sobre como ocorre a contrarreferência das gestantes que realizam o pré-natal de alto risco na Maternidade Cachoeirinha e como são reinseridas na UBS após o parto.

Essa entrevista não acarretará riscos e danos para àquele que aceitar participar voluntariamente desta pesquisa e a qualquer momento poderá ser interrompida caso o entrevistado se sinta desconfortável por qualquer razão.

Os resultados deste estudo poderão contribuir para o aprimoramento e maior interligação da rede de referência e contra-referência das gestantes que realizam pré-natal de alto-risco na Maternidade Cachoeirinha.

Esclareço ainda que você poderá me pedir maiores informações a respeito do estudo a qualquer momento através do meu telefone que ficará disponível 24 horas e que tem todo o direito de se recusar a participar da pesquisa, inclusive podendo desistir quando desejar, mesmo após a realização da entrevista, sem que isso lhe traga prejuízos de qualquer espécie. Após a conclusão desta pesquisa você será informado através de sua instituição dos resultados obtidos

Não será necessário que se identifique. O seu anonimato e o sigilo dos dados confidenciais serão mantidos por ocasião da divulgação dos resultados da pesquisa em eventos e/ou periódicos. 
O TCLE deve ser rubricado em todas as suas páginas e assinado nas duas vias. Você também receberá uma via do Termo de Consentimento Livre e Esclarecido assinada e rubricada por mim.

Gostaria de esclarecer que sua participação no estudo é voluntária e que não será cobrado por ela, assim como não haverá remuneração financeira caso você participe e também nenhuma despesa financeira decorrente de sua participação na pesquisa.

O principal pesquisador é a Sra. Ana Carolina Brito de Oliveira que pode ser encontrado no endereço: Av. Salgado Filho, n²845 - Apto 32 Bloco A. Telefone(s): (11) 97479-8599 (24 horas) e-mail: caroll_brito@yahoo.com.br. A orientadora desse projeto é Prof ${ }^{\mathrm{a}}$ Dr $^{\mathrm{a}}$ Anna Luiza de Fátima Pinho Lins Gryschek, telefone: 3061 - 9752, email: gryschek@usp.br. Caso você tenha alguma consideração ou dúvida sobre a ética da pesquisa, entre em contato com o Comitê de Ética em Pesquisa (CEP USP) - Endereço - Av. Dr. Enéas de Carvalho Aguiar, 419 - Cerqueira Cesar - São Paulo/SP CEP - 05403000 Telefone - (11) 30618858 e-mail - cepee@usp.br e com o CEP da Secretaria Municipal de Saúde (SMS) pelo e-mail: smscep@gmail.com, telefone: (11) 33972464.

Dados dos Coparticipantes:

HOSPITAL E MATERNIDADE ESCOLA CACHOEIRINHA

Av. Dep. Emílio Carlos, 3100 - Vila Nova Cachoeirinha, São Paulo - SP, 02720200 Telefone: (11)3982-1058 E-mail: echalem@ prefeitura.sp.gov.br

COORDENADORIA REGIONAL DE SAÚDE NORTE

Rua Paineira do Campo, 902 - Santana - CEP: 02012-040

Telefone: 2224-6850 / 2224-6808 coordenadorianorte@prefeitura.sp.gov.br

Esta pesquisa atende todas as especificações da Resolução 466, de 12 de dezembro de 2012 que aprova as diretrizes e normas regulamentadoras de pesquisas envolvendo seres humanos.

Assinatura do pesquisador

Assinatura do participante/representante legal

Data 


\section{APÊNDICE B - Roteiro de Entrevista dos Trabalhadores de Saúde}

\section{Parte 1 - Apresentação}

Idade

Formação

Trajetória profissional

No seu trabalho dentro da APS você teve capacitação para atendimento de pré-natal?

Se sim, fale-me sobre essa capacitação.

No seu trabalho dentro da APS você teve capacitação para a grade de referência e contra-referência? Se sim, fale-me sobre essa capacitação.

Como essas temáticas foram abordadas no seu curso de graduação?

\section{Parte 2 - Demanda}

Qual a sua rotina de atendimento de consulta de pré-natal?

Você tem dados estatísticos das gestantes que são identificadas como alto- risco e encaminhadas para as unidades de referência?

\section{Parte 3 - Atendimento}

Quando as gestantes são encaminhadas para o alto risco você permanece com o acompanhamento das gestantes na APS?

Se não, por quê?

Se sim, como?

A unidade de alto risco encaminha relatórios periódicos das gestantes para a

UBS? Se sim quais?

Há dificuldades em elaborar relatórios solicitados pelo Comitê de Mortalidade Materna-Infantil das gestantes de alto risco? Se sim quais?

Como ocorre o retorno das puérperas para a UBS?

Quando as puérperas retornam em atendimento para a UBS há algum levantamento de dados relacionados ao pré-natal?

Para você como deveria ser este relatório de retorno da puérpera de alto risco para a UBS? 